\title{
Potomac Science Center \\ Methods
}

\section{Research Fellow: \\ Cynthia Smith \\ Associate Professor \\ George Mason University \\ Research Assistant: \\ MacKenzie Earl \\ George Mason University}

\section{Firm Liaisons:}

Stephanie Roa, Designer

LandDesign

Alison Peckett, Senior Designer

LandDesign

Lisa Biddle, Associate

Land Design

This investigation was conducted as part of the Landscape Architecture Foundation's 2020 Case Study Investigation (CSI) program. CSI matches faculty-student research teams with design practitioners to document the benefits of exemplary high-performing landscape projects. Teams develop methods to quantify environmental, social, and economic benefits and produce Case Study Briefs for LAF's Landscape Performance Series.

The full case study can be found at: https://landscapeperformance.org/case-studybriefs/potomac-science-center

To cite:

Smith, Cynthia B. and MacKenzie Earl. "Potomac Science Center Methods" Landscape Performance Series. Landscape Architecture Foundation, 2020.

https://doi.org/10.31353/cs1661 


\section{Table of Contents}

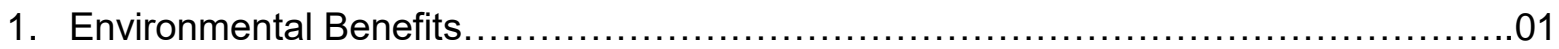

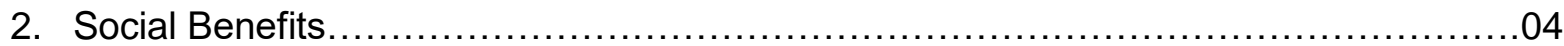

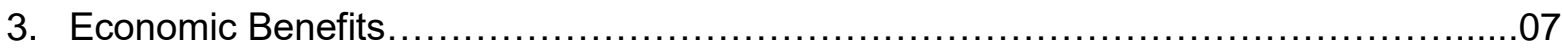

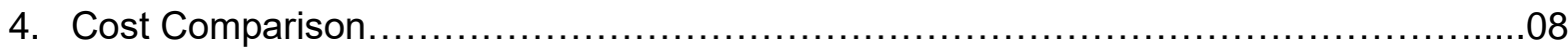

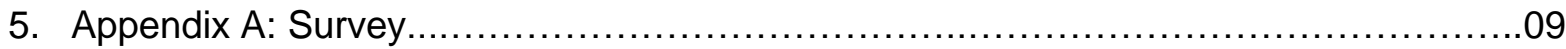

\section{Environmental Benefits}

- Saves 2,400 gallons of water annually by using recycled water to irrigate a 250-sf green wall. This is equivalent to a year of drinking water for 13 people.

Background: $100 \%$ of water used to irrigate the green wall is reclaimed from the site and provided through a 5,000-gallon cistern that captures rainwater from the roof of the building and water condensation from the air conditioning system. The 250-sf Sempergreen Flexipanel vertical wall system (green wall) is located along the main plaza of the outdoor patio. Each flexipanel has a channel at the top for a drip hose which is used for delivering water and nutrients to the plants. This system is irrigated by the rainwater harvesting cistern.

Method: Since there is no gauge in the green wall to indicate water usage, this benefit is based on the average water use of a Sempergreen Flexipanel vertical wall system per square foot. This information was sourced from the manufacturer Sempergreen. Using the estimate provided ( 1 gallon per $38 \mathrm{sf} /$ day), the water required to irrigate the green wall for one year was calculated (see Calculations 1 \& 2).

Calculations: All calculations are rounded to the appropriate significant figures.

Calculation 1: Volume of water required to irrigate green wall per day

(square feet of sempergreen flexipanel vertical wall system )(manufacturer water estimate) $=$ approximate volume of water required (250sf) ( 1 gallon per 38 square foot / day)= approximate volume of water required daily $(250 \mathrm{sf})(0.026$ gallons per $\mathrm{sf})=6.5$ gallons of water required daily

Calculation 2: Volume of water required to irrigate green wall per year (gallons needed to irrigate green wall every day) (number of days in a year)= Volume of water required to irrigate green wall annually (6.5 gallons) ( 365 days) $=2,400$ gallons of water annually Average adult male needs 182.5 gallons annually $=13.2$ people

The green wall at the Potomac Science Center uses approximately 2,400 gallons of recycled water for irrigation every year, without accounting for weather, climate, and other factors affecting required irrigation (see Limitations). 
Sources: Irrigation requirement for sempergreen flexipanel vertical wall system provided by Joep van Vilsteren, GRP, Program Director Sempergreen Services.

Limitations: The volume of water for irrigation is based on an estimation by the manufacturer. Ideally, this information would have been gathered based on data collected at the site. This estimation fails to account for the specific climate of our site and other factors that might influence water usage since water use is very project- and site-specific. Some plants have an evapotranspiration rate that is significantly higher than other plants, typically due to plant size and leaf structure. Orientation and location of green walls also have a significant effect on the amount of water needed for irrigation.

\section{- Restored 9,280 sf of habitat along the Occoquan River with native plantings.}

Background: This site was previously a greenfield with little meaningful ecologically diverse vegetation other than turfgrass. 65 species of native plants including trees, perennials, and groundcovers were planted. These were selected for their appropriateness for the Potomac River ecosystem, their ability to provide year-round habitat, and to add to the visual interest of the space. With the exception of turf areas in outdoor classroom areas or as required for fire lane access (approximately 1,268 sf), the landscape is made up of $100 \%$ native plants suited for the Occoquan River's riparian environment. This includes approximately 10,000 sf of riparian buffer restoration planting, 10, 548 sf of revegetated area and 2,181 sf of shoreline restoration area. These plantings include Cephalanthus occidentalis (buttonbush), Physocarpus opulifolius (ninebark) and Spiraea alba (sweetmeadow). As of fall 2020, five tree species have been labeled on an educational map created by the George Mason University Arboretum. See map here: https://www.plantsmap.com/organizations/george-mason-university-arboretum

Method: The entire site was planted with native vegetation with the exception of turf used in outdoor classroom areas and turf used to allow fire lane access. To calculate the total square footage of native plant revegetation, the area of these natively exempt areas were subtracted from the total revegetated area of the site (provided by the planting plan).

Calculations:

All calculations were completed on Texas Instruments TI-30Xa Solar Scientific Calculator. All calculations are rounded to the appropriate significant figures.

Calculation 1: Total area of revegetated land (Revegetated Area - Unforested - Hand Watered 6,709 Sf)+ (Revegetated Area Unforested - Irrigated 1,347 Sf)+ (Revegetated Area - Woodland Edge 2,492 Sf) = total area of revegetated land

$(6,709 \mathrm{Sf})+(1,347 \mathrm{Sf})+(2,492 \mathrm{Sf})=10,548 \mathrm{sf}$ 
Calculation 2: Total area of native revegetation

Total area of revegetated land - (outdoor classrooms or fire land access areas) $=$ total area of native revegetated land

$(10,548 \mathrm{sf})-(1,268 \mathrm{sf})=9,280 \mathrm{sf}$

This site contains approximately 9,280 sf of native revegetation.

Sources: The planting plan for this site included the square footage of each revegetation area. These figures were used in the above calculations.

Limitations: This method only accounts for the square footage of land revegetated with native plants at the time of planting. Over time this area has changed and field methods to verify current plant mix would have been beneficial. These were impossible under the time of study due to site access limitations related to the COVID-19 pandemic in 2020.

- Sequesters $1,358 \mathrm{lbs}$ of atmospheric carbon annually in tree plantings at the site. As of January 2021, trees on site are estimated to have stored 1,766 lbs of CO2 equivalent.

Method: This benefit was estimated using i-Tree Design version 6. This software application is designed to use either a) data collected from single trees b) complete inventories or $\mathrm{c}$ ) randomly located plots throughout a study area. For this project, a complete inventory was used to quantify the carbon sequestration capacity of this site. The original planting plan was used as a reference for this site data.

Calculations: These calculations were completed using iTree Design version 6. For more information or details on how these estimates are calculated, visit

https://landscape.itreetools.org/.

One of the data points required by iTree Design is the estimated diameter of trees at the time of planting. The original planting plan for this project provided diameter ranges. For example, 3 sourwood trees were planted in Riparian Area 2 with a diameter range of $3 / 4$ " to $1 \frac{1}{2}$. . In these cases, an average of the two diameters was used.

Limitations: There were a few pieces of data that were not retroactively available. For example, each of the trees entered into i-Tree Design required a 'condition' variable. Without any way to tell the condition of individual trees when they were first planted in 2018, each tree was considered in 'excellent' condition.

The revegetated areas of this site have shifted since original planting/construction. An on-site evaluation of which of these areas were still planted was conducted by a member of the design firm but did not enter into this analysis. They found that trees are generally planted as shown on the original planting plan except several pine trees along the pond-side of building were replaced with hollies. 


\section{Social Benefits}

- Increased engagement with the Occoquan River, with $54 \%$ of 15 survey respondents reporting enjoying the view of the river during their visits and $39 \%$ engaging in ecological-based recreational activities like bird-watching and plant identification.

Background: Prior to the construction of the Potomac Science Center, the land was a greenfield with no measurable indicator of community engagement. The National Heritage Scenic Trail passed through the site but there was nothing else to engage visitors. In this benefit we endeavored to measure the ways in which individuals have interacted with the site and the space since the construction of the Potomac Science Center.

Method: This data was collected through the use of an IRB-approved survey distributed digitally to past visitors of the Potomac Science Center entitled 'Potomac Science Center Visitor Assessment Survey'. The survey is described to respondents as such: "This research is being conducted to evaluate how the construction and maintenance of the Potomac Science Center landscape has impacted the surrounding community. This information will be used to inform future landscape design projects at George Mason University and the larger landscape design industry (through submission to the Landscape Architecture Foundation)." A copy of this survey is included in Appendix A.

Use of the patio for yoga has also been observed as a recreational activity on site.

Calculations: The survey received 15 total responses. The statistics generated are directly from the survey's Google Forms survey response dashboard.

How would you rate your level of engagement with the site indicated PRIOR to the construction of the Potomac Science Center in 2017?

14 responses

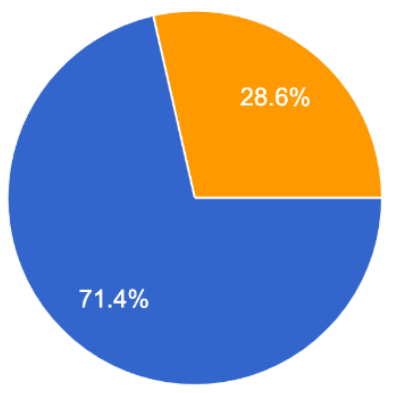

0. I never engaged with this site prior to 2017.

b. 1. I rarely engaged with this site prior to 2017 .

c. 2 . I engaged with this site prior to 2017 3-4 times prior to 2017.

d. 3 . I often engaged with this site prior to construction in 2017.

e. 4. I often engaged with this site prior to construction in 2017 - including freq.. 
Please indicate all of the ways you engaged with the site PRIOR to the construction of the Potomac Science Center in 2017.

4 responses

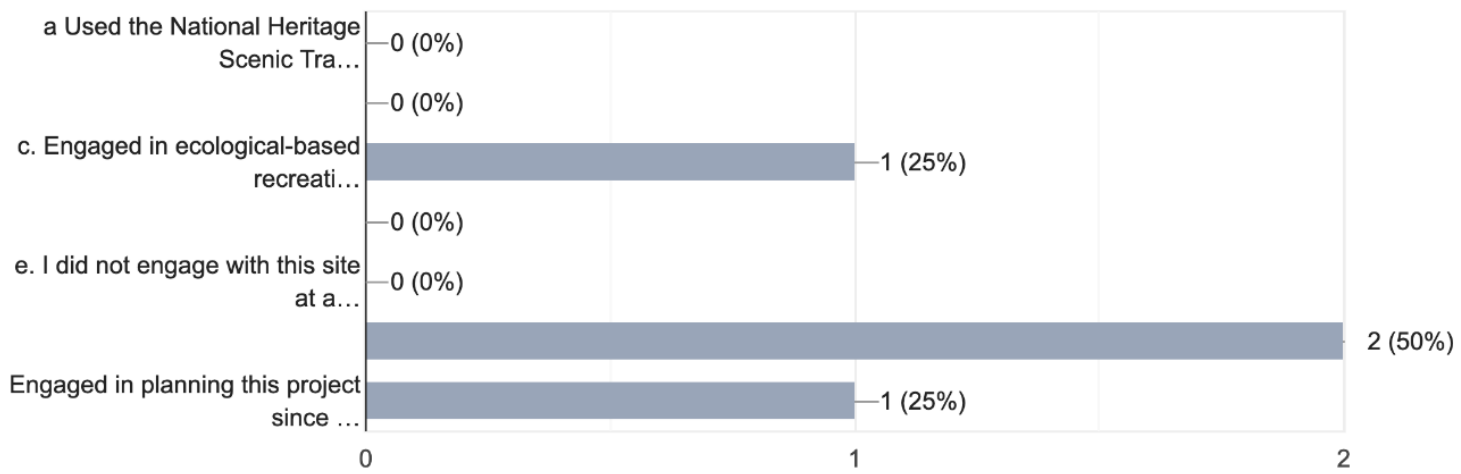

How would you rate your level of engagement with the site indicated AFTER the construction of the Potomac Science Center in 2017?

14 responses

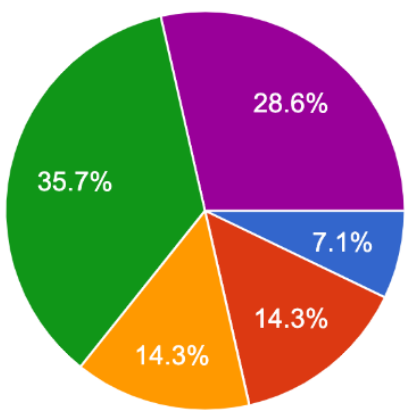

a. I never engage with this site.

b. I rarely engage with this site.

c. I engaged with this site 3-4 times a year.

d. I often engage with this site.

e. I often engage with this site including frequent use of the National Heritage Scenic Trail.

Please indicate all of the ways you engaged with the site AFTER its construction concluded? 13 responses

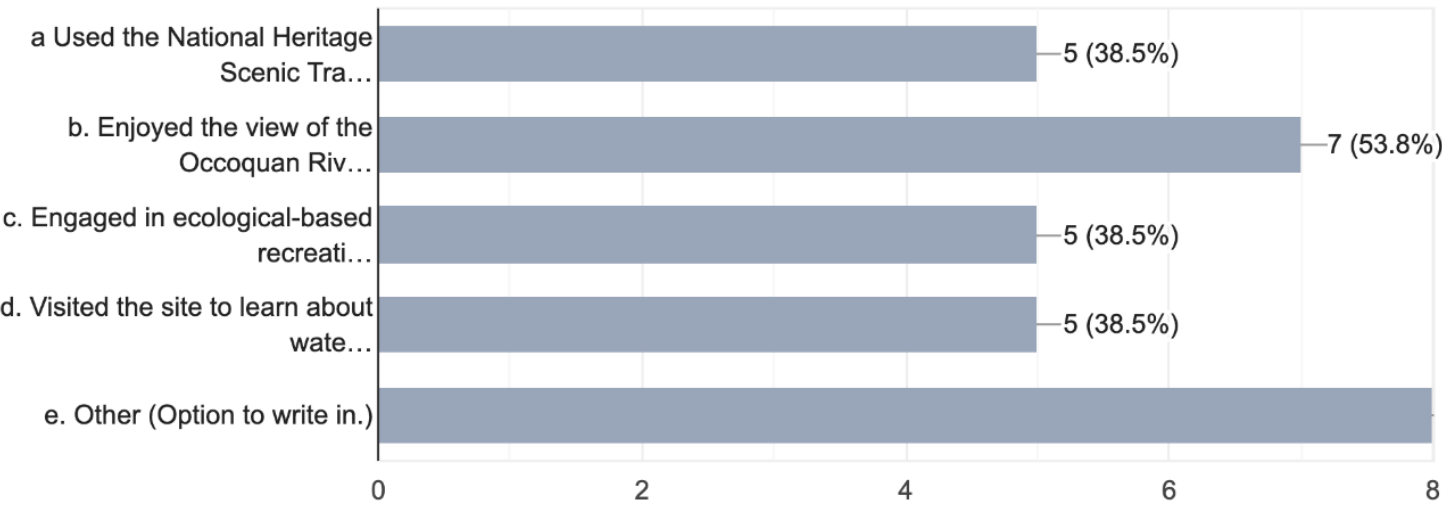


Sources: Survey conducted by George Mason CSI team, 2020.

Limitations: This survey was distributed during the COVID-19 pandemic. This eliminated the option to conduct this survey on-site with real-time visitors. Given this restriction, this survey was distributed to former visitors of the site, employees, students and faculty of George Mason University, and organizations that have partnered with the Potomac Science Center in the past. This targeted approach to distribution may have unintended consequences in skewing the data. The number of respondents is lower than anticipated due to the COVID-19 pandemic.

- Provides educational value, with $100 \%$ of 13 surveyed visitors who were familiar with the site reporting that they noticed and learned about the green wall, rainwater harvesting system, and other water-related features. $62 \%$ felt that the "Water Story" features greatly enriched their learning experience at the site.

Methods, Sources, and Limitations: See above for survey information. 2 of the 15 survey-takers were not familiar with the site/had not visited. The survey (see Appendix A) explained to surveytakers what was included in the "water story" (roof drain with weir into rain garden, roof scuppers, table top installation) and even showed images and a map.

What specific features of the Potomac Science Center outdoor landscape have you seen or learned about during your time at the site?

13 responses

a. Roof drain with a weir into a rain $\mathrm{g}$...

b. Scuppers installed on the roof

c. Table top installation to replicate

d. 5,000-gallon rainwater harvesting ci..

e. A 250-sf green wall located along th..

f. A series of rain gardens and Infiltr...

$4\left(30.8^{c}\right.$ a. Roof drain with a weir into a rain $\mathbf{g} . .$. Count: 9
$-9(69.2 \%)$

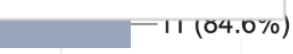

$-12(92.3 \%)$

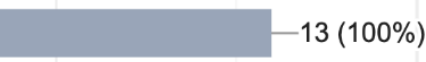

$-9(69.2 \%)$

10 
How do you feel like the Water Story features of this site influenced your experience with this site? 13 responses

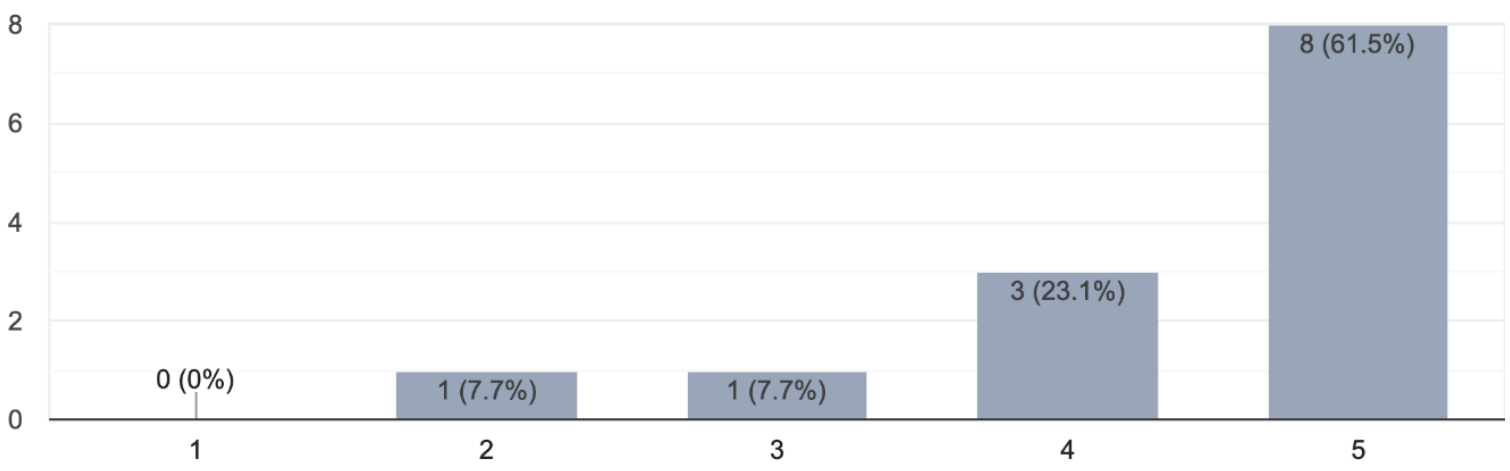

A rating of 1 indicates that they were unaware the water story features existed; a rating of 5 is "they have greatly enriched my learning experience at the site." (See Appendix A)

\section{Economic Benefits}

- Helped to catalyze the awarding of $\$ 842,403$ in research grants to projects headquartered in the Potomac Science Center in 2019. With new researchers moving into the Science Center, funding is predicted to increase.

Background: The Potomac Science Center facility is positioned less than $150 \mathrm{ft}$ from the Occoquan River, allowing researchers and students to easily access and experience the tidal river. The research facility houses laboratories for teaching and research. The landscape of this campus, which allows access to the water, is a key reason research is conducted on the site.

Method: This includes funds awarded to the Potomac Environmental Research and Education Center (PEREC) housed at the Potomac Science Center.

Calculations: The only calculation required for this benefit was the summation of all grants awarded in Fiscal Year 2019. This was provided with the data from Cheryl Scholnik.

Sources: Cheryl Scholnik, Grants and Finance Analyst at George Mason University

Limitations: Research conducted at the site that was not directed through PEREC Grants and Contracts are not included in this number. The data used for this benefit are solely from fiscal year 2019 and are not a complete picture of the research funds made possible by the Potomac Science Center since its completion in 2017. 


\section{Cost Comparison}

- Cast-in-place concrete walls (including finishes) cost approximately one-third of the projected cost of gabion construction for the amphitheater. Cast-in-place walls also use more recycled materials than gabion walls, which consist of more raw materials.

Background: The budget of the landscape design project was provided by the University at the beginning of this project. Any negotiation of cost versus benefit for specific features of the site were within the parameters of this initial budget. Different cost options for amphitheater construction materials was considered during this project by the landscape architect. Cast-inplace walls were used in lieu of gabion walls for the construction of the amphitheater because they utilize a larger amount of recycled materials than the gabion walls which consist of more raw materials.

Calculations: Cast-in-place concrete walls (even with finishes, etc.) cost approximately one-third of the projected cost of gabion construction. Per linear foot, those walls were about 2-3' high. Gabion - $\$ 100 /$ square face foot. Concrete walls $\$ 43 /$ square foot. Calculations provided by the Potomac Science Center general contractor.

Sources: Information provided by Land Design, Alison Peckett 
Appendix A: Survey 


\section{Potomac Science Center Visitor Assessment Survey}

This research is being conducted to evaluate how the construction and maintenance of the Potomac Science Center landscape has impacted the surrounding community. This information will be used to inform future landscape design projects at George Mason University and the larger landscape design industry (through submission to the Landscape Architecture Foundation).

\section{Informed Consent}

This research is being conducted to evaluate how the construction and maintenance of the Potomac Science Center landscape has impacted the surrounding community. This information will be used to inform future landscape design projects at George Mason University and the larger landscape design industry (through submission to the Landscape Architecture Foundation). If you agree to participate, you will be asked to complete a 10-minute online survey.

RISKS: There are no foreseeable risks for participating in this research.

BENEFITS: There are no benefits to you as a participant other than to further research in the landscape design field.

CONFIDENTIALITY: The data in this study will be confidential. Names and other identifiers will not be placed on research data. Participant's names and contact information will not be included on the surveys and other collectible data. If you choose to opt into sharing your contact information with us, it will be collected through a separate survey and completely separate from the data for this survey. This ensures that all data collected is de-identified immediately. The de-identified data could be used for future research without additional consent from participants. The Institutional Review Board (IRB) committee that monitors the research on human subjects may inspect study records during internal auditing procedures and are required to keep all information confidential.

PARTICIPATION: Your participation is voluntary, and you may withdraw from the study at any time and for any reason. If you decide not to participate or if you withdraw from the study, there is no penalty or loss of benefits to which you are otherwise entitled. There are no costs to you or any other party.

I have read this form, all of my questions have been answered by the research staff, and I agree to participate in this study.

Accept.

Decline. 


\section{Contact}

This research is being conducted by MacKenzie Earl at George Mason University. She may be reached at (540) 270-6483 or mearl@gmu.edu for questions or to report a research-related problem. Cynthia Smith (faculty advisor) be reached at csmitc@gmu.edu.You may contact the George Mason University Institutional Review Board office at 703-993-4121 or $\underline{I R B} @$ gmu.edu if you have questions or comments regarding your rights as a participant in the research. This research has been reviewed according to George Mason University procedures governing your participation in this research.

\section{Overview}

How would you describe your relation to the Potomac Science Center?

I am a resident of the region.

I am a resident of the Belmont Bay Community Home Owner's Association.

I am a one time visitor to the facility.

I am an employee or contracted worker at the facility.

I am a faculty member or student with George Mason University.

\section{Section 4: Engagement}

How would you rate your level of engagement with the site indicated PRIOR to the construction of the Potomac Science Center in 2017?

0. I never engaged with this site prior to 2017

b. 1 . I rarely engaged with this site prior to 2017 .

c. 2. I engaged with this site prior to 2017 3-4 times prior to 2017.

d. 3. I often engaged with this site prior to construction in 2017.

e. 4. I often engaged with this site prior to construction in 2017 - including frequent use of the National Heritage Scenic Trail. 
Please indicate all of the ways you engaged with the site PRIOR to the construction of the Potomac Science Center in 2017.

$\square$ a Used the National Heritage Scenic Trail for recreational use.

b. Enjoyed the view of the Occoquan River.

c. Engaged in ecological-based recreation (bird watching, plant identification, ect.)

d. Visited the site to learn about watersheds, water ecology, conservation, and other topics.

e. I did not engage with this site at all prior to the construction of the PSC.

Other:

\section{Untitled Section}

How would you rate your level of engagement with the site indicated AFTER the construction of the Potomac Science Center in 2017?

a. I never engage with this site.

b. I rarely engage with this site.

c. I engaged with this site 3-4 times a year.

d. I often engage with this site.

e. I often engage with this site - including frequent use of the National Heritage Scenic Trail. 
Please indicate all of the ways you engaged with the site AFTER its construction concluded?

$\square$ a Used the National Heritage Scenic Trail for recreational use.

$\square$ b. Enjoyed the view of the Occoquan River.

$\square$ c. Engaged in ecological-based recreation (bird watching, plant identification, ect.)

$\square$ d. Visited the site to learn about watersheds, water ecology, conservation, and other topics.

$\square$ e. Other (Option to write in.)

\section{Section 2: General Information}

\section{Current Aerial of the Potomac Science Center}

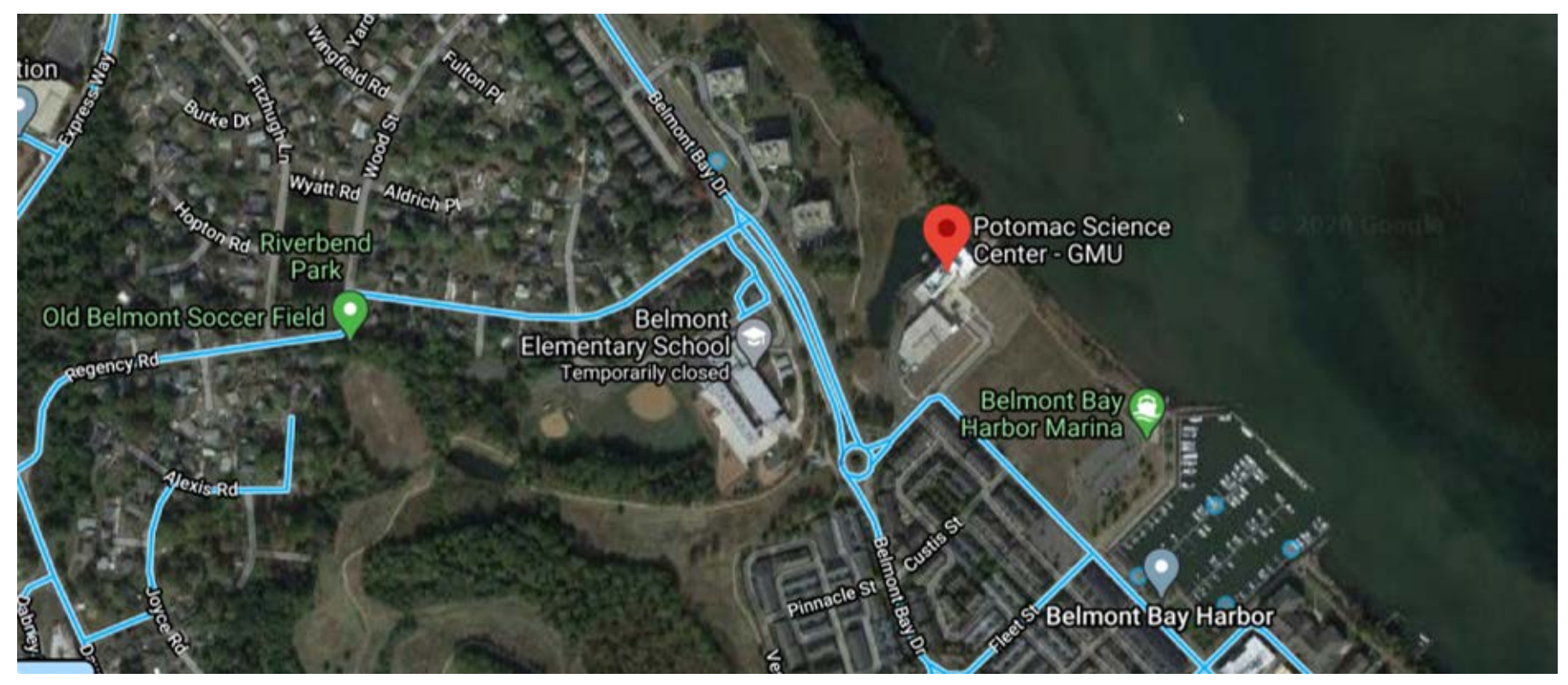


What mode of transport have you used to travel to/ use while at this site?

I have walked to this site as a pedestrian. I did not access this site via the NHST.

b. I have walked to this site as a pedestrian. I accessed this site via the NHST.

c. I have driven to the site and walked around the area.

d. I have visited this site as a cyclist from the NHST.

e. I have visited this site via bicycle without use of the NHST.

f. Other (Please specify.)

When you have visited the Potomac Science Center site, who do you come with?

a. I visit the site alone.

b. I visit with a friend or spouse.

c. I visit with my family (including children).

d. I visit with my family (including multigenerational family).

e. I have visited with a class or educational program.

Section 2: Residents 
How long have you lived in the [Belmont Bay Community Home Owner's Association] neighborhood?
Less than a year
1-2 years
2-4 years
4-6 years
$6+$ years

Would you say that your residency is more appealing because of its proximity to the Potomac Science Center and the outdoor landscape on its campus?
a. Yes
b. No
c. Unsure
d. I am a non-resident.

\section{Section 3: Site Features}

Six "Water Story" features connect to a specific stage in the movement of water throughout the site. These features are designed to visually demonstrate to visitors how a precipitated water droplet travels through the site and into the Occoquan River. These features include a roof drain with a weir into a rain garden, scuppers installed on the roof, and a table top installation to replicate characteristics of a dry creek bed. This is used to educate students and the public about water quality, erosion, and the Occoquan River it overlooks. 
Pictured: Green wall (left), terraced outdoor classroom (center), and rain garden (mid right). All of these are features of the Water Story.

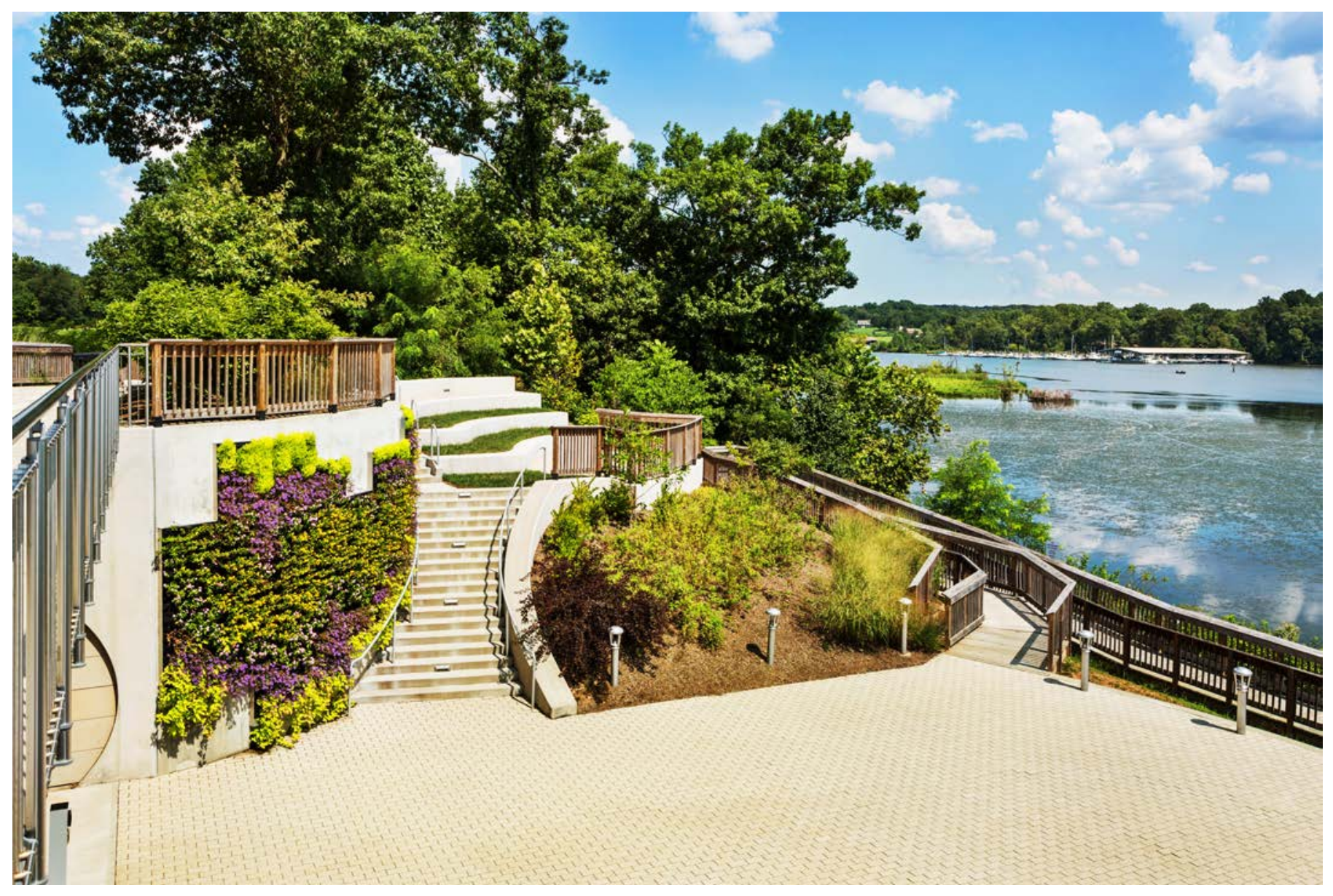


Pictured: Labeled water features at the site.

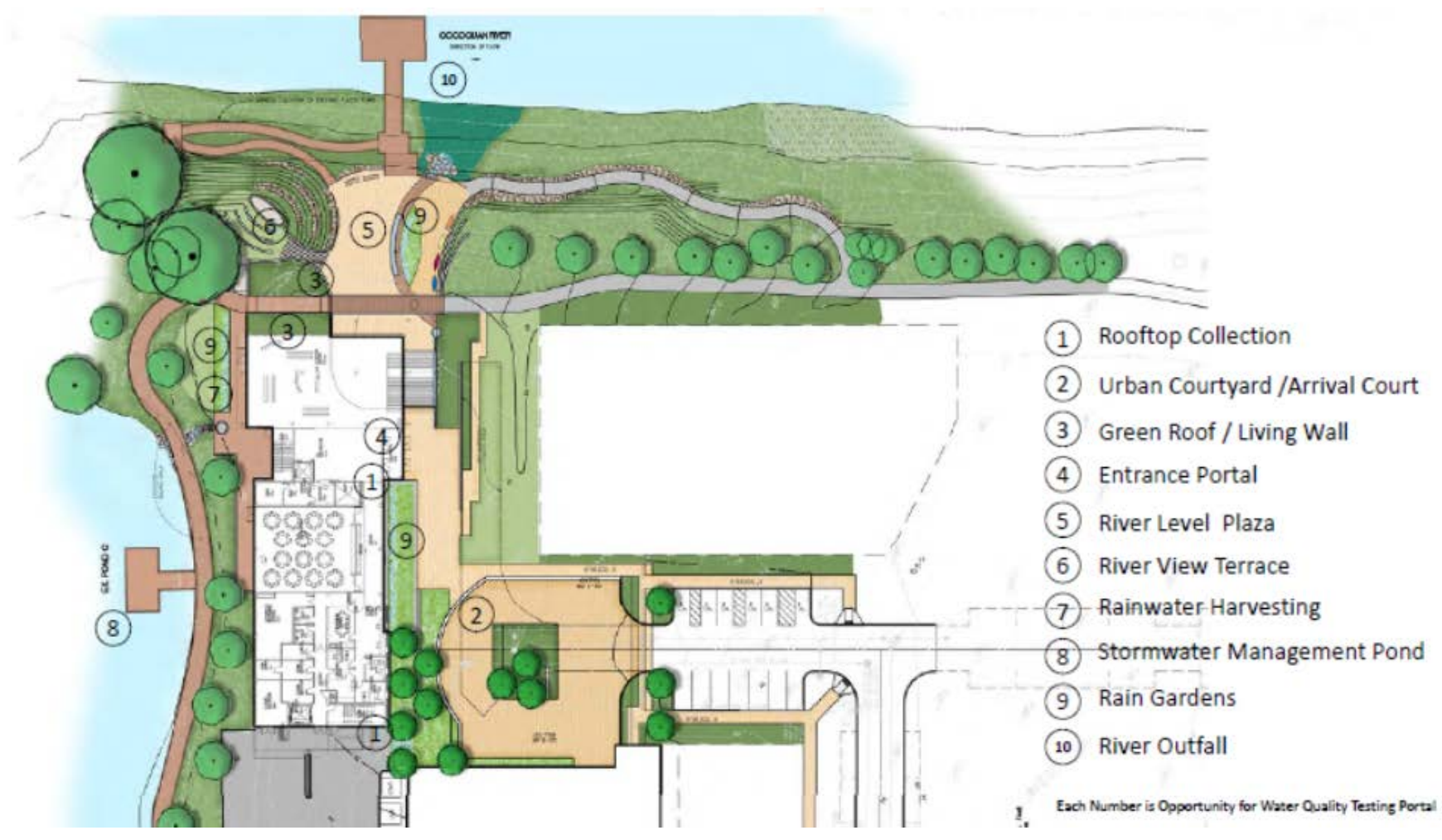

How do you feel like the Water Story features of this site influenced your experience with this site?

$\begin{array}{lllll}1 & 2 & 3 & 4 & 5\end{array}$

0. I was unaware that these Water Story features existed.

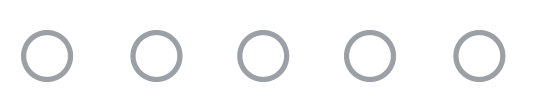

I am aware of most or all of these water features and they have greatly enriched my learning experience at the site. 
What specific features of the Potomac Science Center outdoor landscape have you seen or learned about during your time at the site?

a. Roof drain with a weir into a rain garden

b. Scuppers installed on the roof

c. Table top installation to replicate characteristics of a dry creek bed.

d. 5,000-gallon rainwater harvesting cistern collects water from the roof of the building and water condensation from the air conditioning system.

e. A 250-sf green wall located along the main plaza of the outdoor patio

f. A series of rain gardens and Infiltration swales throughout the site.

Would the addition of signage explaining the significance of each Water Story feature enhance your learning experience at this site?
a. Yes
b. No
c. Unsure

Thank you for your participation!

If you are interested in receiving a copy of this final case study - please share your email address with us. Copy and past the following link into your browser to share: https://forms.gle/d7bfZzi4N56F2SDH6

This form was created outside of your domain. 


\section{Potomac Science Center Visitor Assessment Survey}

This research is being conducted to evaluate how the construction and maintenance of the Potomac Science Center landscape has impacted the surrounding community. This information will be used to inform future landscape design projects at George Mason University and the larger landscape design industry (through submission to the Landscape Architecture Foundation).

\section{Informed Consent}

This research is being conducted to evaluate how the construction and maintenance of the Potomac Science Center landscape has impacted the surrounding community. This information will be used to inform future landscape design projects at George Mason University and the larger landscape design industry (through submission to the Landscape Architecture Foundation). If you agree to participate, you will be asked to complete a 10-minute online survey.

RISKS: There are no foreseeable risks for participating in this research.

BENEFITS: There are no benefits to you as a participant other than to further research in the landscape design field.

CONFIDENTIALITY: The data in this study will be confidential. Names and other identifiers will not be placed on research data. Participant's names and contact information will not be included on the surveys and other collectible data. If you choose to opt into sharing your contact information with us, it will be collected through a separate survey and completely separate from the data for this survey. This ensures that all data collected is de-identified immediately. The de-identified data could be used for future research without additional consent from participants. The Institutional Review Board (IRB) committee that monitors the research on human subjects may inspect study records during internal auditing procedures and are required to keep all information confidential.

PARTICIPATION: Your participation is voluntary, and you may withdraw from the study at any time and for any reason. If you decide not to participate or if you withdraw from the study, there is no penalty or loss of benefits to which you are otherwise entitled. There are no costs to you or any other party.

I have read this form, all of my questions have been answered by the research staff, and I agree to participate in this study.

Accept.

Decline. 


\section{Contact}

This research is being conducted by MacKenzie Earl at George Mason University. She may be reached at (540) 270-6483 or mearl@gmu.edu for questions or to report a research-related problem. Cynthia Smith (faculty advisor) be reached at csmitc@gmu.edu.You may contact the George Mason University Institutional Review Board office at 703-993-4121 or $\underline{I R B} @$ gmu.edu if you have questions or comments regarding your rights as a participant in the research. This research has been reviewed according to George Mason University procedures governing your participation in this research.

\section{Overview}

How would you describe your relation to the Potomac Science Center?

I am a resident of the region.

I am a resident of the Belmont Bay Community Home Owner's Association.

( I am a one time visitor to the facility.

I am an employee or contracted worker at the facility.

I am a faculty member or student with George Mason University.

\section{Section 4: Engagement}

How would you rate your level of engagement with the site indicated PRIOR to the construction of the Potomac Science Center in 2017?

0. I never engaged with this site prior to 2017

b. 1. I rarely engaged with this site prior to 2017.

c. 2. I engaged with this site prior to 2017 3-4 times prior to 2017.

d. 3. I often engaged with this site prior to construction in 2017.

e. 4. I often engaged with this site prior to construction in 2017 - including frequent use of the National Heritage Scenic Trail. 
Please indicate all of the ways you engaged with the site PRIOR to the construction of the Potomac Science Center in 2017.

$\square$ a Used the National Heritage Scenic Trail for recreational use.

b. Enjoyed the view of the Occoquan River.

$\checkmark$ c. Engaged in ecological-based recreation (bird watching, plant identification, ect.)

d. Visited the site to learn about watersheds, water ecology, conservation, and other topics.

e. I did not engage with this site at all prior to the construction of the PSC.

Other:

\section{Untitled Section}

How would you rate your level of engagement with the site indicated AFTER the construction of the Potomac Science Center in 2017?

a. I never engage with this site.

b. I rarely engage with this site.

c. I engaged with this site 3-4 times a year.

(.) I I often engage with this site.

e. I often engage with this site - including frequent use of the National Heritage Scenic Trail. 
Please indicate all of the ways you engaged with the site AFTER its construction concluded?

$\square$ a Used the National Heritage Scenic Trail for recreational use.

$\square$ b. Enjoyed the view of the Occoquan River.

c. Engaged in ecological-based recreation (bird watching, plant identification, ect.)

d. Visited the site to learn about watersheds, water ecology, conservation, and other topics.

e. Other (Option to write in.)

\section{Section 2: General Information}

\section{Current Aerial of the Potomac Science Center}

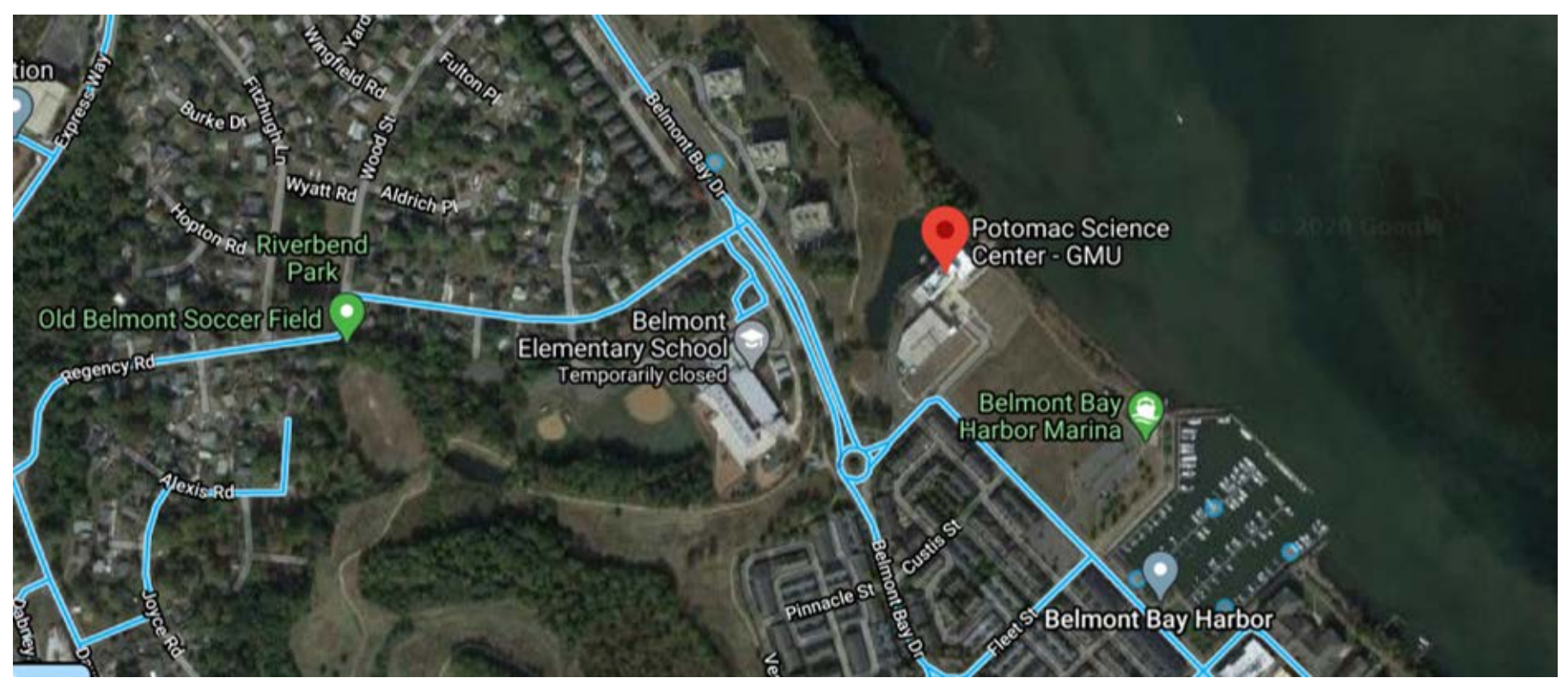


What mode of transport have you used to travel to/ use while at this site?

(-) I have walked to this site as a pedestrian. I did not access this site via the NHST.

b. I have walked to this site as a pedestrian. I accessed this site via the NHST.

c. I have driven to the site and walked around the area.

d. I have visited this site as a cyclist from the NHST.

e. I have visited this site via bicycle without use of the NHST.

f. Other (Please specify.)

When you have visited the Potomac Science Center site, who do you come with?

a. I visit the site alone.

b. I visit with a friend or spouse.

c. I visit with my family (including children).

d. I visit with my family (including multigenerational family).

e. I have visited with a class or educational program.

Section 2: Residents 
How long have you lived in the [Belmont Bay Community Home Owner's Association] neighborhood?
Less than a year
1-2 years
2-4 years
4-6 years
$6+$ years

Would you say that your residency is more appealing because of its proximity to the Potomac Science Center and the outdoor landscape on its campus?
a. Yes
b. No
c. Unsure
d. I am a non-resident.

\section{Section 3: Site Features}

Six "Water Story" features connect to a specific stage in the movement of water throughout the site. These features are designed to visually demonstrate to visitors how a precipitated water droplet travels through the site and into the Occoquan River. These features include a roof drain with a weir into a rain garden, scuppers installed on the roof, and a table top installation to replicate characteristics of a dry creek bed. This is used to educate students and the public about water quality, erosion, and the Occoquan River it overlooks. 
Pictured: Green wall (left), terraced outdoor classroom (center), and rain garden (mid right). All of these are features of the Water Story.

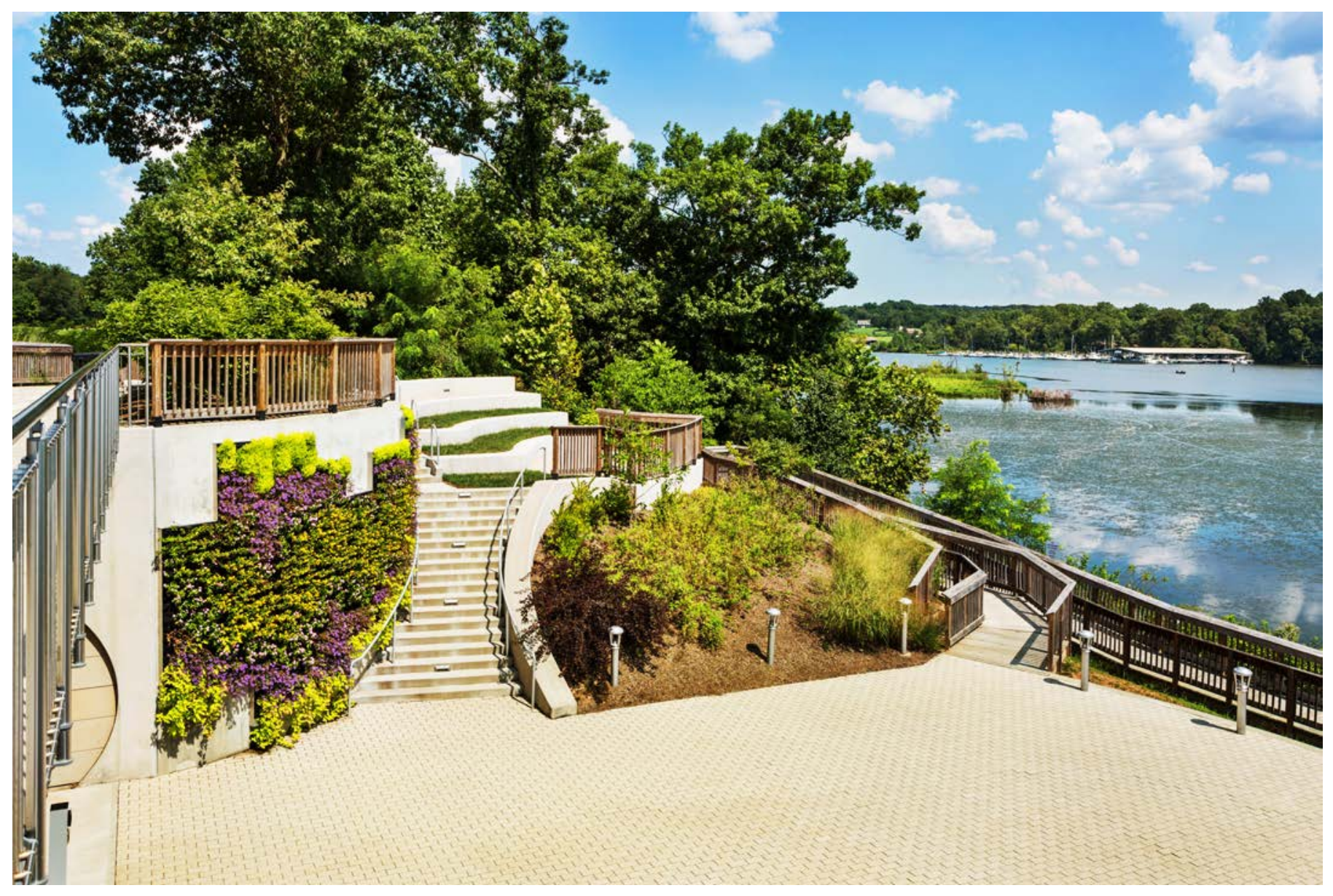


Pictured: Labeled water features at the site.

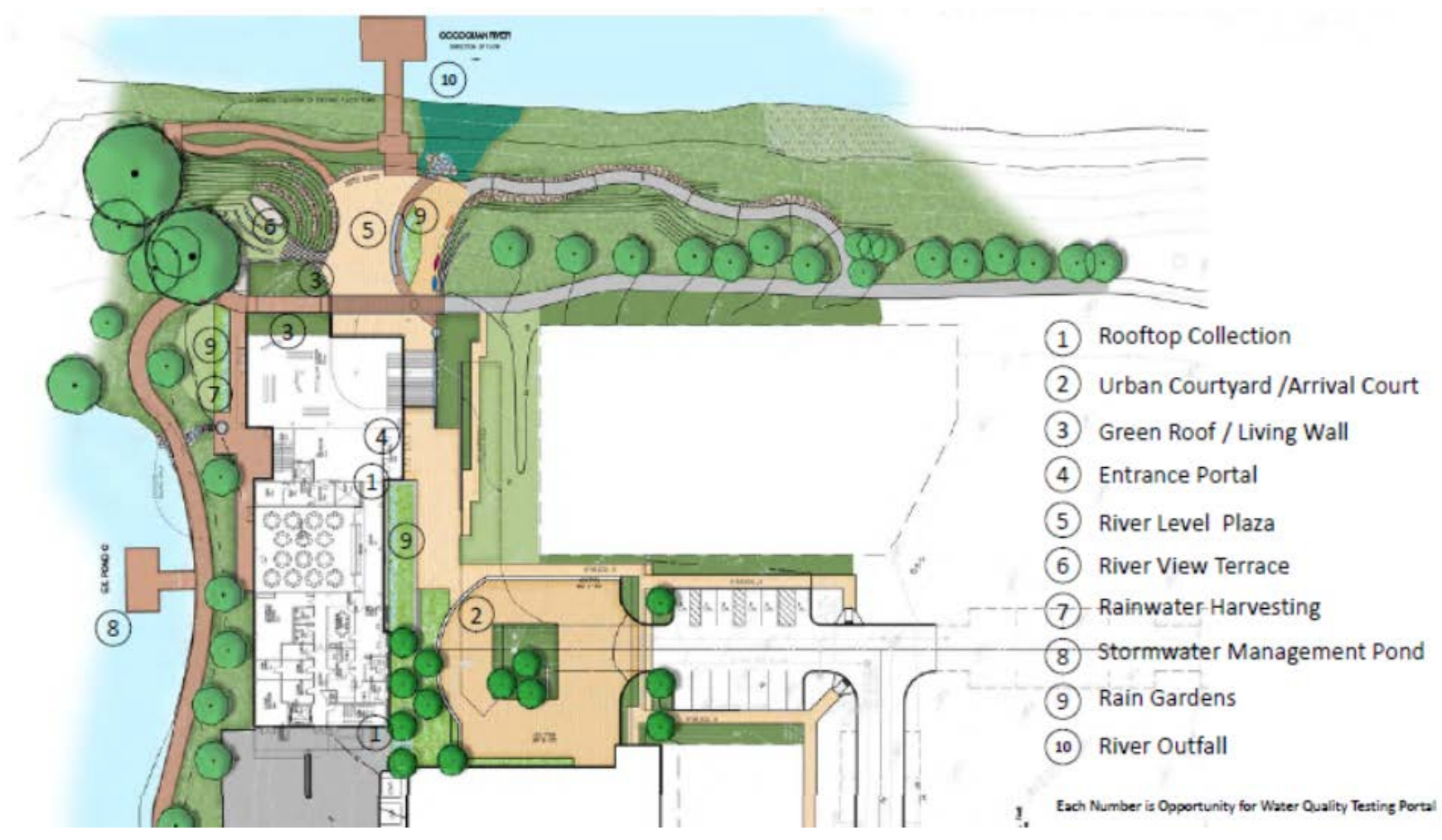

How do you feel like the Water Story features of this site influenced your experience with this site?

$\begin{array}{lllll}1 & 2 & 3 & 4 & 5\end{array}$

0. I was unaware that these Water Story features existed.

$\bigcirc \bigcirc \quad \begin{gathered}\text { I am aware of most or all of these } \\ \text { water features and they have }\end{gathered}$ greatly enriched my learning experience at the site. 
What specific features of the Potomac Science Center outdoor landscape have you seen or learned about during your time at the site?

a. Roof drain with a weir into a rain garden

b. Scuppers installed on the roof

c. Table top installation to replicate characteristics of a dry creek bed.

d. 5,000-gallon rainwater harvesting cistern collects water from the roof of the building and water condensation from the air conditioning system.

$\checkmark$ e. A 250-sf green wall located along the main plaza of the outdoor patio

f. A series of rain gardens and Infiltration swales throughout the site.

Would the addition of signage explaining the significance of each Water Story feature enhance your learning experience at this site?
(O) Yes
b. No
c. Unsure

Thank you for your participation!

If you are interested in receiving a copy of this final case study - please share your email address with us. Copy and past the following link into your browser to share: https://forms.gle/d7bfZzi4N56F2SDH6

This form was created outside of your domain. 


\section{Potomac Science Center Visitor Assessment Survey}

This research is being conducted to evaluate how the construction and maintenance of the Potomac Science Center landscape has impacted the surrounding community. This information will be used to inform future landscape design projects at George Mason University and the larger landscape design industry (through submission to the Landscape Architecture Foundation).

\section{Informed Consent}

This research is being conducted to evaluate how the construction and maintenance of the Potomac Science Center landscape has impacted the surrounding community. This information will be used to inform future landscape design projects at George Mason University and the larger landscape design industry (through submission to the Landscape Architecture Foundation). If you agree to participate, you will be asked to complete a 10-minute online survey.

RISKS: There are no foreseeable risks for participating in this research.

BENEFITS: There are no benefits to you as a participant other than to further research in the landscape design field.

CONFIDENTIALITY: The data in this study will be confidential. Names and other identifiers will not be placed on research data. Participant's names and contact information will not be included on the surveys and other collectible data. If you choose to opt into sharing your contact information with us, it will be collected through a separate survey and completely separate from the data for this survey. This ensures that all data collected is de-identified immediately. The de-identified data could be used for future research without additional consent from participants. The Institutional Review Board (IRB) committee that monitors the research on human subjects may inspect study records during internal auditing procedures and are required to keep all information confidential.

PARTICIPATION: Your participation is voluntary, and you may withdraw from the study at any time and for any reason. If you decide not to participate or if you withdraw from the study, there is no penalty or loss of benefits to which you are otherwise entitled. There are no costs to you or any other party.

I have read this form, all of my questions have been answered by the research staff, and I agree to participate in this study.

Accept.

Decline. 


\section{Contact}

This research is being conducted by MacKenzie Earl at George Mason University. She may be reached at (540) 270-6483 or mearl@gmu.edu for questions or to report a research-related problem. Cynthia Smith (faculty advisor) be reached at csmitc@gmu.edu.You may contact the George Mason University Institutional Review Board office at 703-993-4121 or $\underline{I R B} @$ gmu.edu if you have questions or comments regarding your rights as a participant in the research. This research has been reviewed according to George Mason University procedures governing your participation in this research.

\section{Overview}

How would you describe your relation to the Potomac Science Center?

I am a resident of the region.

I am a resident of the Belmont Bay Community Home Owner's Association.

I am a one time visitor to the facility.

I am an employee or contracted worker at the facility.

(- I am a faculty member or student with George Mason University.

\section{Section 4: Engagement}

How would you rate your level of engagement with the site indicated PRIOR to the construction of the Potomac Science Center in 2017?

0. I never engaged with this site prior to 2017

b. 1. I rarely engaged with this site prior to 2017.

c. 2. I engaged with this site prior to 2017 3-4 times prior to 2017.

d. 3. I often engaged with this site prior to construction in 2017.

e. 4. I often engaged with this site prior to construction in 2017 - including frequent use of the National Heritage Scenic Trail. 
Please indicate all of the ways you engaged with the site PRIOR to the construction of the Potomac Science Center in 2017.

$\square$ a Used the National Heritage Scenic Trail for recreational use.

b. Enjoyed the view of the Occoquan River.

c. Engaged in ecological-based recreation (bird watching, plant identification, ect.)

d. Visited the site to learn about watersheds, water ecology, conservation, and other topics.

e. I did not engage with this site at all prior to the construction of the PSC.

Other:

\section{Untitled Section}

How would you rate your level of engagement with the site indicated AFTER the construction of the Potomac Science Center in 2017?

a. I never engage with this site.

b. I rarely engage with this site.

c. I engaged with this site 3-4 times a year.

d. I often engage with this site.

(2) I often engage with this site - including frequent use of the National Heritage Scenic Trail. 
Please indicate all of the ways you engaged with the site AFTER its construction concluded?

a Used the National Heritage Scenic Trail for recreational use.

b. Enjoyed the view of the Occoquan River.

c. Engaged in ecological-based recreation (bird watching, plant identification, ect.)

d. Visited the site to learn about watersheds, water ecology, conservation, and other topics.

e. Other (Option to write in.)

\section{Section 2: General Information}

Current Aerial of the Potomac Science Center

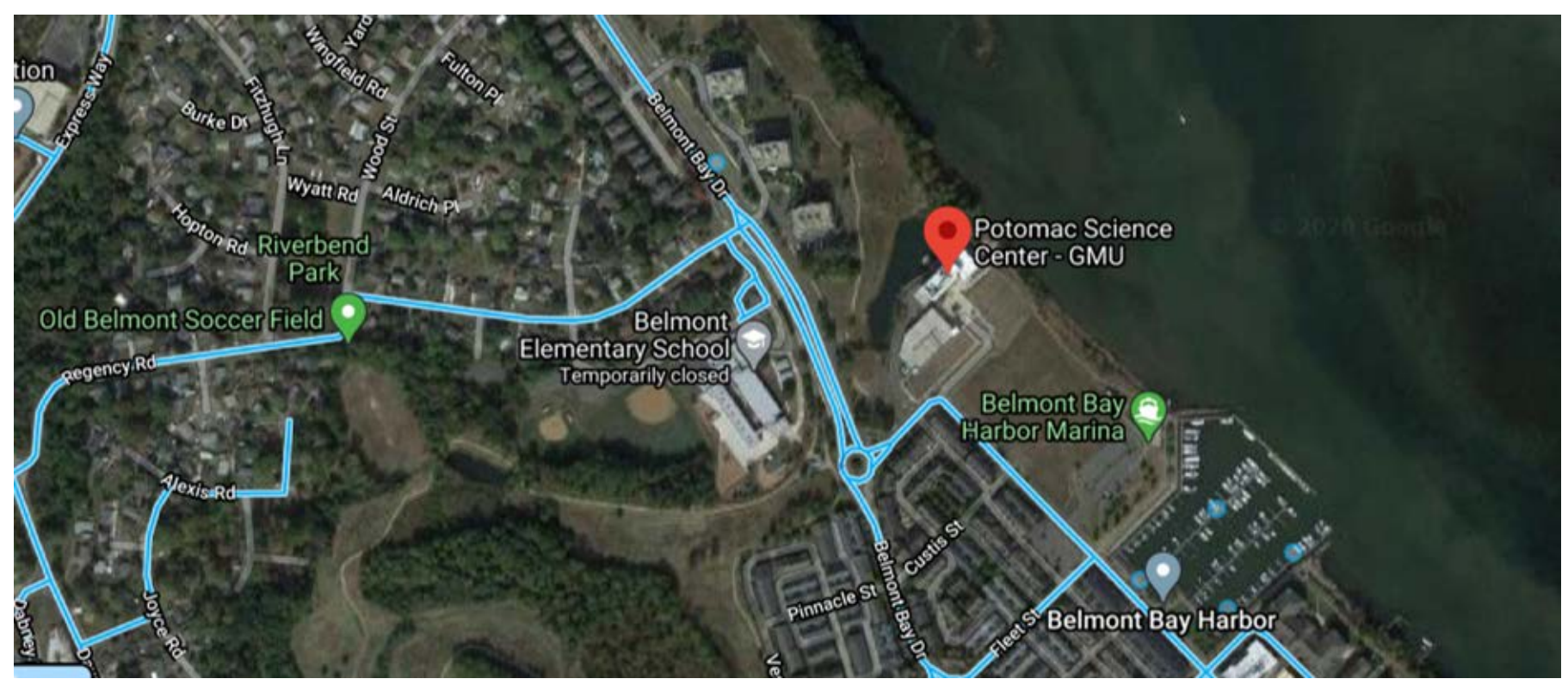


What mode of transport have you used to travel to/ use while at this site?

I have walked to this site as a pedestrian. I did not access this site via the NHST.

b. I have walked to this site as a pedestrian. I accessed this site via the NHST.

(- c. I have driven to the site and walked around the area.

d. I have visited this site as a cyclist from the NHST.

e. I have visited this site via bicycle without use of the NHST.

f. Other (Please specify.)

When you have visited the Potomac Science Center site, who do you come with?

$\checkmark$ a. I visit the site alone.

b. I visit with a friend or spouse.

c. I visit with my family (including children).

d. I visit with my family (including multigenerational family).

e. I have visited with a class or educational program.

Section 2: Residents 
How long have you lived in the [Belmont Bay Community Home Owner's Association] neighborhood?
Less than a year
1-2 years
2-4 years
4-6 years
$6+$ years

Would you say that your residency is more appealing because of its proximity to the Potomac Science Center and the outdoor landscape on its campus?
a. Yes
b. No
c. Unsure
d. I am a non-resident.

\section{Section 3: Site Features}

Six "Water Story" features connect to a specific stage in the movement of water throughout the site. These features are designed to visually demonstrate to visitors how a precipitated water droplet travels through the site and into the Occoquan River. These features include a roof drain with a weir into a rain garden, scuppers installed on the roof, and a table top installation to replicate characteristics of a dry creek bed. This is used to educate students and the public about water quality, erosion, and the Occoquan River it overlooks. 
Pictured: Green wall (left), terraced outdoor classroom (center), and rain garden (mid right). All of these are features of the Water Story.

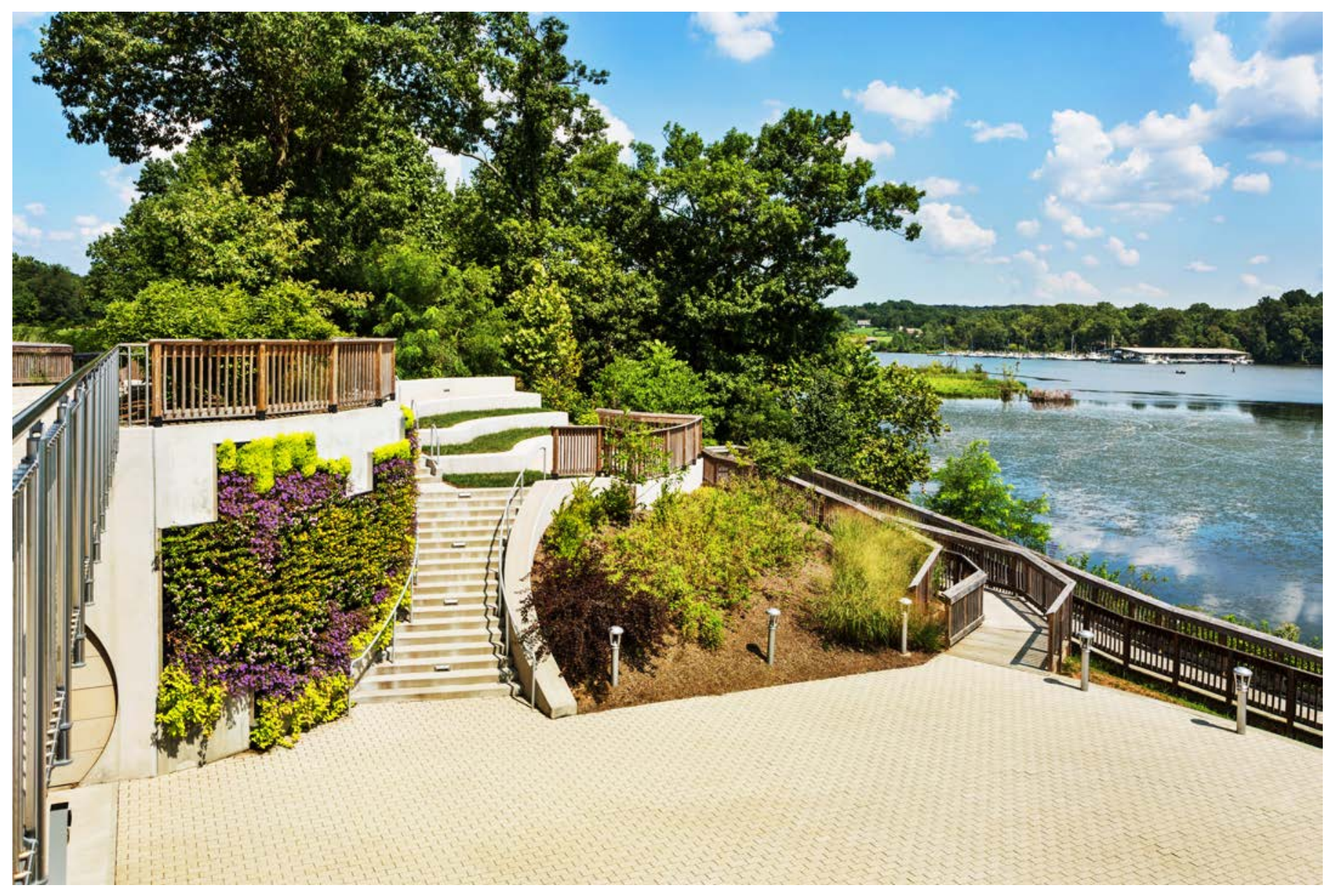


Pictured: Labeled water features at the site.

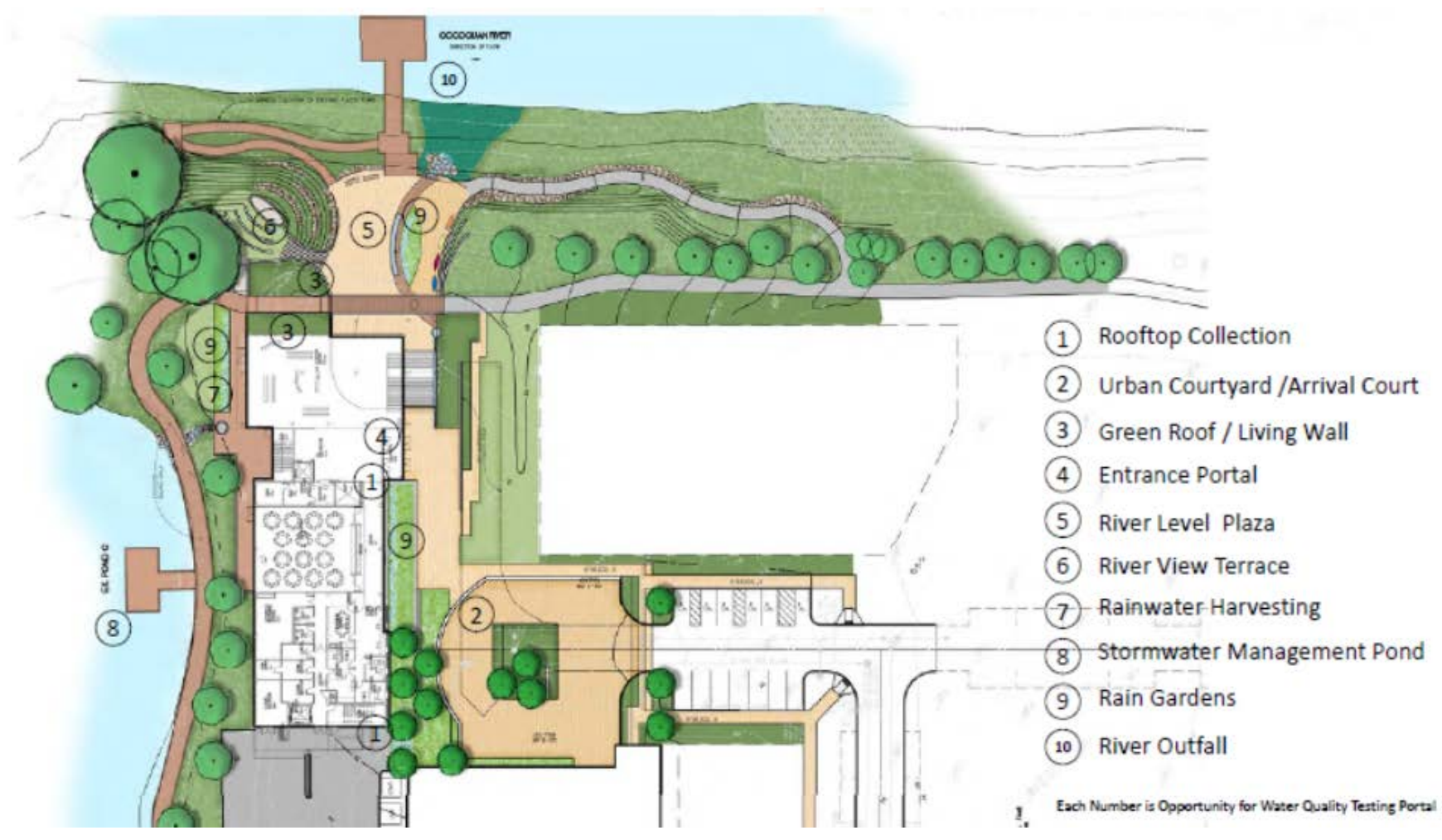

How do you feel like the Water Story features of this site influenced your experience with this site?

$\begin{array}{lllll}1 & 2 & 3 & 4 & 5\end{array}$

0. I was unaware that these Water Story features existed.

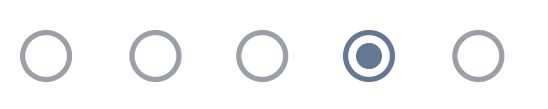

I am aware of most or all of these water features and they have greatly enriched my learning experience at the site. 
What specific features of the Potomac Science Center outdoor landscape have you seen or learned about during your time at the site?

$\checkmark$ a. Roof drain with a weir into a rain garden

b. Scuppers installed on the roof

c. Table top installation to replicate characteristics of a dry creek bed.

d. 5,000-gallon rainwater harvesting cistern collects water from the roof of the building and water condensation from the air conditioning system.

$\checkmark$ e. A 250-sf green wall located along the main plaza of the outdoor patio

f. A series of rain gardens and Infiltration swales throughout the site.

Would the addition of signage explaining the significance of each Water Story feature enhance your learning experience at this site?
a. Yes
b. No
c. Unsure

Thank you for your participation!

If you are interested in receiving a copy of this final case study - please share your email address with us. Copy and past the following link into your browser to share: https://forms.gle/d7bfZzi4N56F2SDH6

This form was created outside of your domain.

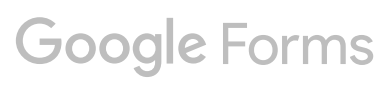




\section{Potomac Science Center Visitor Assessment Survey}

This research is being conducted to evaluate how the construction and maintenance of the Potomac Science Center landscape has impacted the surrounding community. This information will be used to inform future landscape design projects at George Mason University and the larger landscape design industry (through submission to the Landscape Architecture Foundation).

\section{Informed Consent}

This research is being conducted to evaluate how the construction and maintenance of the Potomac Science Center landscape has impacted the surrounding community. This information will be used to inform future landscape design projects at George Mason University and the larger landscape design industry (through submission to the Landscape Architecture Foundation). If you agree to participate, you will be asked to complete a 10-minute online survey.

RISKS: There are no foreseeable risks for participating in this research.

BENEFITS: There are no benefits to you as a participant other than to further research in the landscape design field.

CONFIDENTIALITY: The data in this study will be confidential. Names and other identifiers will not be placed on research data. Participant's names and contact information will not be included on the surveys and other collectible data. If you choose to opt into sharing your contact information with us, it will be collected through a separate survey and completely separate from the data for this survey. This ensures that all data collected is de-identified immediately. The de-identified data could be used for future research without additional consent from participants. The Institutional Review Board (IRB) committee that monitors the research on human subjects may inspect study records during internal auditing procedures and are required to keep all information confidential.

PARTICIPATION: Your participation is voluntary, and you may withdraw from the study at any time and for any reason. If you decide not to participate or if you withdraw from the study, there is no penalty or loss of benefits to which you are otherwise entitled. There are no costs to you or any other party.

I have read this form, all of my questions have been answered by the research staff, and I agree to participate in this study.

Accept.

Decline. 


\section{Contact}

This research is being conducted by MacKenzie Earl at George Mason University. She may be reached at (540) 270-6483 or mearl@gmu.edu for questions or to report a research-related problem. Cynthia Smith (faculty advisor) be reached at csmitc@gmu.edu.You may contact the George Mason University Institutional Review Board office at 703-993-4121 or $\underline{I R B} @$ gmu.edu if you have questions or comments regarding your rights as a participant in the research. This research has been reviewed according to George Mason University procedures governing your participation in this research.

\section{Overview}

How would you describe your relation to the Potomac Science Center?

( I am a resident of the region.

I am a resident of the Belmont Bay Community Home Owner's Association.

I am a one time visitor to the facility.

I am an employee or contracted worker at the facility.

I am a faculty member or student with George Mason University.

\section{Section 4: Engagement}

How would you rate your level of engagement with the site indicated PRIOR to the construction of the Potomac Science Center in 2017?

0. I never engaged with this site prior to 2017

b. 1 . I rarely engaged with this site prior to 2017 .

c. 2. I engaged with this site prior to 2017 3-4 times prior to 2017.

d. 3. I often engaged with this site prior to construction in 2017.

e. 4. I often engaged with this site prior to construction in 2017 - including frequent use of the National Heritage Scenic Trail. 
Please indicate all of the ways you engaged with the site PRIOR to the construction of the Potomac Science Center in 2017.

$\square$ a Used the National Heritage Scenic Trail for recreational use.

b. Enjoyed the view of the Occoquan River.

c. Engaged in ecological-based recreation (bird watching, plant identification, ect.)

d. Visited the site to learn about watersheds, water ecology, conservation, and other topics.

e. I did not engage with this site at all prior to the construction of the PSC.

Other:

\section{Untitled Section}

How would you rate your level of engagement with the site indicated AFTER the construction of the Potomac Science Center in 2017?

(-) a. I never engage with this site.

b. I rarely engage with this site.

c. I engaged with this site 3-4 times a year.

d. I often engage with this site.

e. I often engage with this site - including frequent use of the National Heritage Scenic Trail. 
Please indicate all of the ways you engaged with the site AFTER its construction concluded?

$\square$ a Used the National Heritage Scenic Trail for recreational use.

$\square$ b. Enjoyed the view of the Occoquan River.

$\square$ c. Engaged in ecological-based recreation (bird watching, plant identification, ect.)

$\square$ d. Visited the site to learn about watersheds, water ecology, conservation, and other topics.

$\square$ e. Other (Option to write in.)

\section{Section 2: General Information}

\section{Current Aerial of the Potomac Science Center}

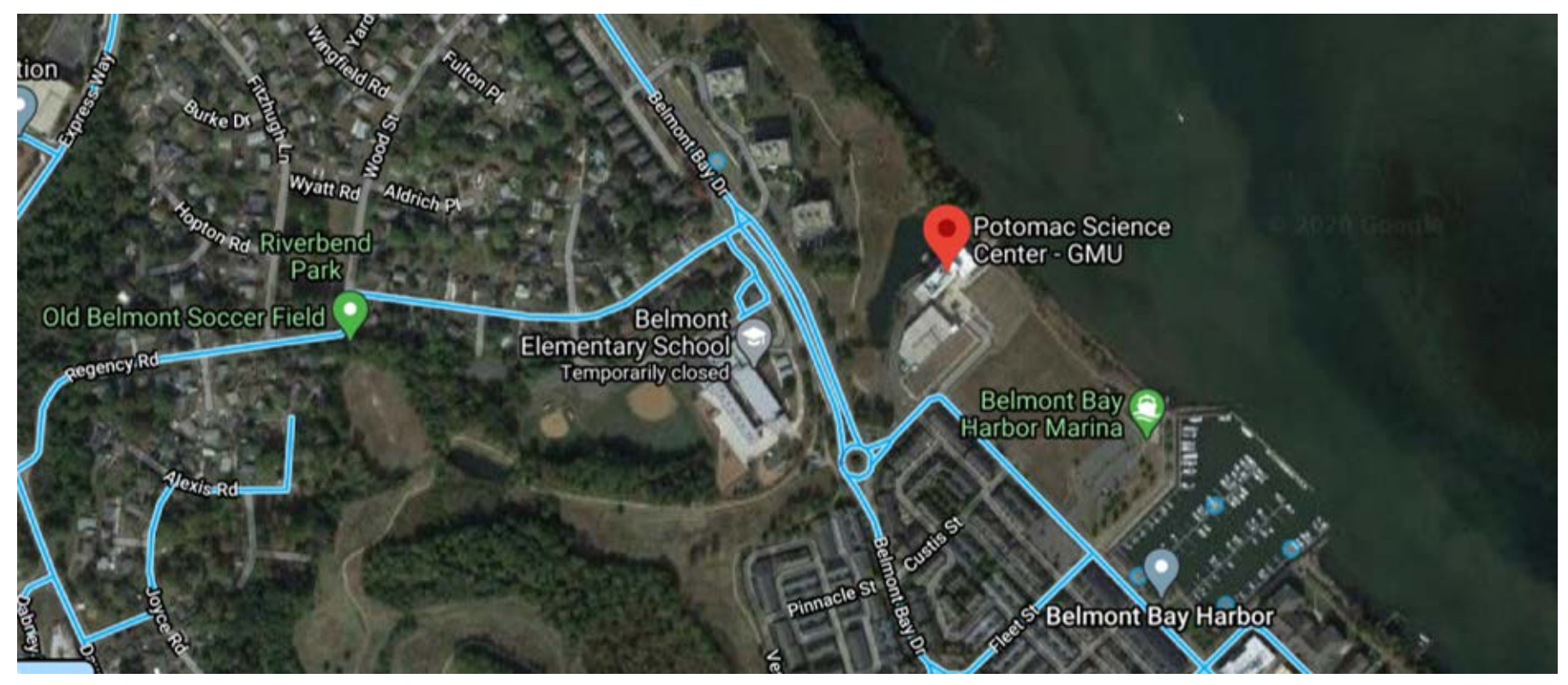


What mode of transport have you used to travel to/ use while at this site?

I have walked to this site as a pedestrian. I did not access this site via the NHST.

b. I have walked to this site as a pedestrian. I accessed this site via the NHST.

c. I have driven to the site and walked around the area.

d. I have visited this site as a cyclist from the NHST.

e. I have visited this site via bicycle without use of the NHST.

f. Other (Please specify.)

When you have visited the Potomac Science Center site, who do you come with?

a. I visit the site alone.

b. I visit with a friend or spouse.

c. I visit with my family (including children).

d. I visit with my family (including multigenerational family).

e. I have visited with a class or educational program.

Section 2: Residents 
How long have you lived in the [Belmont Bay Community Home Owner's Association] neighborhood?
Less than a year
1-2 years
2-4 years
4-6 years
$6+$ years

Would you say that your residency is more appealing because of its proximity to the Potomac Science Center and the outdoor landscape on its campus?
a. Yes
b. No
c. Unsure
d. I am a non-resident.

\section{Section 3: Site Features}

Six "Water Story" features connect to a specific stage in the movement of water throughout the site. These features are designed to visually demonstrate to visitors how a precipitated water droplet travels through the site and into the Occoquan River. These features include a roof drain with a weir into a rain garden, scuppers installed on the roof, and a table top installation to replicate characteristics of a dry creek bed. This is used to educate students and the public about water quality, erosion, and the Occoquan River it overlooks. 
Pictured: Green wall (left), terraced outdoor classroom (center), and rain garden (mid right). All of these are features of the Water Story.

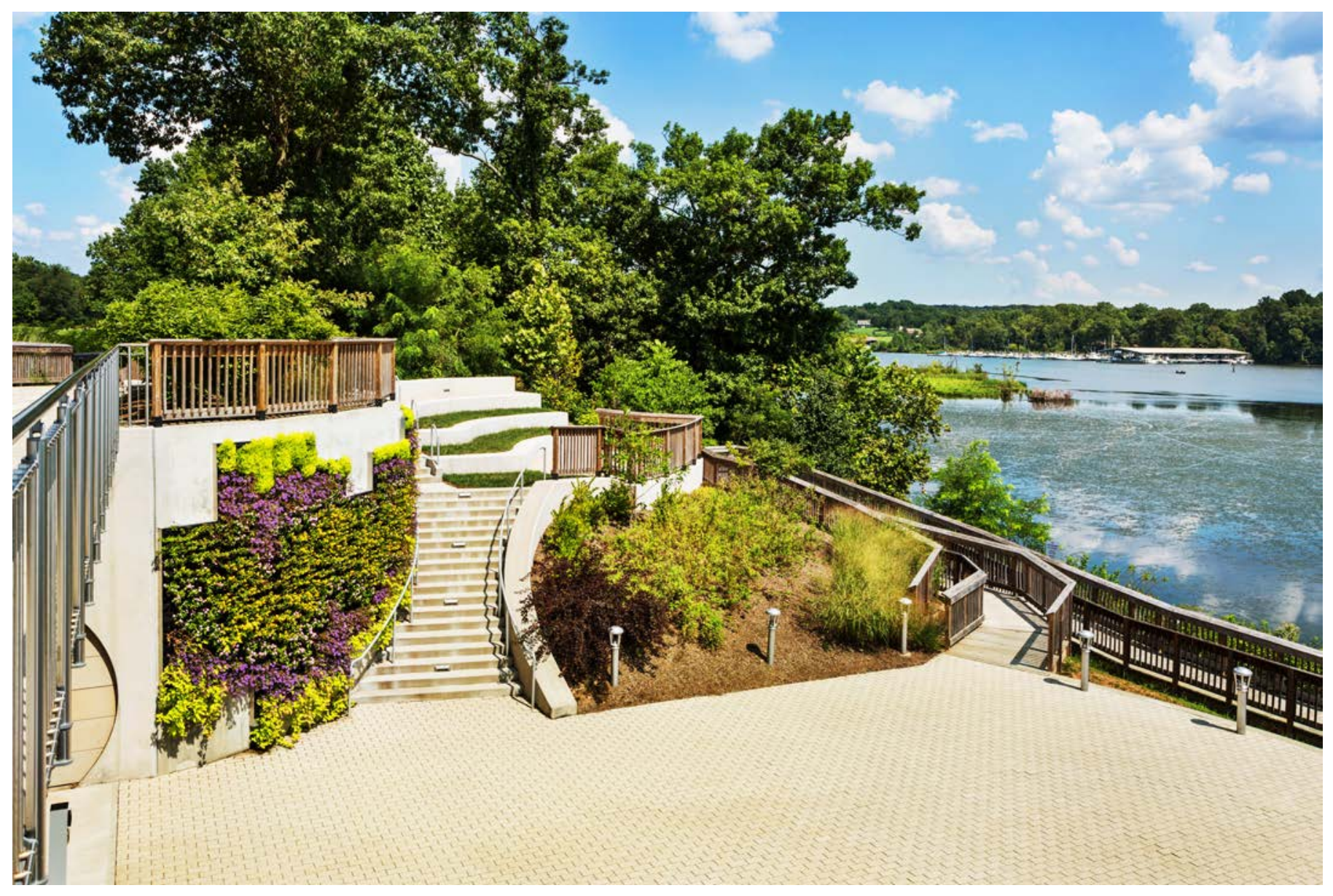


Pictured: Labeled water features at the site.

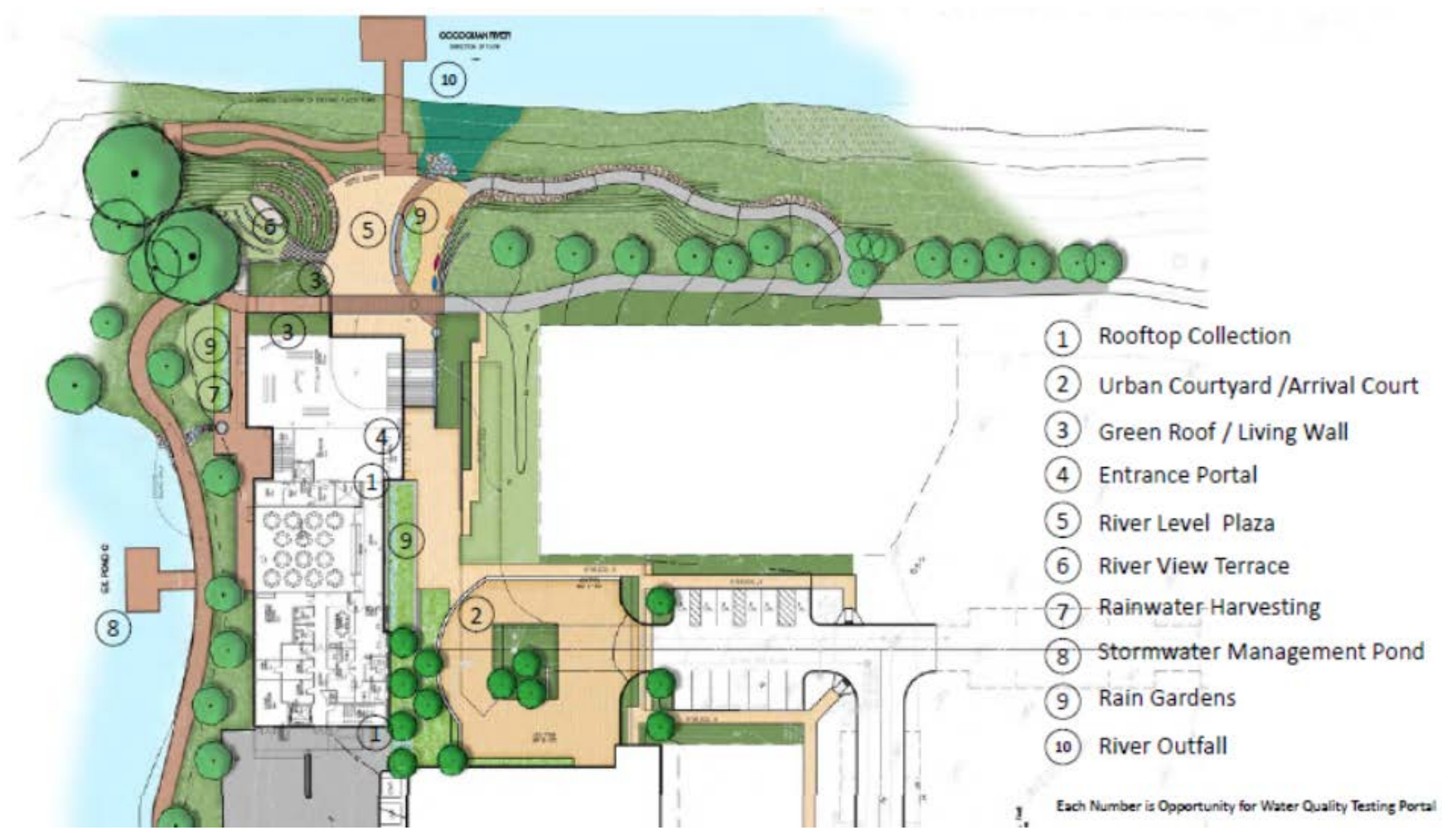

How do you feel like the Water Story features of this site influenced your experience with this site?

$\begin{array}{lllll}1 & 2 & 3 & 4 & 5\end{array}$

0. I was unaware that these Water Story features existed.

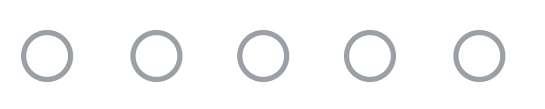

I am aware of most or all of these water features and they have greatly enriched my learning experience at the site. 
What specific features of the Potomac Science Center outdoor landscape have you seen or learned about during your time at the site?

a. Roof drain with a weir into a rain garden

b. Scuppers installed on the roof

c. Table top installation to replicate characteristics of a dry creek bed.

d. 5,000-gallon rainwater harvesting cistern collects water from the roof of the building and water condensation from the air conditioning system.

e. A 250-sf green wall located along the main plaza of the outdoor patio

f. A series of rain gardens and Infiltration swales throughout the site.

Would the addition of signage explaining the significance of each Water Story feature enhance your learning experience at this site?
a. Yes
b. No
c. Unsure

Thank you for your participation!

If you are interested in receiving a copy of this final case study - please share your email address with us. Copy and past the following link into your browser to share: https://forms.gle/d7bfZzi4N56F2SDH6

This form was created outside of your domain. 


\section{Potomac Science Center Visitor Assessment Survey}

This research is being conducted to evaluate how the construction and maintenance of the Potomac Science Center landscape has impacted the surrounding community. This information will be used to inform future landscape design projects at George Mason University and the larger landscape design industry (through submission to the Landscape Architecture Foundation).

\section{Informed Consent}

This research is being conducted to evaluate how the construction and maintenance of the Potomac Science Center landscape has impacted the surrounding community. This information will be used to inform future landscape design projects at George Mason University and the larger landscape design industry (through submission to the Landscape Architecture Foundation). If you agree to participate, you will be asked to complete a 10-minute online survey.

RISKS: There are no foreseeable risks for participating in this research.

BENEFITS: There are no benefits to you as a participant other than to further research in the landscape design field.

CONFIDENTIALITY: The data in this study will be confidential. Names and other identifiers will not be placed on research data. Participant's names and contact information will not be included on the surveys and other collectible data. If you choose to opt into sharing your contact information with us, it will be collected through a separate survey and completely separate from the data for this survey. This ensures that all data collected is de-identified immediately. The de-identified data could be used for future research without additional consent from participants. The Institutional Review Board (IRB) committee that monitors the research on human subjects may inspect study records during internal auditing procedures and are required to keep all information confidential.

PARTICIPATION: Your participation is voluntary, and you may withdraw from the study at any time and for any reason. If you decide not to participate or if you withdraw from the study, there is no penalty or loss of benefits to which you are otherwise entitled. There are no costs to you or any other party.

I have read this form, all of my questions have been answered by the research staff, and I agree to participate in this study.

Accept.

Decline. 


\section{Contact}

This research is being conducted by MacKenzie Earl at George Mason University. She may be reached at (540) 270-6483 or mearl@gmu.edu for questions or to report a research-related problem. Cynthia Smith (faculty advisor) be reached at csmitc@gmu.edu.You may contact the George Mason University Institutional Review Board office at 703-993-4121 or $\underline{I R B} @$ gmu.edu if you have questions or comments regarding your rights as a participant in the research. This research has been reviewed according to George Mason University procedures governing your participation in this research.

\section{Overview}

How would you describe your relation to the Potomac Science Center?

I am a resident of the region.

I am a resident of the Belmont Bay Community Home Owner's Association.

I am a one time visitor to the facility.

I am an employee or contracted worker at the facility.

( I am a faculty member or student with George Mason University.

\section{Section 4: Engagement}

How would you rate your level of engagement with the site indicated PRIOR to the construction of the Potomac Science Center in 2017?

0. I never engaged with this site prior to 2017

b. 1. I rarely engaged with this site prior to 2017.

c. 2. I engaged with this site prior to 2017 3-4 times prior to 2017.

d. 3. I often engaged with this site prior to construction in 2017.

e. 4. I often engaged with this site prior to construction in 2017 - including frequent use of the National Heritage Scenic Trail. 
Please indicate all of the ways you engaged with the site PRIOR to the construction of the Potomac Science Center in 2017.

$\square$ a Used the National Heritage Scenic Trail for recreational use.

b. Enjoyed the view of the Occoquan River.

c. Engaged in ecological-based recreation (bird watching, plant identification, ect.)

d. Visited the site to learn about watersheds, water ecology, conservation, and other topics.

e. I did not engage with this site at all prior to the construction of the PSC.

Other:

\section{Untitled Section}

How would you rate your level of engagement with the site indicated AFTER the construction of the Potomac Science Center in 2017?

a. I never engage with this site.

b. I rarely engage with this site.

c. I engaged with this site 3-4 times a year.

(.) d. I often engage with this site.

e. I often engage with this site - including frequent use of the National Heritage Scenic Trail. 
Please indicate all of the ways you engaged with the site AFTER its construction concluded?

$\square$ a Used the National Heritage Scenic Trail for recreational use.

b. Enjoyed the view of the Occoquan River.

c. Engaged in ecological-based recreation (bird watching, plant identification, ect.)

d. Visited the site to learn about watersheds, water ecology, conservation, and other topics.

e. Other (Option to write in.)

\section{Section 2: General Information}

\section{Current Aerial of the Potomac Science Center}

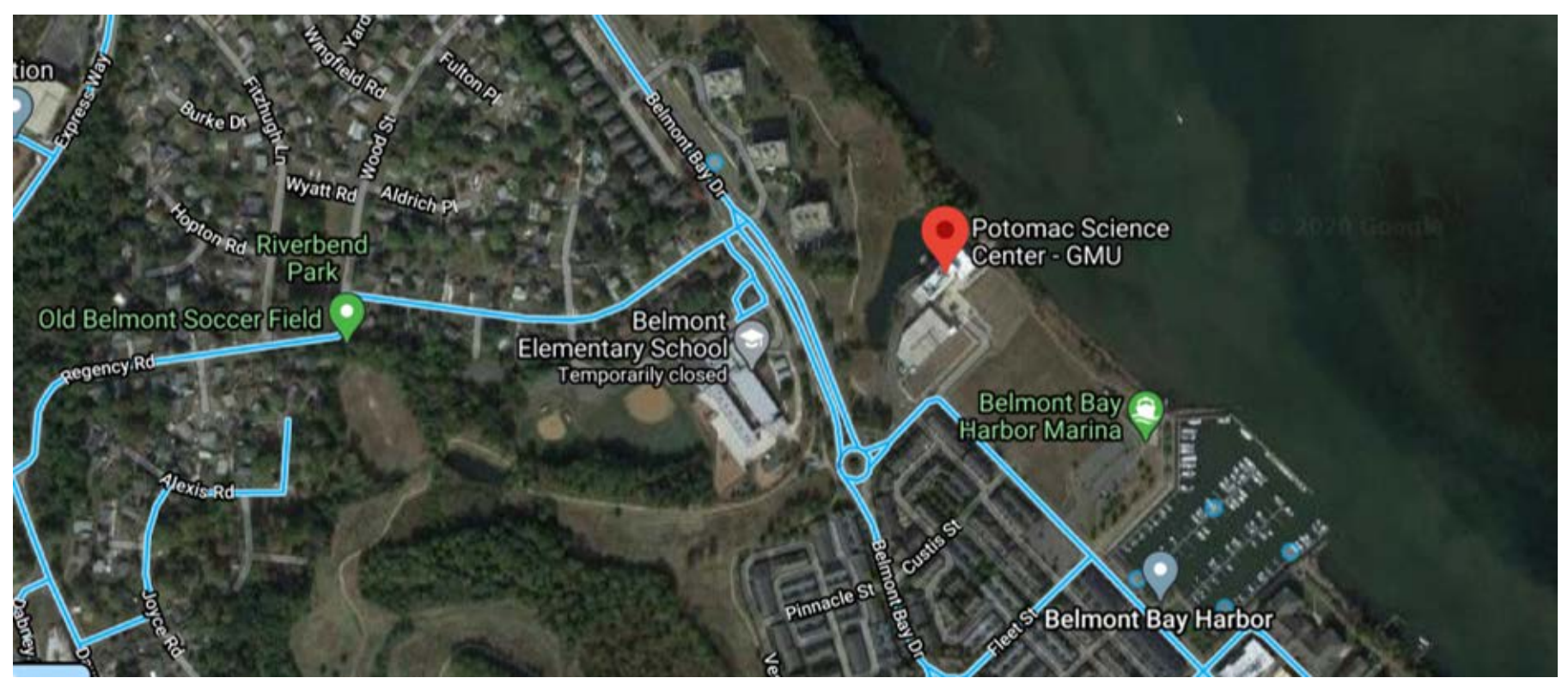


What mode of transport have you used to travel to/ use while at this site?

I have walked to this site as a pedestrian. I did not access this site via the NHST.

b. I have walked to this site as a pedestrian. I accessed this site via the NHST.

(- c. I have driven to the site and walked around the area.

d. I have visited this site as a cyclist from the NHST.

e. I have visited this site via bicycle without use of the NHST.

f. Other (Please specify.)

When you have visited the Potomac Science Center site, who do you come with?

$\checkmark$ a. I visit the site alone.

b. I visit with a friend or spouse.

c. I visit with my family (including children).

d. I visit with my family (including multigenerational family).

e. I have visited with a class or educational program.

Section 2: Residents 
How long have you lived in the [Belmont Bay Community Home Owner's Association] neighborhood?
Less than a year
1-2 years
2-4 years
4-6 years
$6+$ years

Would you say that your residency is more appealing because of its proximity to the Potomac Science Center and the outdoor landscape on its campus?
a. Yes
b. No
c. Unsure
d. I am a non-resident.

\section{Section 3: Site Features}

Six "Water Story" features connect to a specific stage in the movement of water throughout the site. These features are designed to visually demonstrate to visitors how a precipitated water droplet travels through the site and into the Occoquan River. These features include a roof drain with a weir into a rain garden, scuppers installed on the roof, and a table top installation to replicate characteristics of a dry creek bed. This is used to educate students and the public about water quality, erosion, and the Occoquan River it overlooks. 
Pictured: Green wall (left), terraced outdoor classroom (center), and rain garden (mid right). All of these are features of the Water Story.

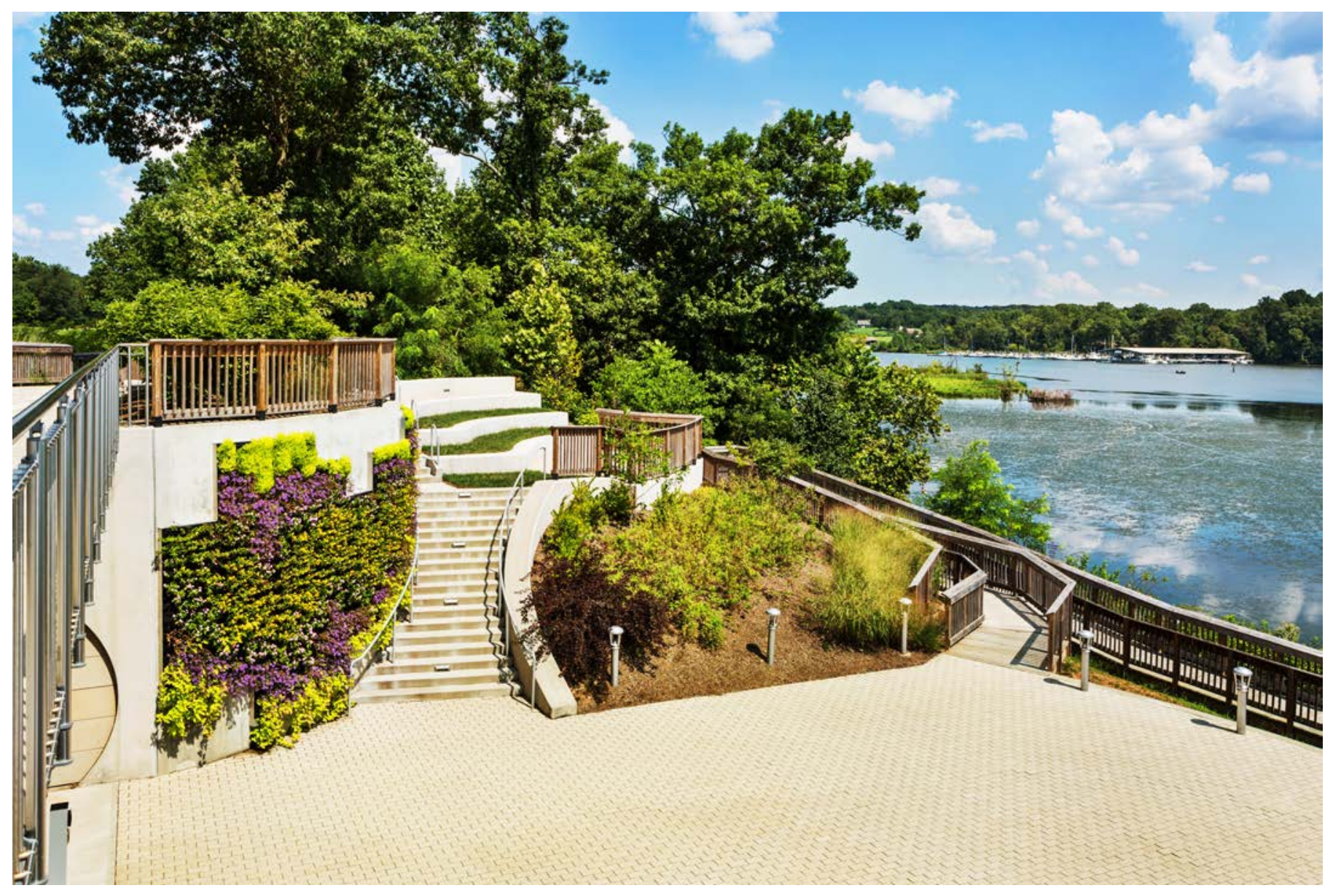


Pictured: Labeled water features at the site.

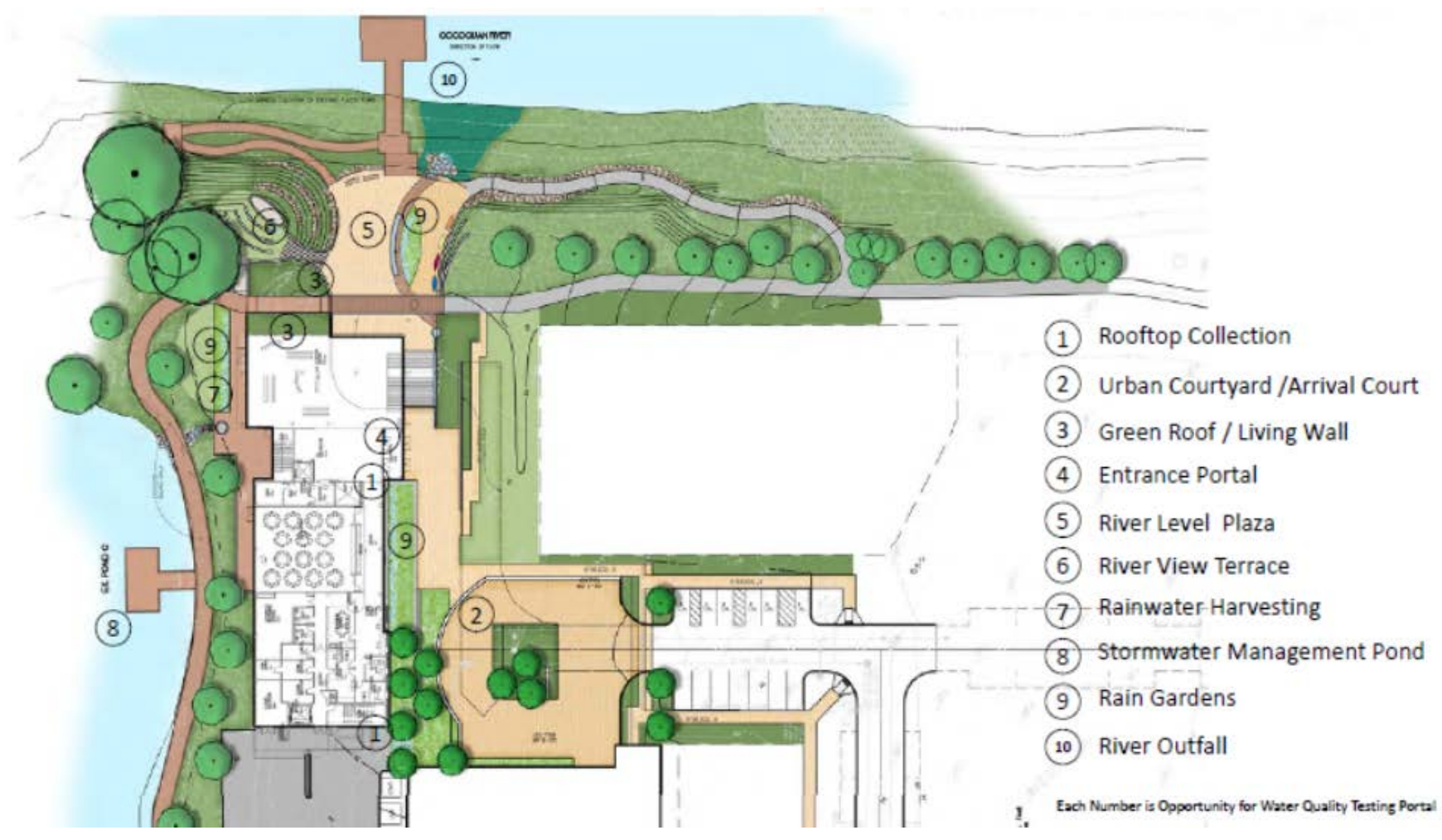

How do you feel like the Water Story features of this site influenced your experience with this site?

$\begin{array}{lllll}1 & 2 & 3 & 4 & 5\end{array}$

0 . I was unaware that these Water Story features existed.

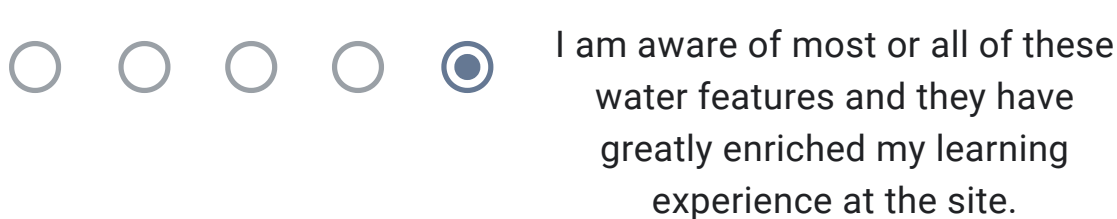


What specific features of the Potomac Science Center outdoor landscape have you seen or learned about during your time at the site?

a. Roof drain with a weir into a rain garden

b. Scuppers installed on the roof

c. Table top installation to replicate characteristics of a dry creek bed.

d. 5,000-gallon rainwater harvesting cistern collects water from the roof of the building and water condensation from the air conditioning system.

$\checkmark$ e. A 250-sf green wall located along the main plaza of the outdoor patio

$\checkmark$ f. A series of rain gardens and Infiltration swales throughout the site.

Would the addition of signage explaining the significance of each Water Story feature enhance your learning experience at this site?
() a. Yes
b. No
c. Unsure

Thank you for your participation!

If you are interested in receiving a copy of this final case study - please share your email address with us. Copy and past the following link into your browser to share: https://forms.gle/d7bfZzi4N56F2SDH6

This form was created outside of your domain. 


\section{Potomac Science Center Visitor Assessment Survey}

This research is being conducted to evaluate how the construction and maintenance of the Potomac Science Center landscape has impacted the surrounding community. This information will be used to inform future landscape design projects at George Mason University and the larger landscape design industry (through submission to the Landscape Architecture Foundation).

\section{Informed Consent}

This research is being conducted to evaluate how the construction and maintenance of the Potomac Science Center landscape has impacted the surrounding community. This information will be used to inform future landscape design projects at George Mason University and the larger landscape design industry (through submission to the Landscape Architecture Foundation). If you agree to participate, you will be asked to complete a 10-minute online survey.

RISKS: There are no foreseeable risks for participating in this research.

BENEFITS: There are no benefits to you as a participant other than to further research in the landscape design field.

CONFIDENTIALITY: The data in this study will be confidential. Names and other identifiers will not be placed on research data. Participant's names and contact information will not be included on the surveys and other collectible data. If you choose to opt into sharing your contact information with us, it will be collected through a separate survey and completely separate from the data for this survey. This ensures that all data collected is de-identified immediately. The de-identified data could be used for future research without additional consent from participants. The Institutional Review Board (IRB) committee that monitors the research on human subjects may inspect study records during internal auditing procedures and are required to keep all information confidential.

PARTICIPATION: Your participation is voluntary, and you may withdraw from the study at any time and for any reason. If you decide not to participate or if you withdraw from the study, there is no penalty or loss of benefits to which you are otherwise entitled. There are no costs to you or any other party.

I have read this form, all of my questions have been answered by the research staff, and I agree to participate in this study.

Accept.

Decline. 


\section{Contact}

This research is being conducted by MacKenzie Earl at George Mason University. She may be reached at (540) 270-6483 or mearl@gmu.edu for questions or to report a research-related problem. Cynthia Smith (faculty advisor) be reached at csmitc@gmu.edu.You may contact the George Mason University Institutional Review Board office at 703-993-4121 or $\underline{I R B} @$ gmu.edu if you have questions or comments regarding your rights as a participant in the research. This research has been reviewed according to George Mason University procedures governing your participation in this research.

\section{Overview}

How would you describe your relation to the Potomac Science Center?

I am a resident of the region.

I am a resident of the Belmont Bay Community Home Owner's Association.

I am a one time visitor to the facility.

( I am an employee or contracted worker at the facility.

I am a faculty member or student with George Mason University.

\section{Section 4: Engagement}

How would you rate your level of engagement with the site indicated PRIOR to the construction of the Potomac Science Center in 2017?

0. I never engaged with this site prior to 2017

b. 1 . I rarely engaged with this site prior to 2017

c. 2. I engaged with this site prior to 2017 3-4 times prior to 2017.

d. 3. I often engaged with this site prior to construction in 2017.

e. 4. I often engaged with this site prior to construction in 2017 - including frequent use of the National Heritage Scenic Trail. 
Please indicate all of the ways you engaged with the site PRIOR to the construction of the Potomac Science Center in 2017.

$\square$ a Used the National Heritage Scenic Trail for recreational use.

b. Enjoyed the view of the Occoquan River.

c. Engaged in ecological-based recreation (bird watching, plant identification, ect.)

d. Visited the site to learn about watersheds, water ecology, conservation, and other topics.

e. I did not engage with this site at all prior to the construction of the PSC.

Other:

\section{Untitled Section}

How would you rate your level of engagement with the site indicated AFTER the construction of the Potomac Science Center in 2017?

a. I never engage with this site.

b. I rarely engage with this site.

c. I engaged with this site 3-4 times a year.

d. I often engage with this site.

(2) I often engage with this site - including frequent use of the National Heritage Scenic Trail. 
Please indicate all of the ways you engaged with the site AFTER its construction concluded?

a Used the National Heritage Scenic Trail for recreational use.

b. Enjoyed the view of the Occoquan River.

c. Engaged in ecological-based recreation (bird watching, plant identification, ect.)

d. Visited the site to learn about watersheds, water ecology, conservation, and other topics.

e. Other (Option to write in.)

\section{Section 2: General Information}

Current Aerial of the Potomac Science Center

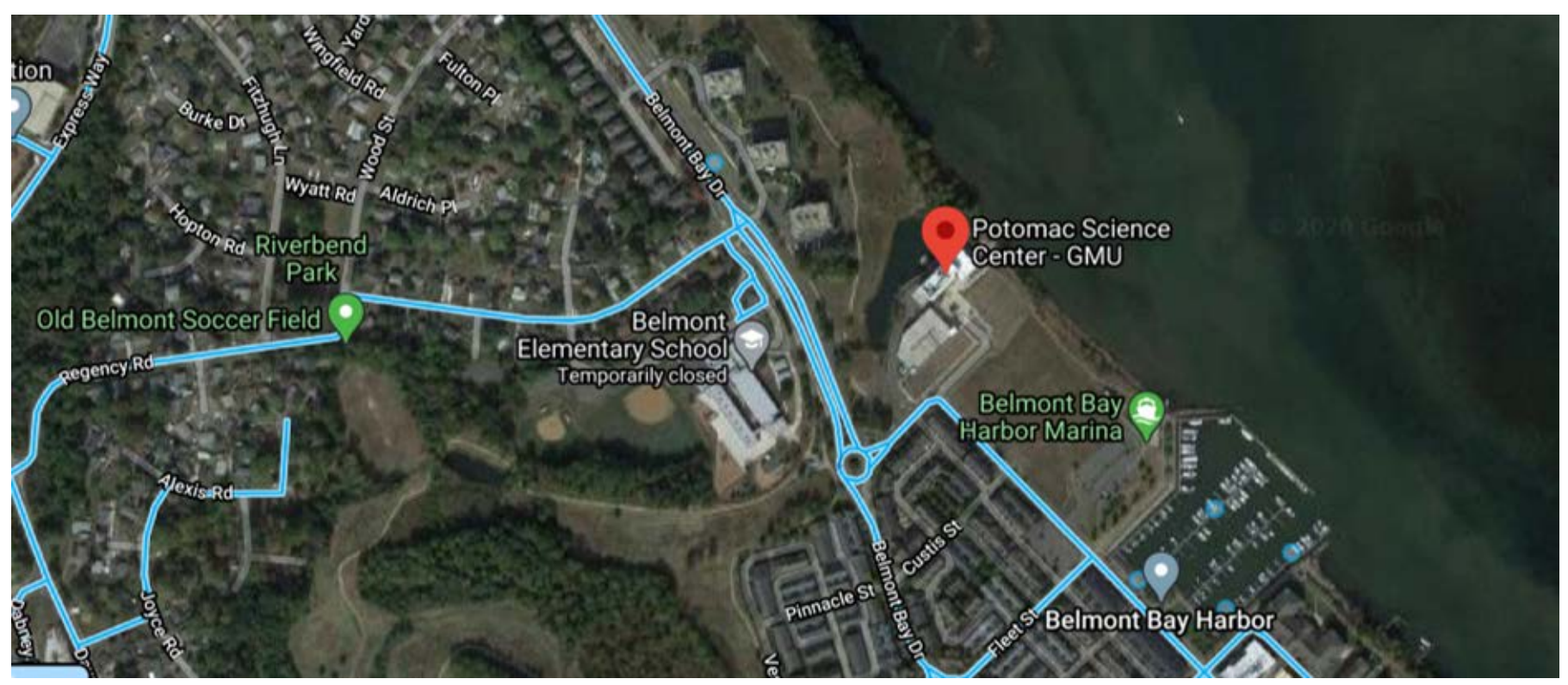


What mode of transport have you used to travel to/ use while at this site?

I have walked to this site as a pedestrian. I did not access this site via the NHST.

b. I have walked to this site as a pedestrian. I accessed this site via the NHST.

(- c. I have driven to the site and walked around the area.

d. I have visited this site as a cyclist from the NHST.

e. I have visited this site via bicycle without use of the NHST.

f. Other (Please specify.)

When you have visited the Potomac Science Center site, who do you come with?

a. I visit the site alone.

b. I visit with a friend or spouse.

c. I visit with my family (including children).

d. I visit with my family (including multigenerational family).

e. I have visited with a class or educational program.

Section 2: Residents 
How long have you lived in the [Belmont Bay Community Home Owner's Association] neighborhood?
Less than a year
1-2 years
2-4 years
4-6 years
$6+$ years

Would you say that your residency is more appealing because of its proximity to the Potomac Science Center and the outdoor landscape on its campus?
a. Yes
b. No
c. Unsure
d. I am a non-resident.

\section{Section 3: Site Features}

Six "Water Story" features connect to a specific stage in the movement of water throughout the site. These features are designed to visually demonstrate to visitors how a precipitated water droplet travels through the site and into the Occoquan River. These features include a roof drain with a weir into a rain garden, scuppers installed on the roof, and a table top installation to replicate characteristics of a dry creek bed. This is used to educate students and the public about water quality, erosion, and the Occoquan River it overlooks. 
Pictured: Green wall (left), terraced outdoor classroom (center), and rain garden (mid right). All of these are features of the Water Story.

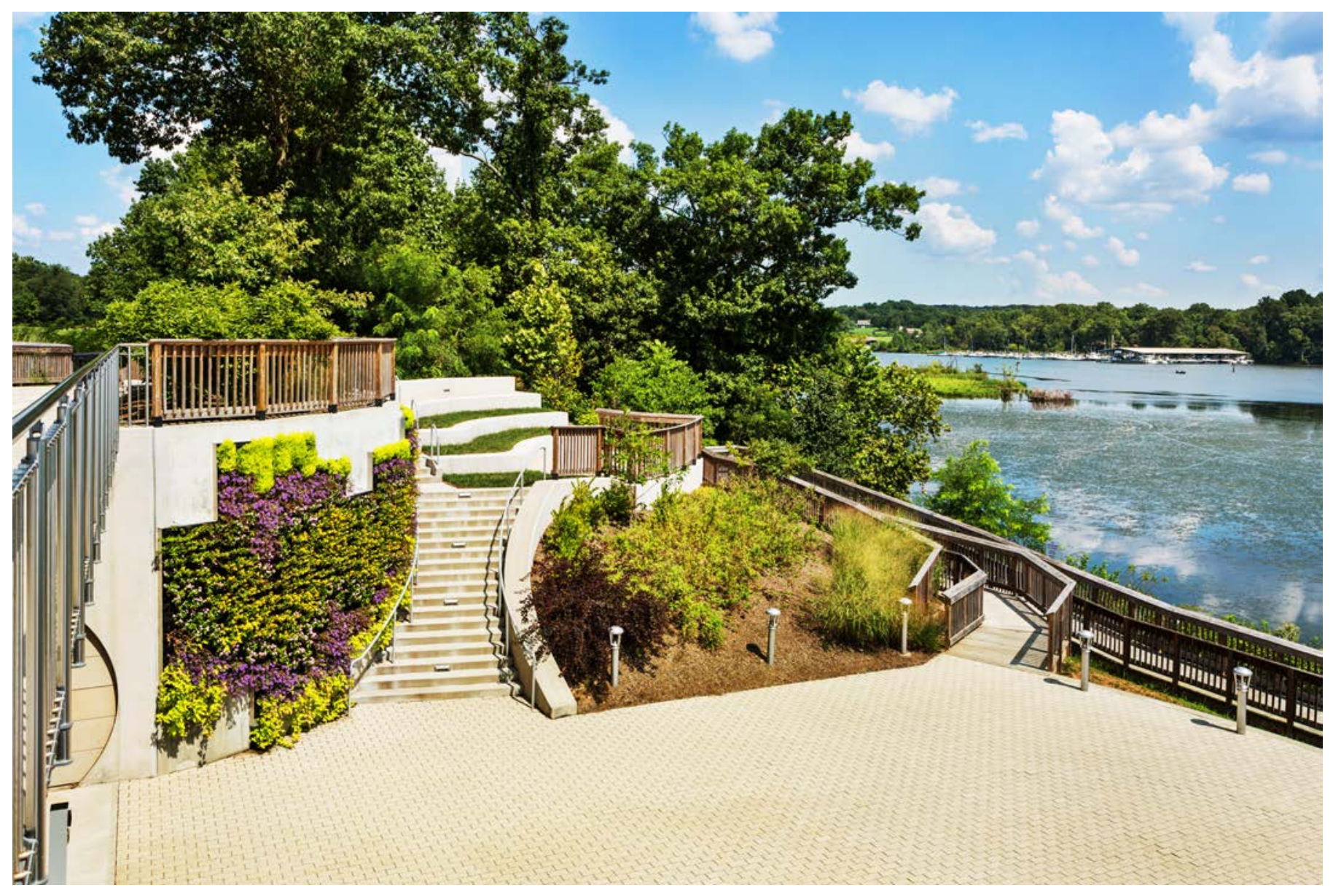


Pictured: Labeled water features at the site.

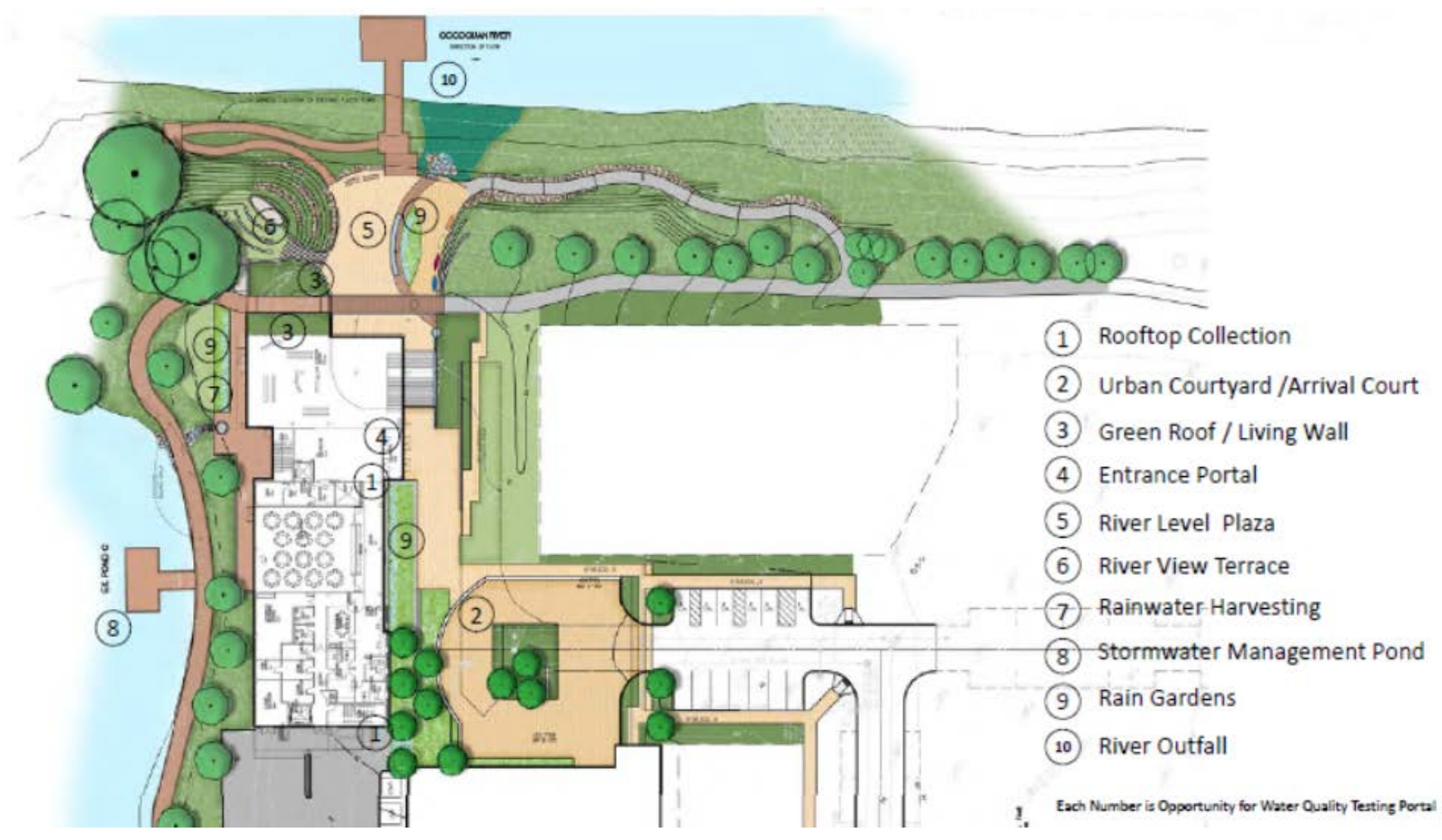

How do you feel like the Water Story features of this site influenced your experience with this site?

$\begin{array}{lllll}1 & 2 & 3 & 4 & 5\end{array}$

0 . I was unaware that these Water Story features existed.

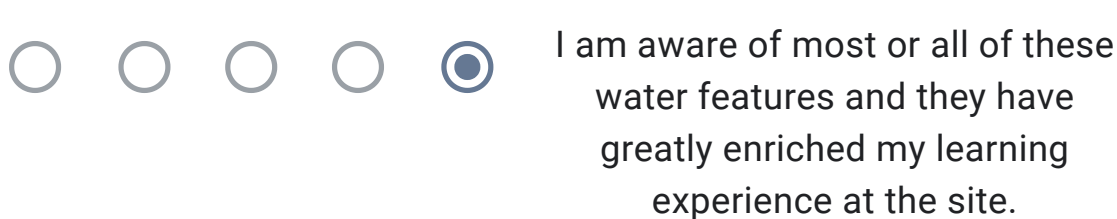


What specific features of the Potomac Science Center outdoor landscape have you seen or learned about during your time at the site?

$\checkmark$ a. Roof drain with a weir into a rain garden

b. Scuppers installed on the roof

c. Table top installation to replicate characteristics of a dry creek bed.

d. 5,000-gallon rainwater harvesting cistern collects water from the roof of the building and water condensation from the air conditioning system.

$\checkmark$ e. A 250-sf green wall located along the main plaza of the outdoor patio

$\checkmark$ f. A series of rain gardens and Infiltration swales throughout the site.

Would the addition of signage explaining the significance of each Water Story feature enhance your learning experience at this site?
() a. Yes
b. No
c. Unsure

Thank you for your participation!

If you are interested in receiving a copy of this final case study - please share your email address with us. Copy and past the following link into your browser to share: https://forms.gle/d7bfZzi4N56F2SDH6

This form was created outside of your domain. 


\section{Potomac Science Center Visitor Assessment Survey}

This research is being conducted to evaluate how the construction and maintenance of the Potomac Science Center landscape has impacted the surrounding community. This information will be used to inform future landscape design projects at George Mason University and the larger landscape design industry (through submission to the Landscape Architecture Foundation).

\section{Informed Consent}

This research is being conducted to evaluate how the construction and maintenance of the Potomac Science Center landscape has impacted the surrounding community. This information will be used to inform future landscape design projects at George Mason University and the larger landscape design industry (through submission to the Landscape Architecture Foundation). If you agree to participate, you will be asked to complete a 10-minute online survey.

RISKS: There are no foreseeable risks for participating in this research.

BENEFITS: There are no benefits to you as a participant other than to further research in the landscape design field.

CONFIDENTIALITY: The data in this study will be confidential. Names and other identifiers will not be placed on research data. Participant's names and contact information will not be included on the surveys and other collectible data. If you choose to opt into sharing your contact information with us, it will be collected through a separate survey and completely separate from the data for this survey. This ensures that all data collected is de-identified immediately. The de-identified data could be used for future research without additional consent from participants. The Institutional Review Board (IRB) committee that monitors the research on human subjects may inspect study records during internal auditing procedures and are required to keep all information confidential.

PARTICIPATION: Your participation is voluntary, and you may withdraw from the study at any time and for any reason. If you decide not to participate or if you withdraw from the study, there is no penalty or loss of benefits to which you are otherwise entitled. There are no costs to you or any other party.

I have read this form, all of my questions have been answered by the research staff, and I agree to participate in this study.

Accept.

Decline. 


\section{Contact}

This research is being conducted by MacKenzie Earl at George Mason University. She may be reached at (540) 270-6483 or mearl@gmu.edu for questions or to report a research-related problem. Cynthia Smith (faculty advisor) be reached at csmitc@gmu.edu.You may contact the George Mason University Institutional Review Board office at 703-993-4121 or $\underline{I R B} @$ gmu.edu if you have questions or comments regarding your rights as a participant in the research. This research has been reviewed according to George Mason University procedures governing your participation in this research.

\section{Overview}

How would you describe your relation to the Potomac Science Center?

I am a resident of the region.

I am a resident of the Belmont Bay Community Home Owner's Association.

I am a one time visitor to the facility.

I am an employee or contracted worker at the facility.

(- I am a faculty member or student with George Mason University.

\section{Section 4: Engagement}

How would you rate your level of engagement with the site indicated PRIOR to the construction of the Potomac Science Center in 2017?

0. I never engaged with this site prior to 2017

b. 1. I rarely engaged with this site prior to 2017.

c. 2. I engaged with this site prior to 2017 3-4 times prior to 2017.

d. 3. I often engaged with this site prior to construction in 2017.

e. 4. I often engaged with this site prior to construction in 2017 - including frequent use of the National Heritage Scenic Trail. 
Please indicate all of the ways you engaged with the site PRIOR to the construction of the Potomac Science Center in 2017.

$\square$ a Used the National Heritage Scenic Trail for recreational use.

b. Enjoyed the view of the Occoquan River.

c. Engaged in ecological-based recreation (bird watching, plant identification, ect.)

d. Visited the site to learn about watersheds, water ecology, conservation, and other topics.

e. I did not engage with this site at all prior to the construction of the PSC.

$\checkmark$ Other: Engaged in planning this project since 2005

\section{Untitled Section}

How would you rate your level of engagement with the site indicated AFTER the construction of the Potomac Science Center in 2017?

a. I never engage with this site.

b. I rarely engage with this site.

c. I engaged with this site 3-4 times a year.

d. I often engage with this site.

e. I often engage with this site - including frequent use of the National Heritage Scenic Trail. 
Please indicate all of the ways you engaged with the site AFTER its construction concluded?

$\square$ a Used the National Heritage Scenic Trail for recreational use.

$\square$ b. Enjoyed the view of the Occoquan River.

$\square$ c. Engaged in ecological-based recreation (bird watching, plant identification, ect.)

$\square$ d. Visited the site to learn about watersheds, water ecology, conservation, and other topics.

e. Other (Option to write in.)

Section 2: General Information

Current Aerial of the Potomac Science Center

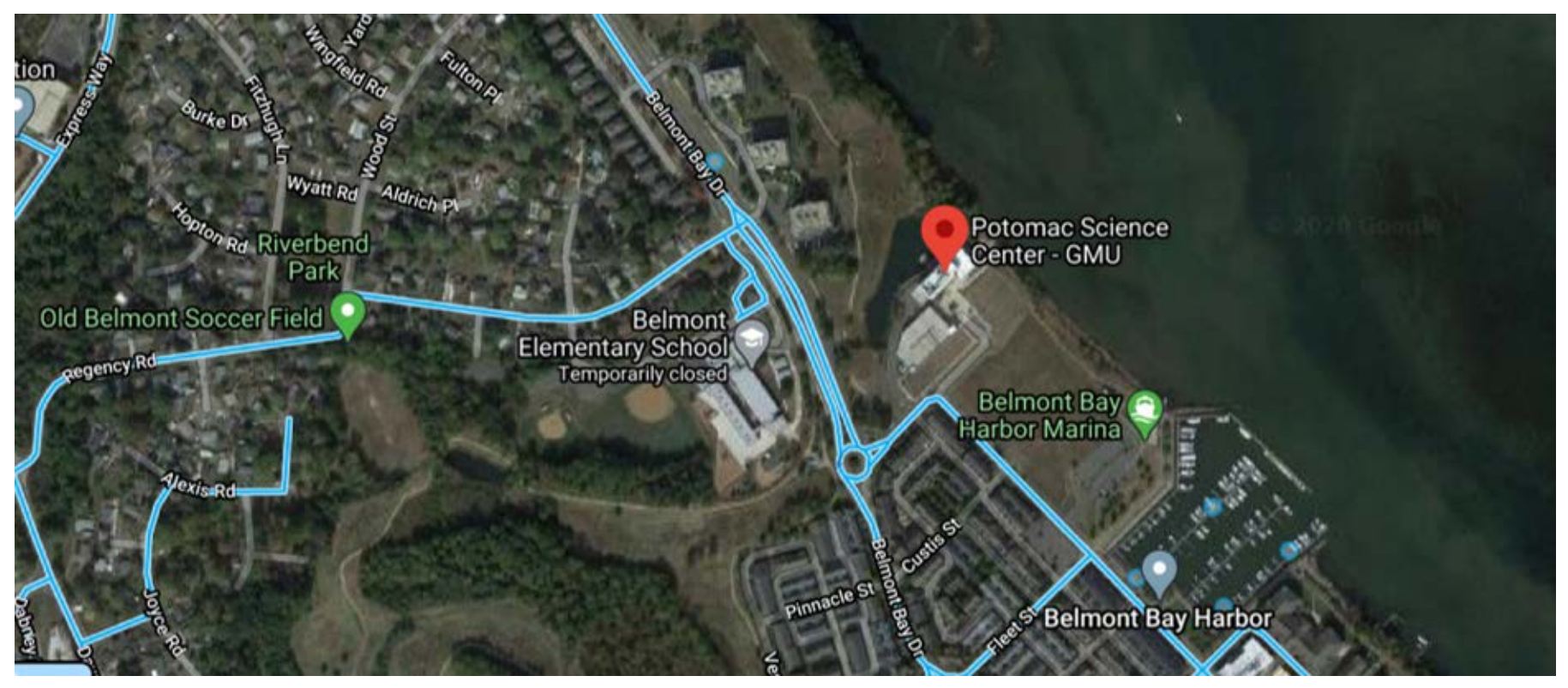


What mode of transport have you used to travel to/ use while at this site?

I have walked to this site as a pedestrian. I did not access this site via the NHST.

b. I have walked to this site as a pedestrian. I accessed this site via the NHST.

(- c. I have driven to the site and walked around the area.

d. I have visited this site as a cyclist from the NHST.

e. I have visited this site via bicycle without use of the NHST.

f. Other (Please specify.)

When you have visited the Potomac Science Center site, who do you come with?

$\checkmark$ a. I visit the site alone.

b. I visit with a friend or spouse.

c. I visit with my family (including children).

d. I visit with my family (including multigenerational family).

e. I have visited with a class or educational program.

Section 2: Residents 
How long have you lived in the [Belmont Bay Community Home Owner's Association] neighborhood?
Less than a year
1-2 years
2-4 years
4-6 years
$6+$ years

Would you say that your residency is more appealing because of its proximity to the Potomac Science Center and the outdoor landscape on its campus?
a. Yes
b. No
c. Unsure
d. I am a non-resident.

\section{Section 3: Site Features}

Six "Water Story" features connect to a specific stage in the movement of water throughout the site. These features are designed to visually demonstrate to visitors how a precipitated water droplet travels through the site and into the Occoquan River. These features include a roof drain with a weir into a rain garden, scuppers installed on the roof, and a table top installation to replicate characteristics of a dry creek bed. This is used to educate students and the public about water quality, erosion, and the Occoquan River it overlooks. 
Pictured: Green wall (left), terraced outdoor classroom (center), and rain garden (mid right). All of these are features of the Water Story.

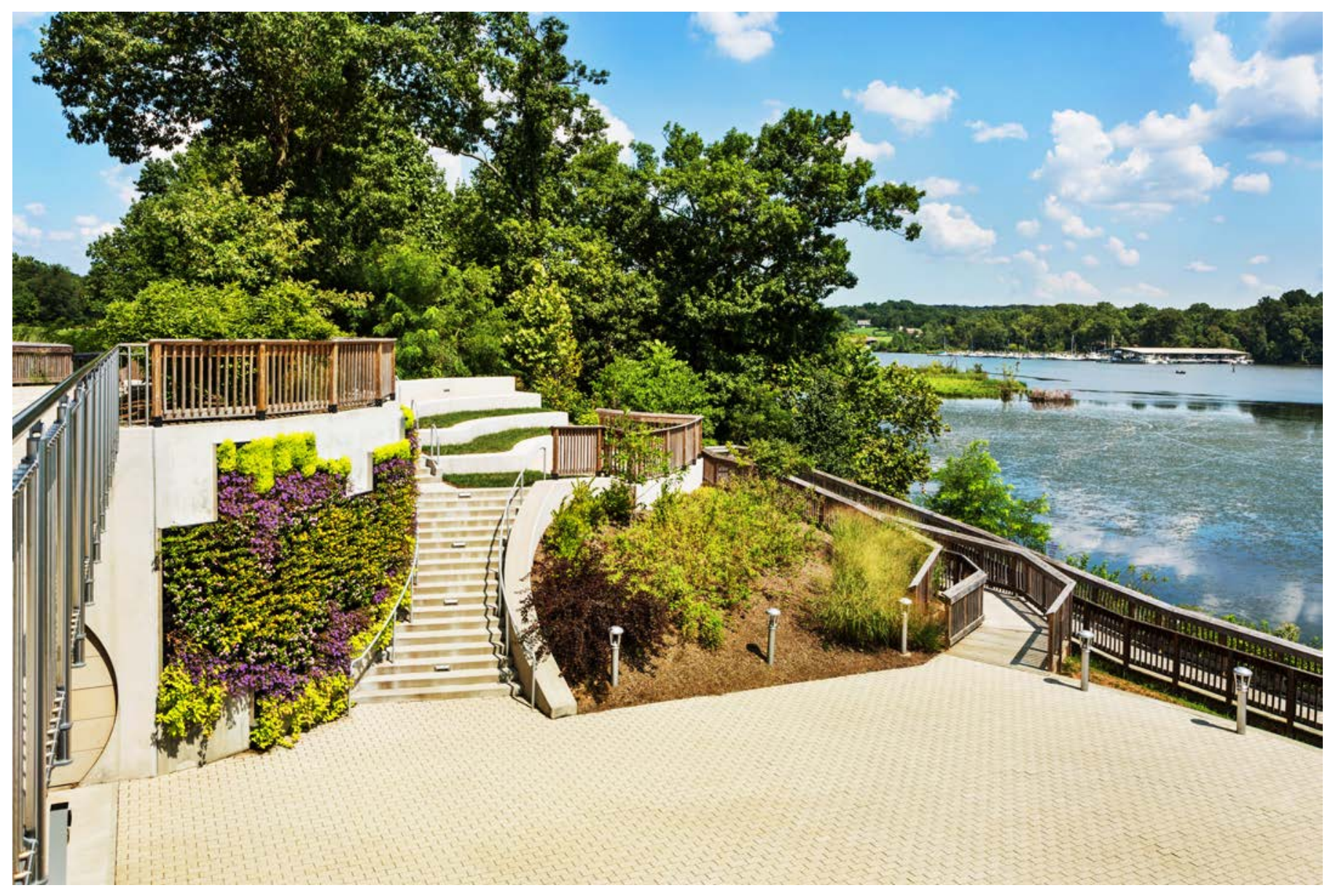


Pictured: Labeled water features at the site.

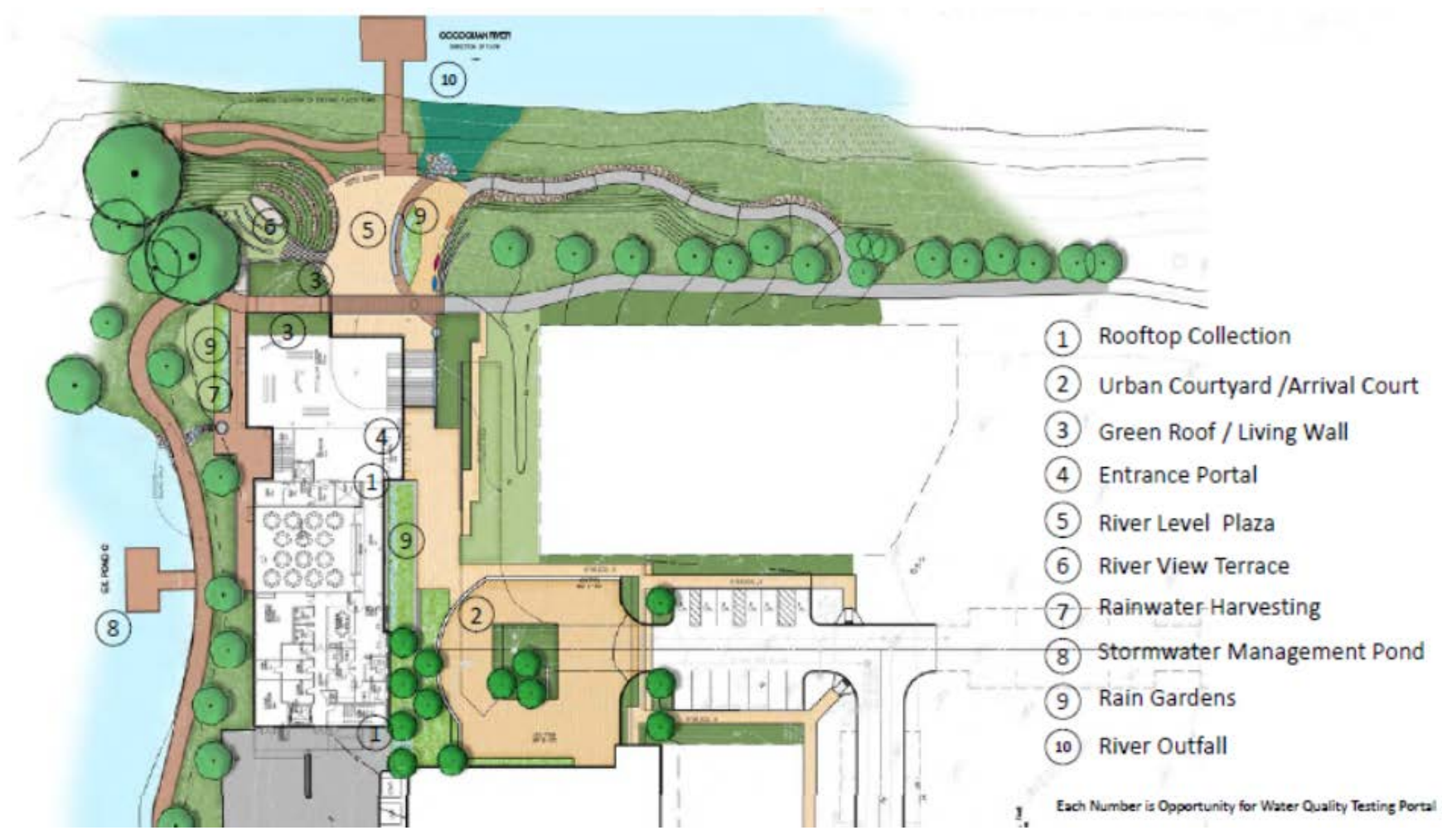

How do you feel like the Water Story features of this site influenced your experience with this site?

$\begin{array}{lllll}1 & 2 & 3 & 4 & 5\end{array}$

0 . I was unaware that these Water Story features existed.

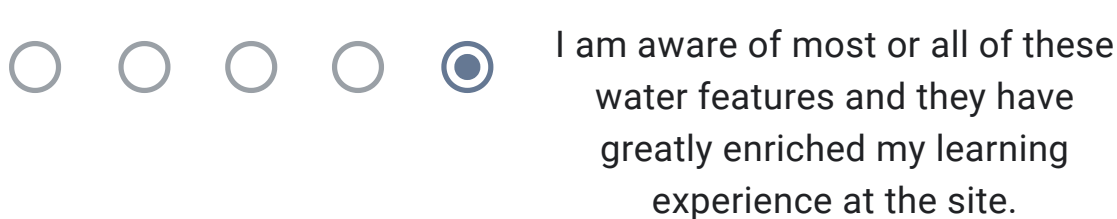


What specific features of the Potomac Science Center outdoor landscape have you seen or learned about during your time at the site?

$\checkmark$ a. Roof drain with a weir into a rain garden

b. Scuppers installed on the roof

c. Table top installation to replicate characteristics of a dry creek bed.

d. 5,000-gallon rainwater harvesting cistern collects water from the roof of the building and water condensation from the air conditioning system.

$\checkmark$ e. A 250-sf green wall located along the main plaza of the outdoor patio

$\checkmark$ f. A series of rain gardens and Infiltration swales throughout the site.

Would the addition of signage explaining the significance of each Water Story feature enhance your learning experience at this site?
() a. Yes
b. No
c. Unsure

Thank you for your participation!

If you are interested in receiving a copy of this final case study - please share your email address with us. Copy and past the following link into your browser to share: https://forms.gle/d7bfZzi4N56F2SDH6

This form was created outside of your domain. 


\section{Potomac Science Center Visitor Assessment Survey}

This research is being conducted to evaluate how the construction and maintenance of the Potomac Science Center landscape has impacted the surrounding community. This information will be used to inform future landscape design projects at George Mason University and the larger landscape design industry (through submission to the Landscape Architecture Foundation).

\section{Informed Consent}

This research is being conducted to evaluate how the construction and maintenance of the Potomac Science Center landscape has impacted the surrounding community. This information will be used to inform future landscape design projects at George Mason University and the larger landscape design industry (through submission to the Landscape Architecture Foundation). If you agree to participate, you will be asked to complete a 10-minute online survey.

RISKS: There are no foreseeable risks for participating in this research.

BENEFITS: There are no benefits to you as a participant other than to further research in the landscape design field.

CONFIDENTIALITY: The data in this study will be confidential. Names and other identifiers will not be placed on research data. Participant's names and contact information will not be included on the surveys and other collectible data. If you choose to opt into sharing your contact information with us, it will be collected through a separate survey and completely separate from the data for this survey. This ensures that all data collected is de-identified immediately. The de-identified data could be used for future research without additional consent from participants. The Institutional Review Board (IRB) committee that monitors the research on human subjects may inspect study records during internal auditing procedures and are required to keep all information confidential.

PARTICIPATION: Your participation is voluntary, and you may withdraw from the study at any time and for any reason. If you decide not to participate or if you withdraw from the study, there is no penalty or loss of benefits to which you are otherwise entitled. There are no costs to you or any other party.

I have read this form, all of my questions have been answered by the research staff, and I agree to participate in this study.

Accept.

Decline. 


\section{Contact}

This research is being conducted by MacKenzie Earl at George Mason University. She may be reached at (540) 270-6483 or mearl@gmu.edu for questions or to report a research-related problem. Cynthia Smith (faculty advisor) be reached at csmitc@gmu.edu.You may contact the George Mason University Institutional Review Board office at 703-993-4121 or $\underline{I R B} @$ gmu.edu if you have questions or comments regarding your rights as a participant in the research. This research has been reviewed according to George Mason University procedures governing your participation in this research.

\section{Overview}

How would you describe your relation to the Potomac Science Center?

I am a resident of the region.

I am a resident of the Belmont Bay Community Home Owner's Association.

I am a one time visitor to the facility.

I am an employee or contracted worker at the facility.

(- I am a faculty member or student with George Mason University.

\section{Section 4: Engagement}

How would you rate your level of engagement with the site indicated PRIOR to the construction of the Potomac Science Center in 2017?

0. I never engaged with this site prior to 2017

b. 1 . I rarely engaged with this site prior to 2017

c. 2. I engaged with this site prior to 2017 3-4 times prior to 2017.

d. 3. I often engaged with this site prior to construction in 2017.

e. 4. I often engaged with this site prior to construction in 2017 - including frequent use of the National Heritage Scenic Trail. 
Please indicate all of the ways you engaged with the site PRIOR to the construction of the Potomac Science Center in 2017.

$\square$ a Used the National Heritage Scenic Trail for recreational use.

b. Enjoyed the view of the Occoquan River.

c. Engaged in ecological-based recreation (bird watching, plant identification, ect.)

d. Visited the site to learn about watersheds, water ecology, conservation, and other topics.

e. I did not engage with this site at all prior to the construction of the PSC.

Other:

\section{Untitled Section}

How would you rate your level of engagement with the site indicated AFTER the construction of the Potomac Science Center in 2017?

a. I never engage with this site.

b. I rarely engage with this site.

c. I engaged with this site 3-4 times a year.

d. I often engage with this site.

e. I often engage with this site - including frequent use of the National Heritage Scenic Trail. 
Please indicate all of the ways you engaged with the site AFTER its construction concluded?

$\square$ a Used the National Heritage Scenic Trail for recreational use.

b. Enjoyed the view of the Occoquan River.

c. Engaged in ecological-based recreation (bird watching, plant identification, ect.)

d. Visited the site to learn about watersheds, water ecology, conservation, and other topics.

e. Other (Option to write in.)

\section{Section 2: General Information}

\section{Current Aerial of the Potomac Science Center}

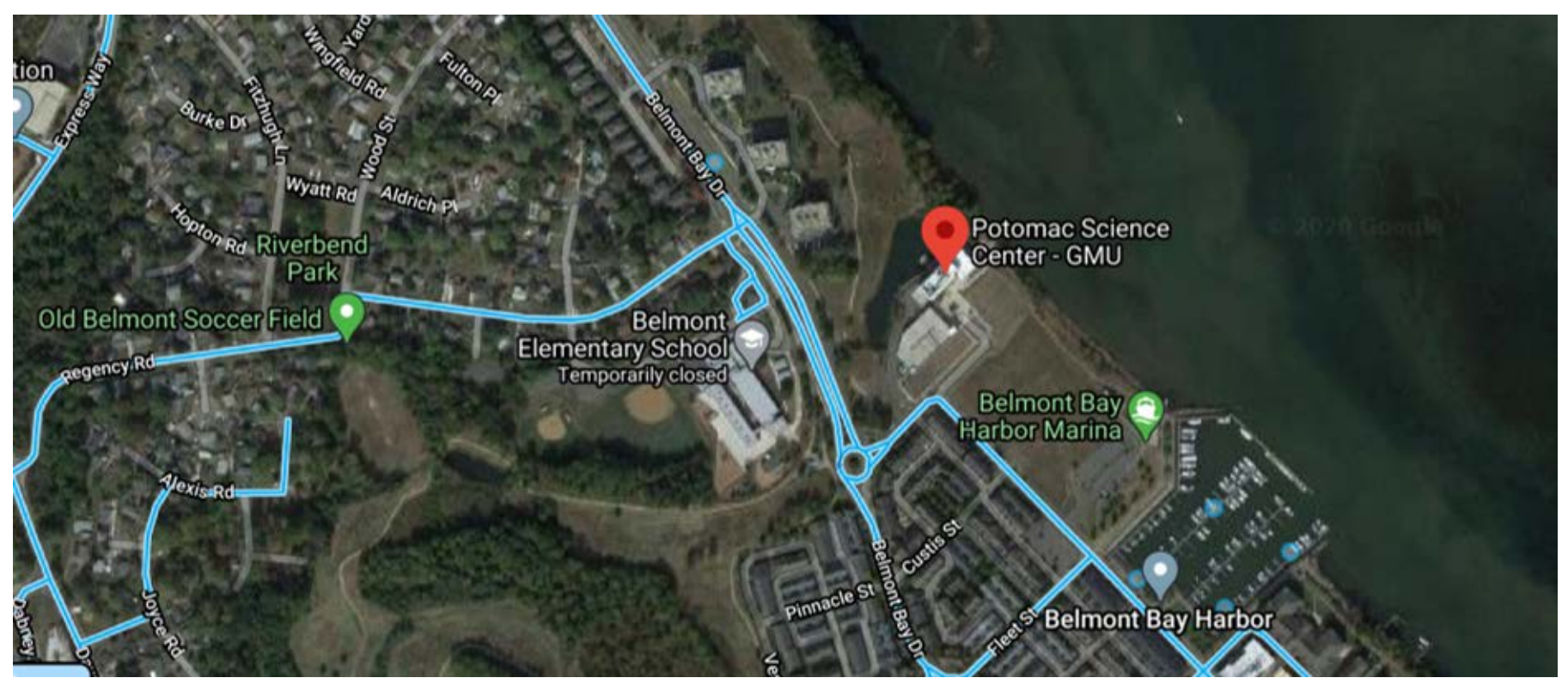


What mode of transport have you used to travel to/ use while at this site?

I have walked to this site as a pedestrian. I did not access this site via the NHST.

b. I have walked to this site as a pedestrian. I accessed this site via the NHST.

(- c. I have driven to the site and walked around the area.

d. I have visited this site as a cyclist from the NHST.

e. I have visited this site via bicycle without use of the NHST.

f. Other (Please specify.)

When you have visited the Potomac Science Center site, who do you come with?

a. I visit the site alone.

b. I visit with a friend or spouse.

c. I visit with my family (including children).

d. I visit with my family (including multigenerational family).

e. I have visited with a class or educational program.

Section 2: Residents 
How long have you lived in the [Belmont Bay Community Home Owner's Association] neighborhood?
Less than a year
1-2 years
2-4 years
4-6 years
$6+$ years

Would you say that your residency is more appealing because of its proximity to the Potomac Science Center and the outdoor landscape on its campus?
a. Yes
b. No
c. Unsure
d. I am a non-resident.

\section{Section 3: Site Features}

Six "Water Story" features connect to a specific stage in the movement of water throughout the site. These features are designed to visually demonstrate to visitors how a precipitated water droplet travels through the site and into the Occoquan River. These features include a roof drain with a weir into a rain garden, scuppers installed on the roof, and a table top installation to replicate characteristics of a dry creek bed. This is used to educate students and the public about water quality, erosion, and the Occoquan River it overlooks. 
Pictured: Green wall (left), terraced outdoor classroom (center), and rain garden (mid right). All of these are features of the Water Story.

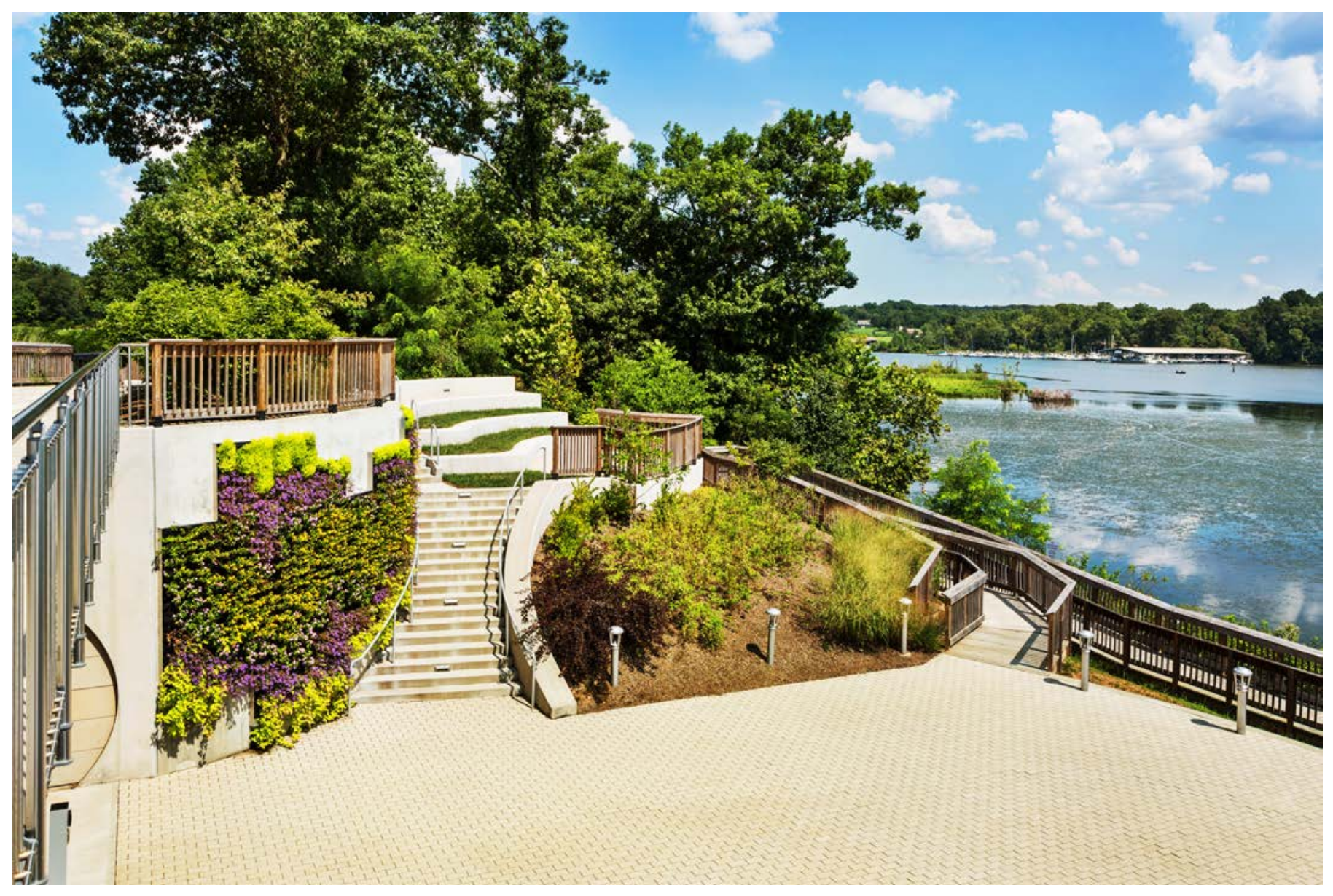


Pictured: Labeled water features at the site.

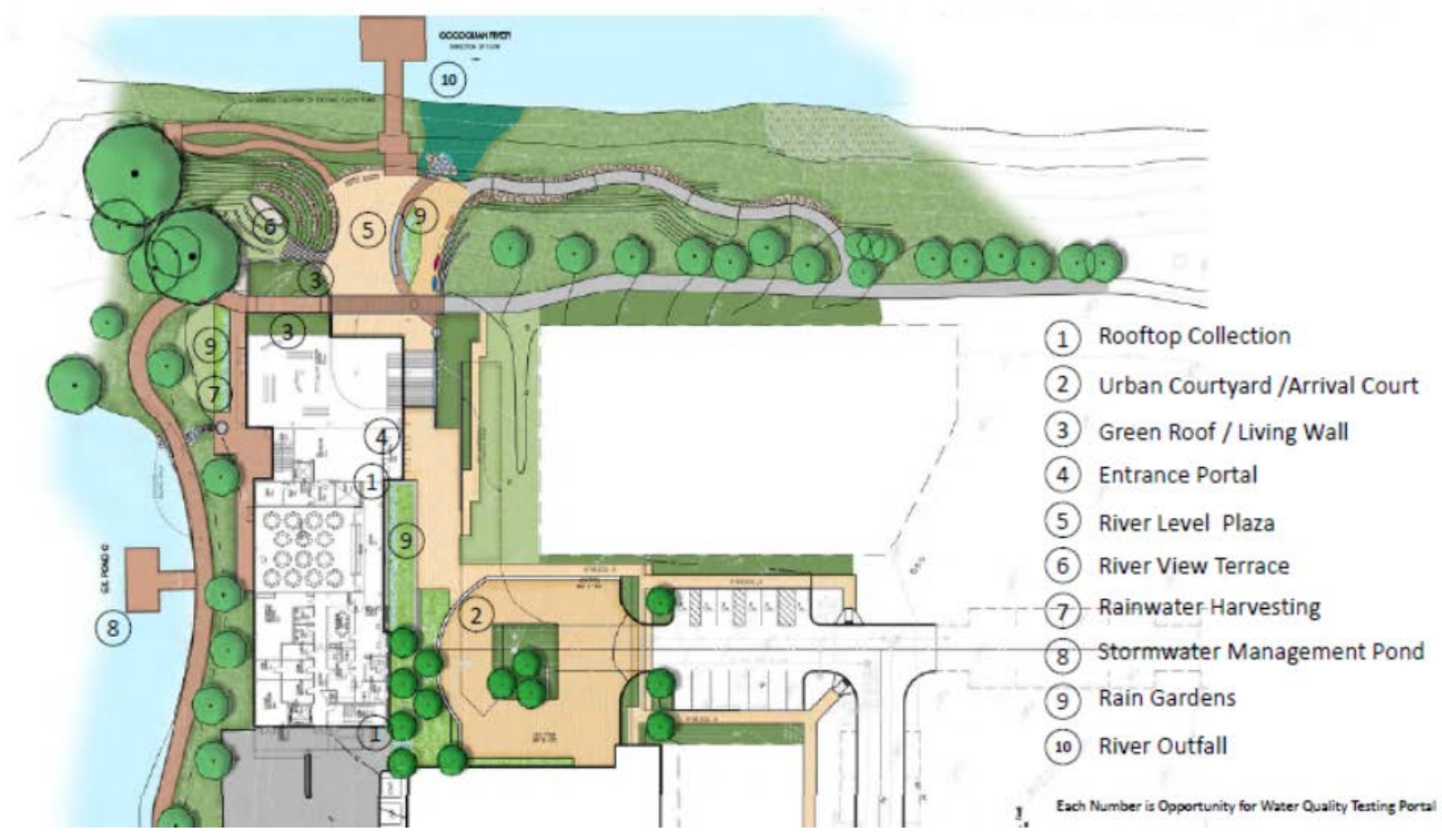

How do you feel like the Water Story features of this site influenced your experience with this site?

$\begin{array}{lllll}1 & 2 & 3 & 4 & 5\end{array}$

0 . I was unaware that these Water Story features existed.

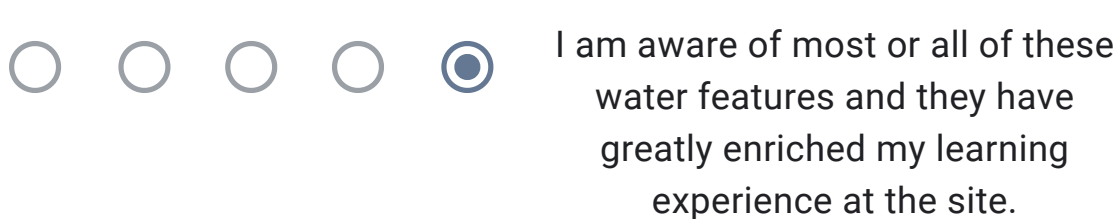


What specific features of the Potomac Science Center outdoor landscape have you seen or learned about during your time at the site?

$\checkmark$ a. Roof drain with a weir into a rain garden

b. Scuppers installed on the roof

c. Table top installation to replicate characteristics of a dry creek bed.

d. 5,000-gallon rainwater harvesting cistern collects water from the roof of the building and water condensation from the air conditioning system.

$\checkmark$ e. A 250-sf green wall located along the main plaza of the outdoor patio

$\checkmark$ f. A series of rain gardens and Infiltration swales throughout the site.

Would the addition of signage explaining the significance of each Water Story feature enhance your learning experience at this site?
() a. Yes
b. No
c. Unsure

Thank you for your participation!

If you are interested in receiving a copy of this final case study - please share your email address with us. Copy and past the following link into your browser to share: https://forms.gle/d7bfZzi4N56F2SDH6

This form was created outside of your domain. 


\section{Potomac Science Center Visitor Assessment Survey}

This research is being conducted to evaluate how the construction and maintenance of the Potomac Science Center landscape has impacted the surrounding community. This information will be used to inform future landscape design projects at George Mason University and the larger landscape design industry (through submission to the Landscape Architecture Foundation).

\section{Informed Consent}

This research is being conducted to evaluate how the construction and maintenance of the Potomac Science Center landscape has impacted the surrounding community. This information will be used to inform future landscape design projects at George Mason University and the larger landscape design industry (through submission to the Landscape Architecture Foundation). If you agree to participate, you will be asked to complete a 10-minute online survey.

RISKS: There are no foreseeable risks for participating in this research.

BENEFITS: There are no benefits to you as a participant other than to further research in the landscape design field.

CONFIDENTIALITY: The data in this study will be confidential. Names and other identifiers will not be placed on research data. Participant's names and contact information will not be included on the surveys and other collectible data. If you choose to opt into sharing your contact information with us, it will be collected through a separate survey and completely separate from the data for this survey. This ensures that all data collected is de-identified immediately. The de-identified data could be used for future research without additional consent from participants. The Institutional Review Board (IRB) committee that monitors the research on human subjects may inspect study records during internal auditing procedures and are required to keep all information confidential.

PARTICIPATION: Your participation is voluntary, and you may withdraw from the study at any time and for any reason. If you decide not to participate or if you withdraw from the study, there is no penalty or loss of benefits to which you are otherwise entitled. There are no costs to you or any other party.

I have read this form, all of my questions have been answered by the research staff, and I agree to participate in this study.

Accept.

Decline. 


\section{Contact}

This research is being conducted by MacKenzie Earl at George Mason University. She may be reached at (540) 270-6483 or mearl@gmu.edu for questions or to report a research-related problem. Cynthia Smith (faculty advisor) be reached at csmitc@gmu.edu.You may contact the George Mason University Institutional Review Board office at 703-993-4121 or $\underline{I R B} @$ gmu.edu if you have questions or comments regarding your rights as a participant in the research. This research has been reviewed according to George Mason University procedures governing your participation in this research.

\section{Overview}

How would you describe your relation to the Potomac Science Center?

I am a resident of the region.

I am a resident of the Belmont Bay Community Home Owner's Association.

( I am a one time visitor to the facility.

I am an employee or contracted worker at the facility.

I am a faculty member or student with George Mason University.

\section{Section 4: Engagement}

How would you rate your level of engagement with the site indicated PRIOR to the construction of the Potomac Science Center in 2017?

0. I never engaged with this site prior to 2017

b. 1. I rarely engaged with this site prior to 2017.

c. 2. I engaged with this site prior to 2017 3-4 times prior to 2017.

d. 3. I often engaged with this site prior to construction in 2017.

e. 4. I often engaged with this site prior to construction in 2017 - including frequent use of the National Heritage Scenic Trail. 
Please indicate all of the ways you engaged with the site PRIOR to the construction of the Potomac Science Center in 2017.

$\square$ a Used the National Heritage Scenic Trail for recreational use.

b. Enjoyed the view of the Occoquan River.

c. Engaged in ecological-based recreation (bird watching, plant identification, ect.)

d. Visited the site to learn about watersheds, water ecology, conservation, and other topics.

e. I did not engage with this site at all prior to the construction of the PSC.

Other:

\section{Untitled Section}

How would you rate your level of engagement with the site indicated AFTER the construction of the Potomac Science Center in 2017?

a. I never engage with this site.

() b. I rarely engage with this site.

c. I engaged with this site 3-4 times a year.

d. I often engage with this site.

e. I often engage with this site - including frequent use of the National Heritage Scenic Trail. 
Please indicate all of the ways you engaged with the site AFTER its construction concluded?

$\square$ a Used the National Heritage Scenic Trail for recreational use.

$\checkmark$ b. Enjoyed the view of the Occoquan River.

$\square$ c. Engaged in ecological-based recreation (bird watching, plant identification, ect.)

$\square$ d. Visited the site to learn about watersheds, water ecology, conservation, and other topics.

$\checkmark$ e. Other (Option to write in.)

\section{Section 2: General Information}

\section{Current Aerial of the Potomac Science Center}

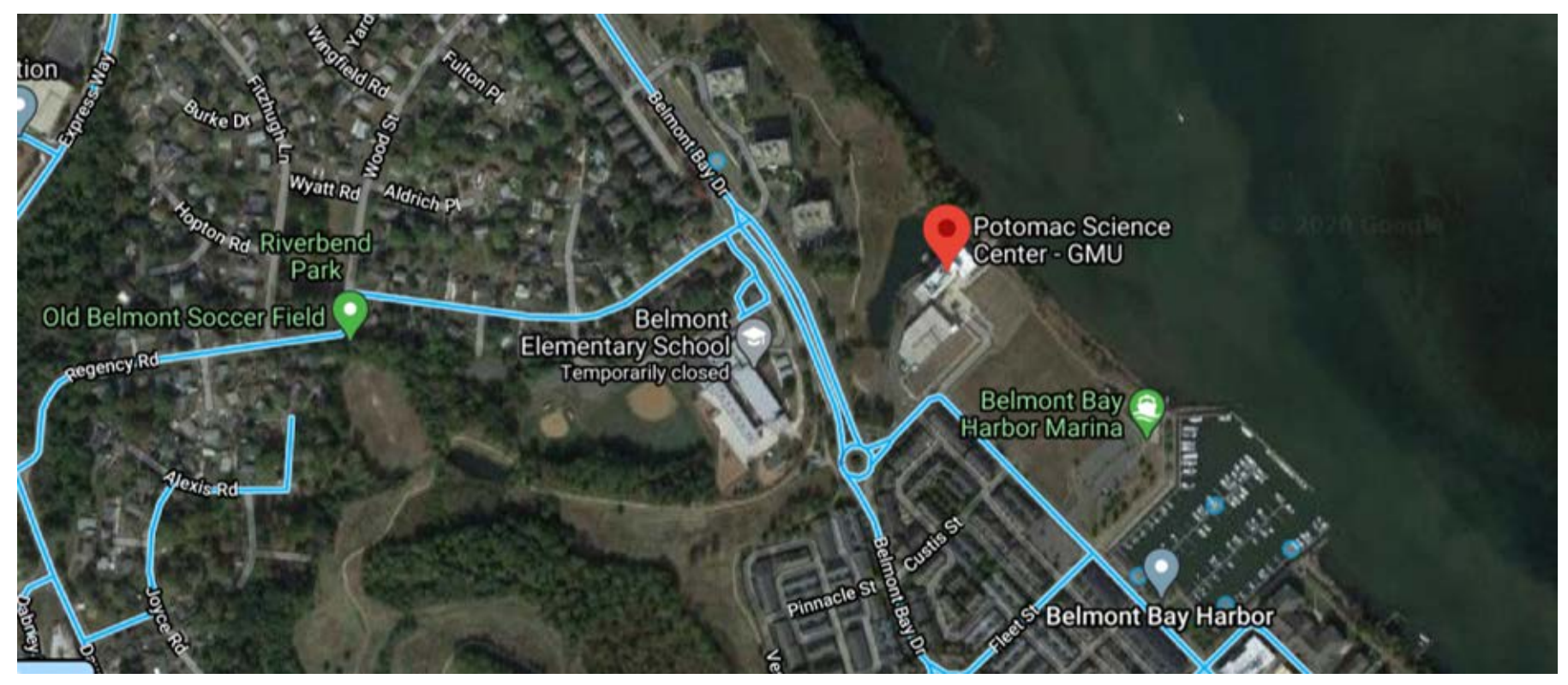


What mode of transport have you used to travel to/ use while at this site?

I have walked to this site as a pedestrian. I did not access this site via the NHST.

b. I have walked to this site as a pedestrian. I accessed this site via the NHST.

(- c. I have driven to the site and walked around the area.

d. I have visited this site as a cyclist from the NHST.

e. I have visited this site via bicycle without use of the NHST.

f. Other (Please specify.)

When you have visited the Potomac Science Center site, who do you come with?

$\checkmark$ a. I visit the site alone.

b. I visit with a friend or spouse.

c. I visit with my family (including children).

d. I visit with my family (including multigenerational family).

e. I have visited with a class or educational program.

Section 2: Residents 
How long have you lived in the [Belmont Bay Community Home Owner's Association] neighborhood?
Less than a year
1-2 years
2-4 years
4-6 years
$6+$ years

Would you say that your residency is more appealing because of its proximity to the Potomac Science Center and the outdoor landscape on its campus?
a. Yes
b. No
c. Unsure
d. I am a non-resident.

\section{Section 3: Site Features}

Six "Water Story" features connect to a specific stage in the movement of water throughout the site. These features are designed to visually demonstrate to visitors how a precipitated water droplet travels through the site and into the Occoquan River. These features include a roof drain with a weir into a rain garden, scuppers installed on the roof, and a table top installation to replicate characteristics of a dry creek bed. This is used to educate students and the public about water quality, erosion, and the Occoquan River it overlooks. 
Pictured: Green wall (left), terraced outdoor classroom (center), and rain garden (mid right). All of these are features of the Water Story.

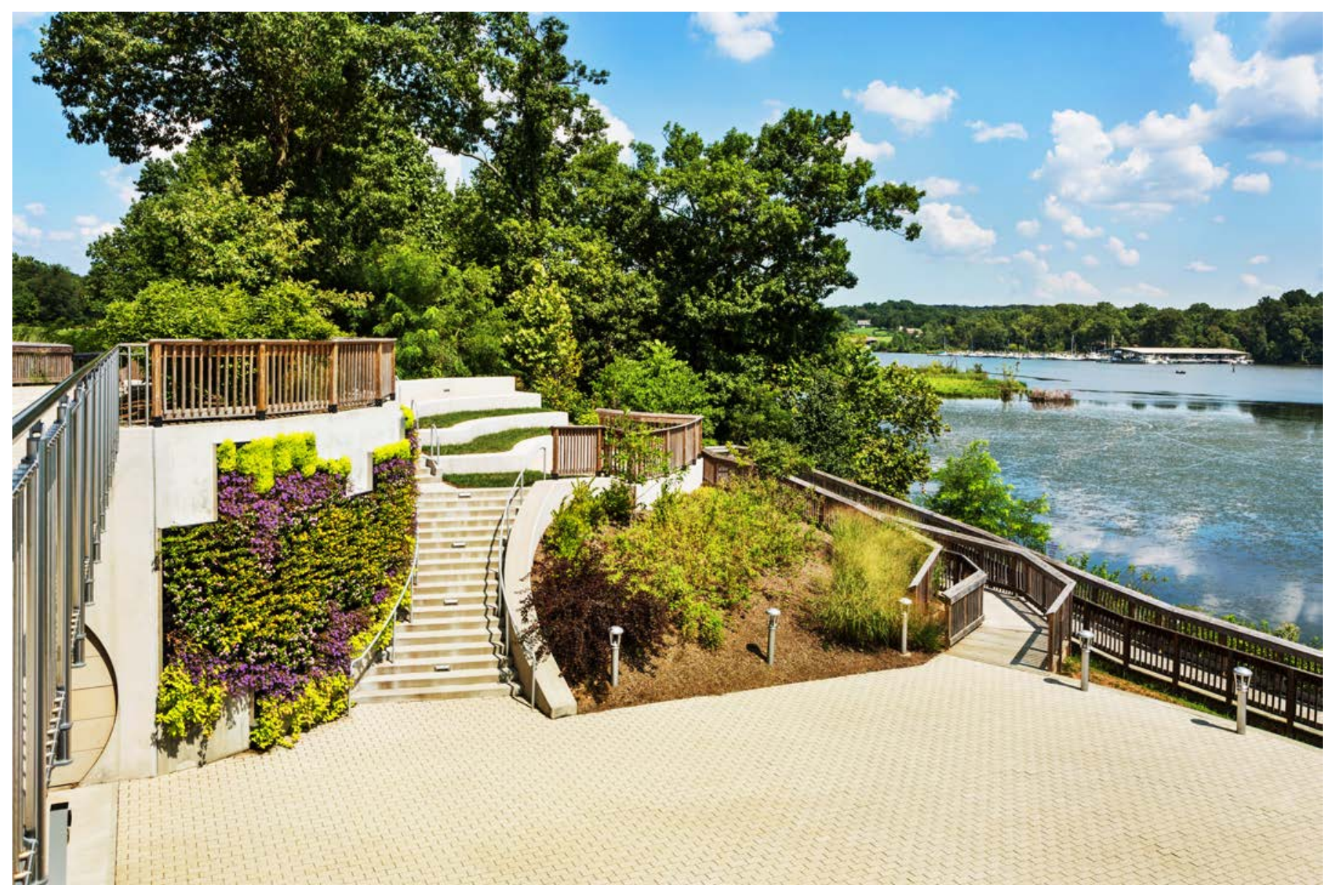


Pictured: Labeled water features at the site.

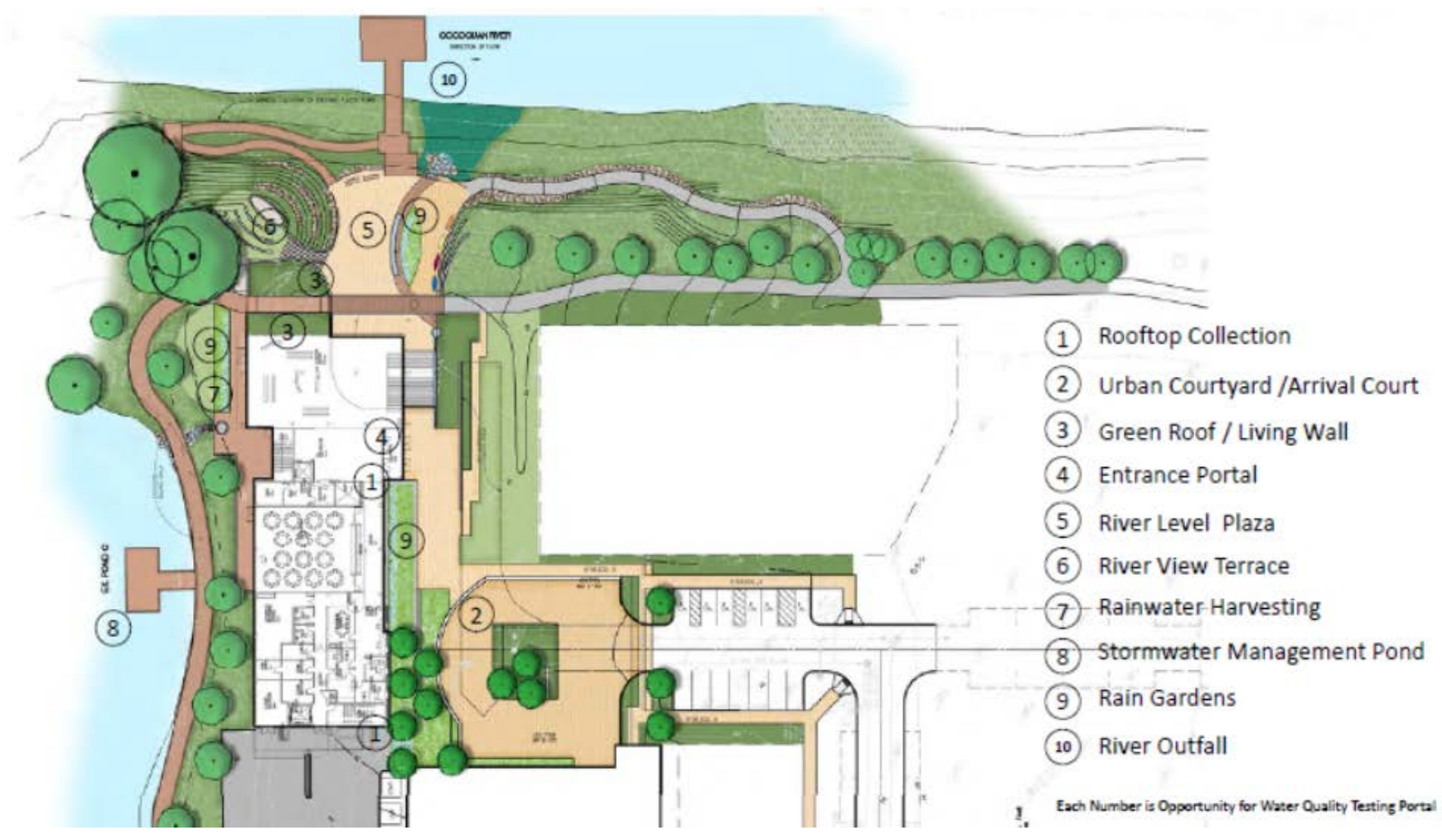

How do you feel like the Water Story features of this site influenced your experience with this site?

$\begin{array}{lllll}1 & 2 & 3 & 4 & 5\end{array}$

0. I was unaware that these Water Story features existed.

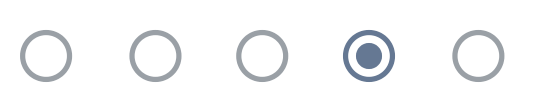

I am aware of most or all of these water features and they have greatly enriched my learning experience at the site. 
What specific features of the Potomac Science Center outdoor landscape have you seen or learned about during your time at the site?

a. Roof drain with a weir into a rain garden

b. Scuppers installed on the roof

c. Table top installation to replicate characteristics of a dry creek bed.

d. 5,000-gallon rainwater harvesting cistern collects water from the roof of the building and water condensation from the air conditioning system.

$\checkmark$ e. A 250-sf green wall located along the main plaza of the outdoor patio

f. A series of rain gardens and Infiltration swales throughout the site.

Would the addition of signage explaining the significance of each Water Story feature enhance your learning experience at this site?
(O) Yes
b. No
c. Unsure

Thank you for your participation!

If you are interested in receiving a copy of this final case study - please share your email address with us. Copy and past the following link into your browser to share: https://forms.gle/d7bfZzi4N56F2SDH6

This form was created outside of your domain. 


\section{Potomac Science Center Visitor Assessment Survey}

This research is being conducted to evaluate how the construction and maintenance of the Potomac Science Center landscape has impacted the surrounding community. This information will be used to inform future landscape design projects at George Mason University and the larger landscape design industry (through submission to the Landscape Architecture Foundation).

\section{Informed Consent}

This research is being conducted to evaluate how the construction and maintenance of the Potomac Science Center landscape has impacted the surrounding community. This information will be used to inform future landscape design projects at George Mason University and the larger landscape design industry (through submission to the Landscape Architecture Foundation). If you agree to participate, you will be asked to complete a 10-minute online survey.

RISKS: There are no foreseeable risks for participating in this research.

BENEFITS: There are no benefits to you as a participant other than to further research in the landscape design field.

CONFIDENTIALITY: The data in this study will be confidential. Names and other identifiers will not be placed on research data. Participant's names and contact information will not be included on the surveys and other collectible data. If you choose to opt into sharing your contact information with us, it will be collected through a separate survey and completely separate from the data for this survey. This ensures that all data collected is de-identified immediately. The de-identified data could be used for future research without additional consent from participants. The Institutional Review Board (IRB) committee that monitors the research on human subjects may inspect study records during internal auditing procedures and are required to keep all information confidential.

PARTICIPATION: Your participation is voluntary, and you may withdraw from the study at any time and for any reason. If you decide not to participate or if you withdraw from the study, there is no penalty or loss of benefits to which you are otherwise entitled. There are no costs to you or any other party.

I have read this form, all of my questions have been answered by the research staff, and I agree to participate in this study.

Accept.

Decline. 


\section{Contact}

This research is being conducted by MacKenzie Earl at George Mason University. She may be reached at (540) 270-6483 or mearl@gmu.edu for questions or to report a research-related problem. Cynthia Smith (faculty advisor) be reached at csmitc@gmu.edu.You may contact the George Mason University Institutional Review Board office at 703-993-4121 or $\underline{I R B} @$ gmu.edu if you have questions or comments regarding your rights as a participant in the research. This research has been reviewed according to George Mason University procedures governing your participation in this research.

\section{Overview}

How would you describe your relation to the Potomac Science Center?

I am a resident of the region.

I am a resident of the Belmont Bay Community Home Owner's Association.

I am a one time visitor to the facility.

( I am an employee or contracted worker at the facility.

I am a faculty member or student with George Mason University.

\section{Section 4: Engagement}

How would you rate your level of engagement with the site indicated PRIOR to the construction of the Potomac Science Center in 2017?

0. I never engaged with this site prior to 2017

b. 1 . I rarely engaged with this site prior to 2017

c. 2. I engaged with this site prior to 2017 3-4 times prior to 2017.

d. 3. I often engaged with this site prior to construction in 2017.

e. 4. I often engaged with this site prior to construction in 2017 - including frequent use of the National Heritage Scenic Trail. 
Please indicate all of the ways you engaged with the site PRIOR to the construction of the Potomac Science Center in 2017.

$\square$ a Used the National Heritage Scenic Trail for recreational use.

b. Enjoyed the view of the Occoquan River.

c. Engaged in ecological-based recreation (bird watching, plant identification, ect.)

d. Visited the site to learn about watersheds, water ecology, conservation, and other topics.

e. I did not engage with this site at all prior to the construction of the PSC.

Other:

\section{Untitled Section}

How would you rate your level of engagement with the site indicated AFTER the construction of the Potomac Science Center in 2017?

a. I never engage with this site.

b. I rarely engage with this site.

c. I engaged with this site 3-4 times a year.

d. I often engage with this site.

(2) I often engage with this site - including frequent use of the National Heritage Scenic Trail. 
Please indicate all of the ways you engaged with the site AFTER its construction concluded?

a Used the National Heritage Scenic Trail for recreational use.

b. Enjoyed the view of the Occoquan River.

c. Engaged in ecological-based recreation (bird watching, plant identification, ect.)

d. Visited the site to learn about watersheds, water ecology, conservation, and other topics.

e. Other (Option to write in.)

\section{Section 2: General Information}

Current Aerial of the Potomac Science Center

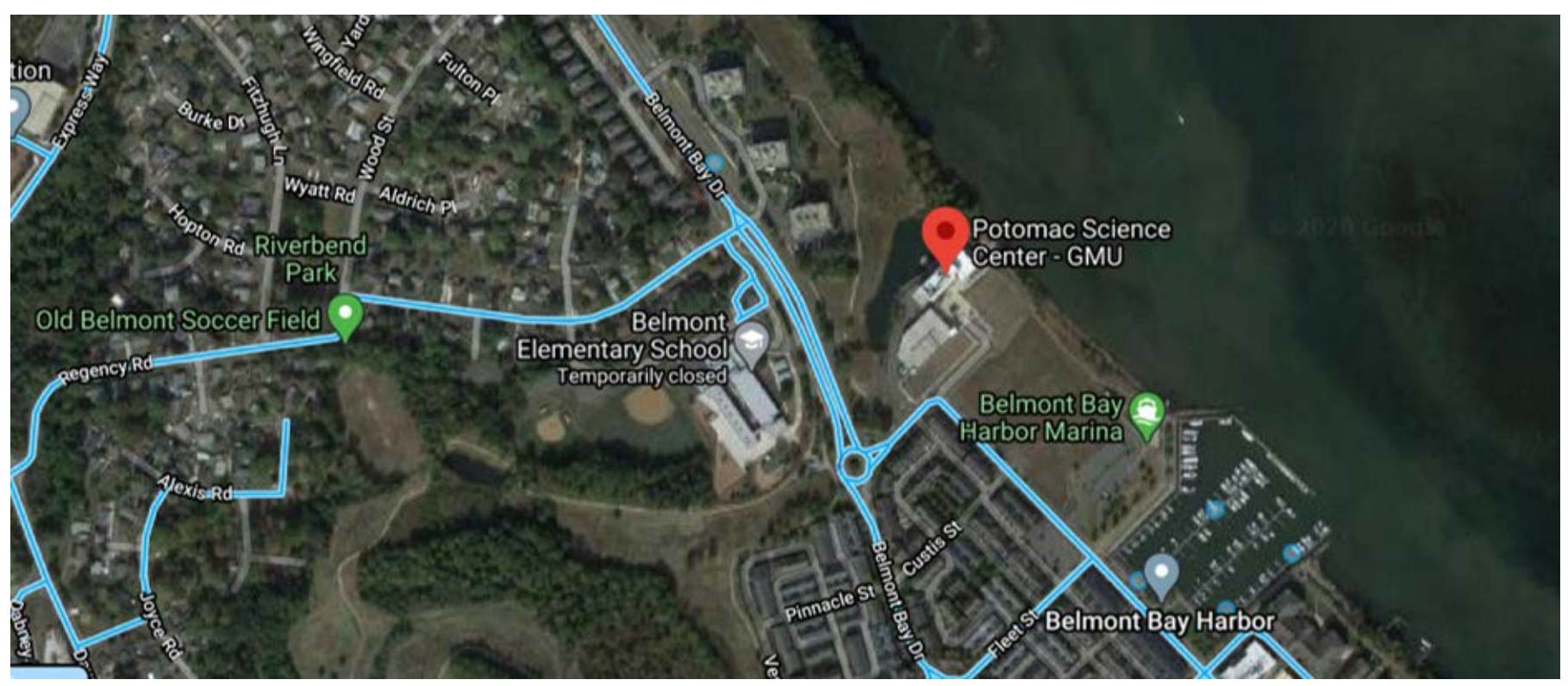


What mode of transport have you used to travel to/ use while at this site?

I have walked to this site as a pedestrian. I did not access this site via the NHST.

b. I have walked to this site as a pedestrian. I accessed this site via the NHST.

() . I have driven to the site and walked around the area.

d. I have visited this site as a cyclist from the NHST.

e. I have visited this site via bicycle without use of the NHST.

f. Other (Please specify.)

When you have visited the Potomac Science Center site, who do you come with?

$\checkmark$ a. I visit the site alone.

$\checkmark$ b. I visit with a friend or spouse.

c. I visit with my family (including children).

d. I visit with my family (including multigenerational family).

e. I have visited with a class or educational program.

Section 2: Residents 
How long have you lived in the [Belmont Bay Community Home Owner's Association] neighborhood?
Less than a year
1-2 years
2-4 years
4-6 years
$6+$ years

Would you say that your residency is more appealing because of its proximity to the Potomac Science Center and the outdoor landscape on its campus?
a. Yes
b. No
c. Unsure
d. I am a non-resident.

\section{Section 3: Site Features}

Six "Water Story" features connect to a specific stage in the movement of water throughout the site. These features are designed to visually demonstrate to visitors how a precipitated water droplet travels through the site and into the Occoquan River. These features include a roof drain with a weir into a rain garden, scuppers installed on the roof, and a table top installation to replicate characteristics of a dry creek bed. This is used to educate students and the public about water quality, erosion, and the Occoquan River it overlooks. 
Pictured: Green wall (left), terraced outdoor classroom (center), and rain garden (mid right). All of these are features of the Water Story.

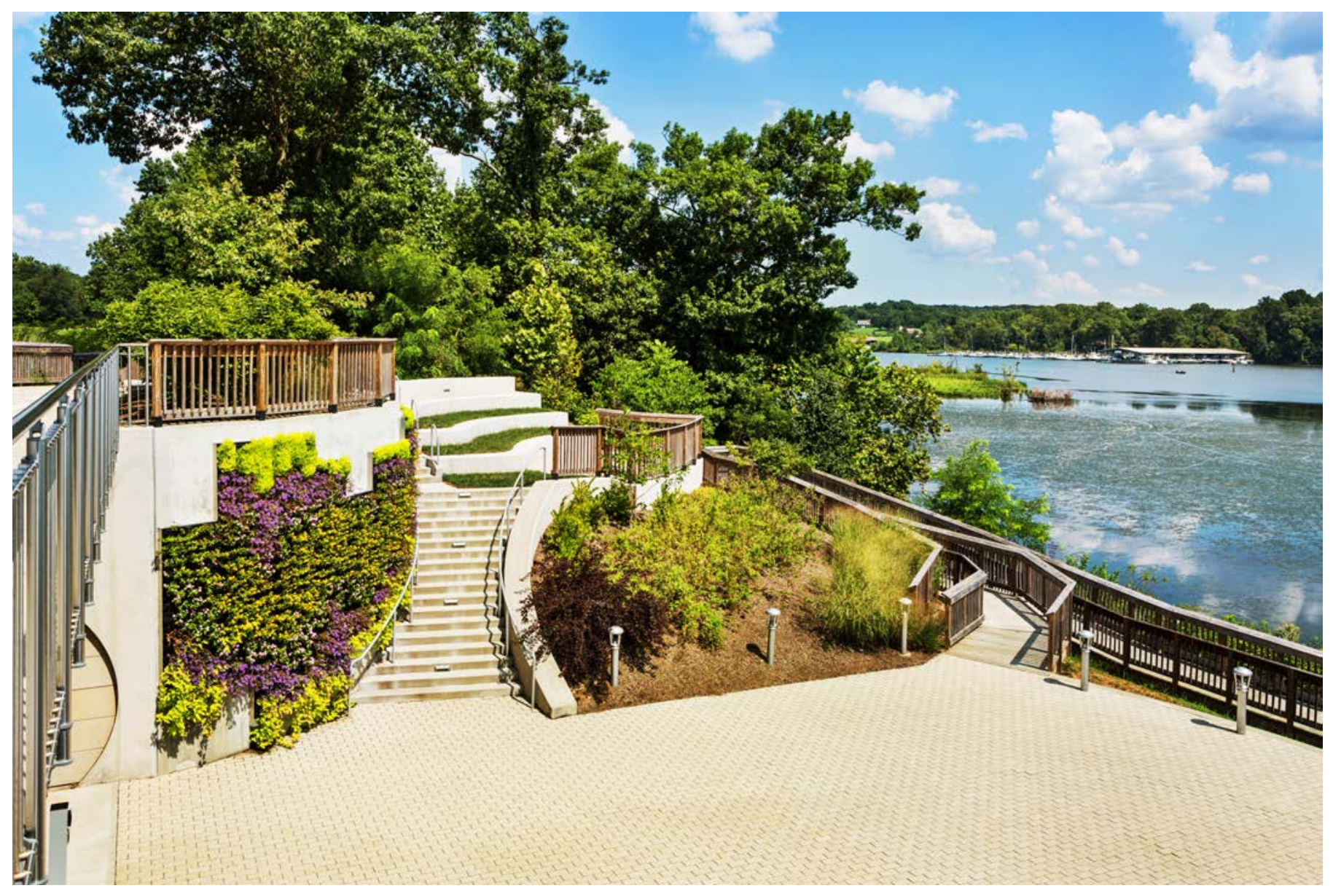


Pictured: Labeled water features at the site.

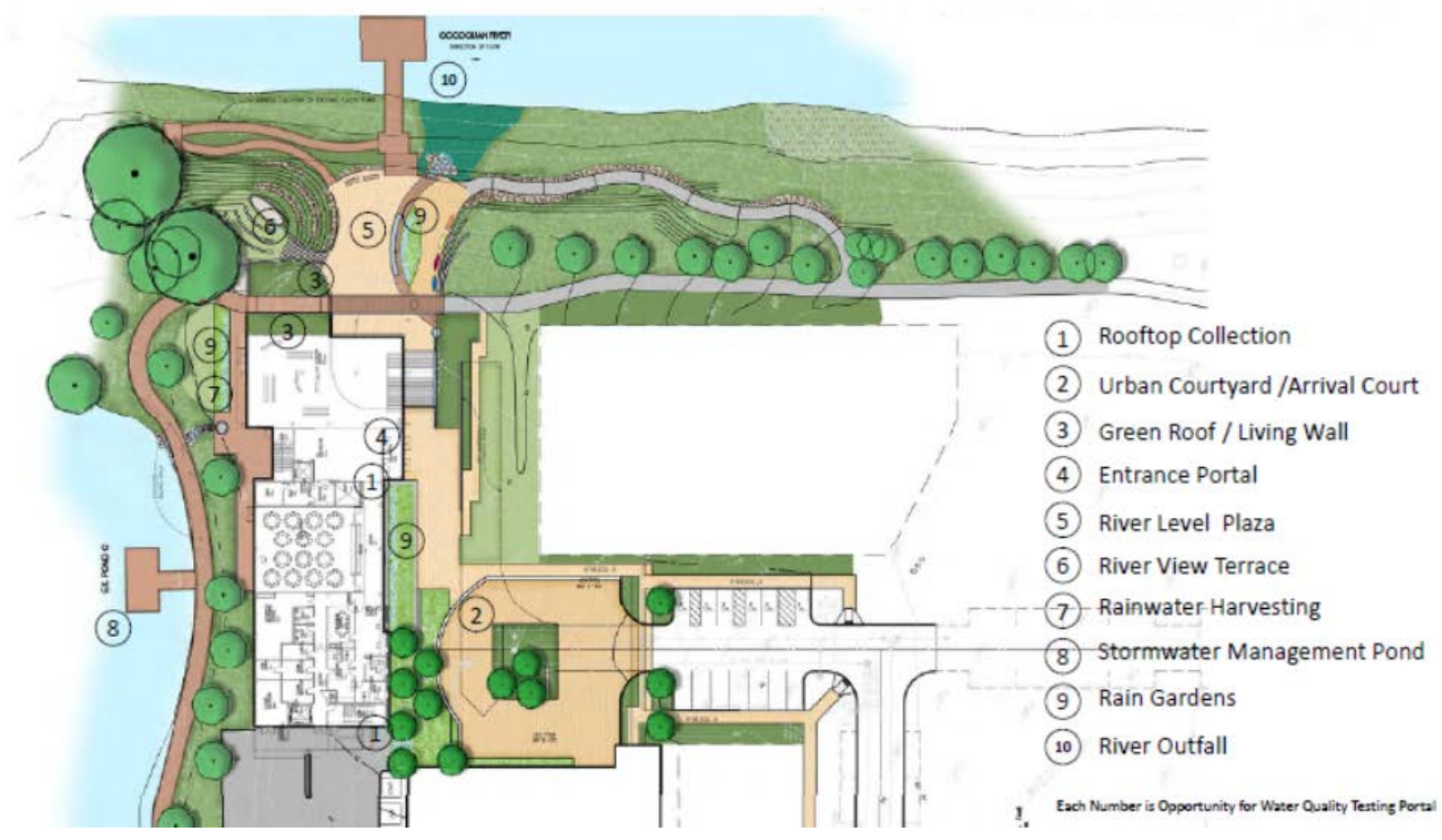

How do you feel like the Water Story features of this site influenced your experience with this site?

$\begin{array}{lllll}1 & 2 & 3 & 4 & 5\end{array}$

0. I was unaware that these Water Story features existed.

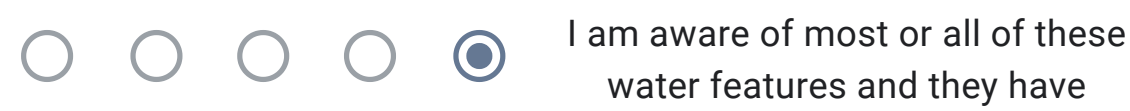
greatly enriched my learning experience at the site. 
What specific features of the Potomac Science Center outdoor landscape have you seen or learned about during your time at the site?

$\checkmark$ a. Roof drain with a weir into a rain garden

$\checkmark$ b. Scuppers installed on the roof

$\checkmark$ c. Table top installation to replicate characteristics of a dry creek bed.

d. 5,000-gallon rainwater harvesting cistern collects water from the roof of the building and water condensation from the air conditioning system.

$\checkmark$ e. A 250-sf green wall located along the main plaza of the outdoor patio

$\checkmark$ f. A series of rain gardens and Infiltration swales throughout the site.

Would the addition of signage explaining the significance of each Water Story feature enhance your learning experience at this site?
() a. Yes
b. No
c. Unsure

Thank you for your participation!

If you are interested in receiving a copy of this final case study - please share your email address with us. Copy and past the following link into your browser to share: https://forms.gle/d7bfZzi4N56F2SDH6

This form was created outside of your domain. 


\section{Potomac Science Center Visitor Assessment Survey}

This research is being conducted to evaluate how the construction and maintenance of the Potomac Science Center landscape has impacted the surrounding community. This information will be used to inform future landscape design projects at George Mason University and the larger landscape design industry (through submission to the Landscape Architecture Foundation).

\section{Informed Consent}

This research is being conducted to evaluate how the construction and maintenance of the Potomac Science Center landscape has impacted the surrounding community. This information will be used to inform future landscape design projects at George Mason University and the larger landscape design industry (through submission to the Landscape Architecture Foundation). If you agree to participate, you will be asked to complete a 10-minute online survey.

RISKS: There are no foreseeable risks for participating in this research.

BENEFITS: There are no benefits to you as a participant other than to further research in the landscape design field.

CONFIDENTIALITY: The data in this study will be confidential. Names and other identifiers will not be placed on research data. Participant's names and contact information will not be included on the surveys and other collectible data. If you choose to opt into sharing your contact information with us, it will be collected through a separate survey and completely separate from the data for this survey. This ensures that all data collected is de-identified immediately. The de-identified data could be used for future research without additional consent from participants. The Institutional Review Board (IRB) committee that monitors the research on human subjects may inspect study records during internal auditing procedures and are required to keep all information confidential.

PARTICIPATION: Your participation is voluntary, and you may withdraw from the study at any time and for any reason. If you decide not to participate or if you withdraw from the study, there is no penalty or loss of benefits to which you are otherwise entitled. There are no costs to you or any other party.

I have read this form, all of my questions have been answered by the research staff, and I agree to participate in this study.

Accept.

Decline. 


\section{Contact}

This research is being conducted by MacKenzie Earl at George Mason University. She may be reached at (540) 270-6483 or mearl@gmu.edu for questions or to report a research-related problem. Cynthia Smith (faculty advisor) be reached at csmitc@gmu.edu.You may contact the George Mason University Institutional Review Board office at 703-993-4121 or $\underline{I R B} @$ gmu.edu if you have questions or comments regarding your rights as a participant in the research. This research has been reviewed according to George Mason University procedures governing your participation in this research.

\section{Overview}

How would you describe your relation to the Potomac Science Center?

I am a resident of the region.

I am a resident of the Belmont Bay Community Home Owner's Association.

I am a one time visitor to the facility.

I am an employee or contracted worker at the facility.

(- I am a faculty member or student with George Mason University.

\section{Section 4: Engagement}

How would you rate your level of engagement with the site indicated PRIOR to the construction of the Potomac Science Center in 2017?

0. I never engaged with this site prior to 2017

b. 1. I rarely engaged with this site prior to 2017.

c. 2. I engaged with this site prior to 2017 3-4 times prior to 2017.

d. 3. I often engaged with this site prior to construction in 2017.

e. 4. I often engaged with this site prior to construction in 2017 - including frequent use of the National Heritage Scenic Trail. 
Please indicate all of the ways you engaged with the site PRIOR to the construction of the Potomac Science Center in 2017.

$\square$ a Used the National Heritage Scenic Trail for recreational use.

b. Enjoyed the view of the Occoquan River.

c. Engaged in ecological-based recreation (bird watching, plant identification, ect.)

d. Visited the site to learn about watersheds, water ecology, conservation, and other topics.

e. I did not engage with this site at all prior to the construction of the PSC.

$\checkmark$ Other: Worked on construction fir the building

\section{Untitled Section}

How would you rate your level of engagement with the site indicated AFTER the construction of the Potomac Science Center in 2017?

a. I never engage with this site.

b. I rarely engage with this site.

c. I engaged with this site 3-4 times a year.

d. I often engage with this site.

e. I often engage with this site - including frequent use of the National Heritage Scenic Trail. 
Please indicate all of the ways you engaged with the site AFTER its construction concluded?

$\square$ a Used the National Heritage Scenic Trail for recreational use.

$\square$ b. Enjoyed the view of the Occoquan River.

$\square$ c. Engaged in ecological-based recreation (bird watching, plant identification, ect.)

$\square$ d. Visited the site to learn about watersheds, water ecology, conservation, and other topics.

e. Other (Option to write in.)

Section 2: General Information

Current Aerial of the Potomac Science Center

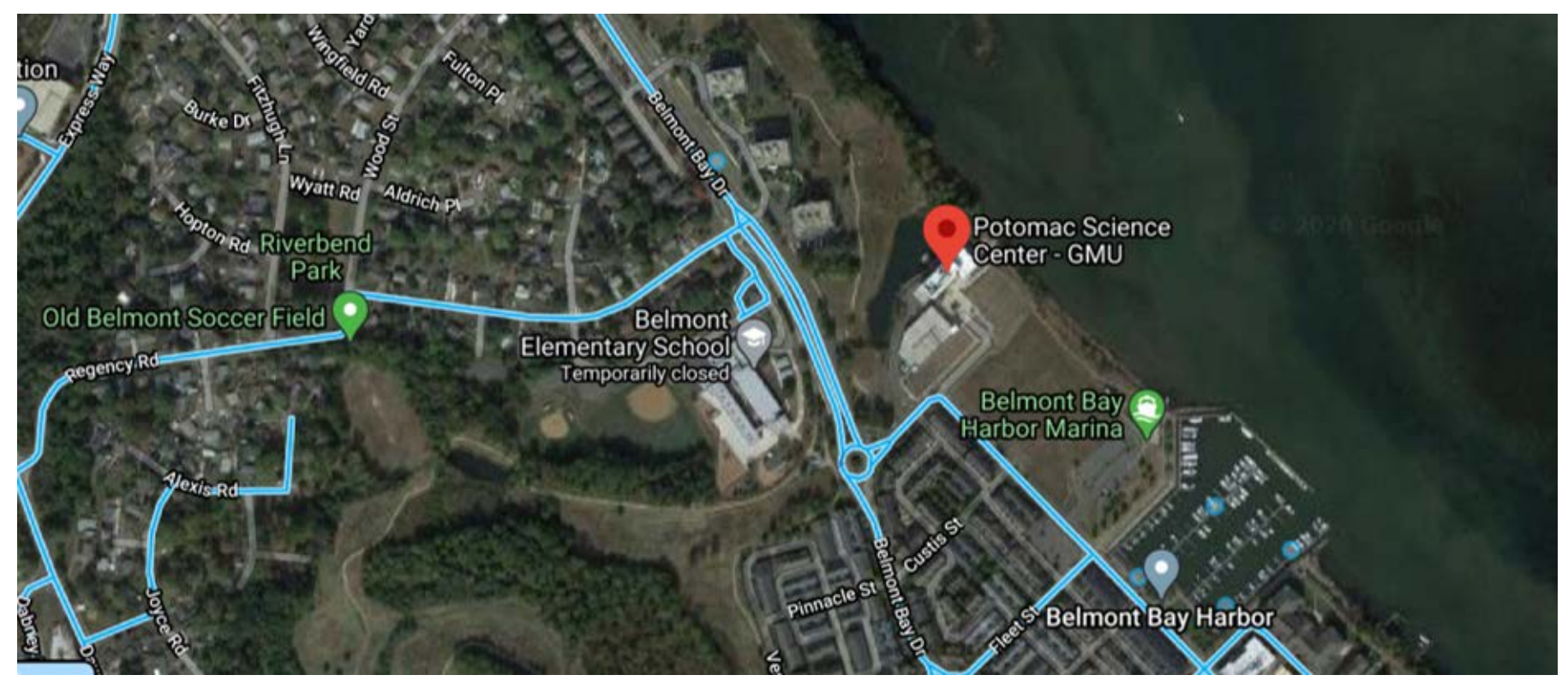


What mode of transport have you used to travel to/ use while at this site?

I have walked to this site as a pedestrian. I did not access this site via the NHST.

b. I have walked to this site as a pedestrian. I accessed this site via the NHST.

(- . I have driven to the site and walked around the area.

d. I have visited this site as a cyclist from the NHST.

e. I have visited this site via bicycle without use of the NHST.

f. Other (Please specify.)

When you have visited the Potomac Science Center site, who do you come with?

$\checkmark$ a. I visit the site alone.

b. I visit with a friend or spouse.

c. I visit with my family (including children).

d. I visit with my family (including multigenerational family).

e. I have visited with a class or educational program.

Section 2: Residents 
How long have you lived in the [Belmont Bay Community Home Owner's Association] neighborhood?
Less than a year
1-2 years
2-4 years
4-6 years
$6+$ years

Would you say that your residency is more appealing because of its proximity to the Potomac Science Center and the outdoor landscape on its campus?
a. Yes
b. No
c. Unsure
d. I am a non-resident.

\section{Section 3: Site Features}

Six "Water Story" features connect to a specific stage in the movement of water throughout the site. These features are designed to visually demonstrate to visitors how a precipitated water droplet travels through the site and into the Occoquan River. These features include a roof drain with a weir into a rain garden, scuppers installed on the roof, and a table top installation to replicate characteristics of a dry creek bed. This is used to educate students and the public about water quality, erosion, and the Occoquan River it overlooks. 
Pictured: Green wall (left), terraced outdoor classroom (center), and rain garden (mid right). All of these are features of the Water Story.

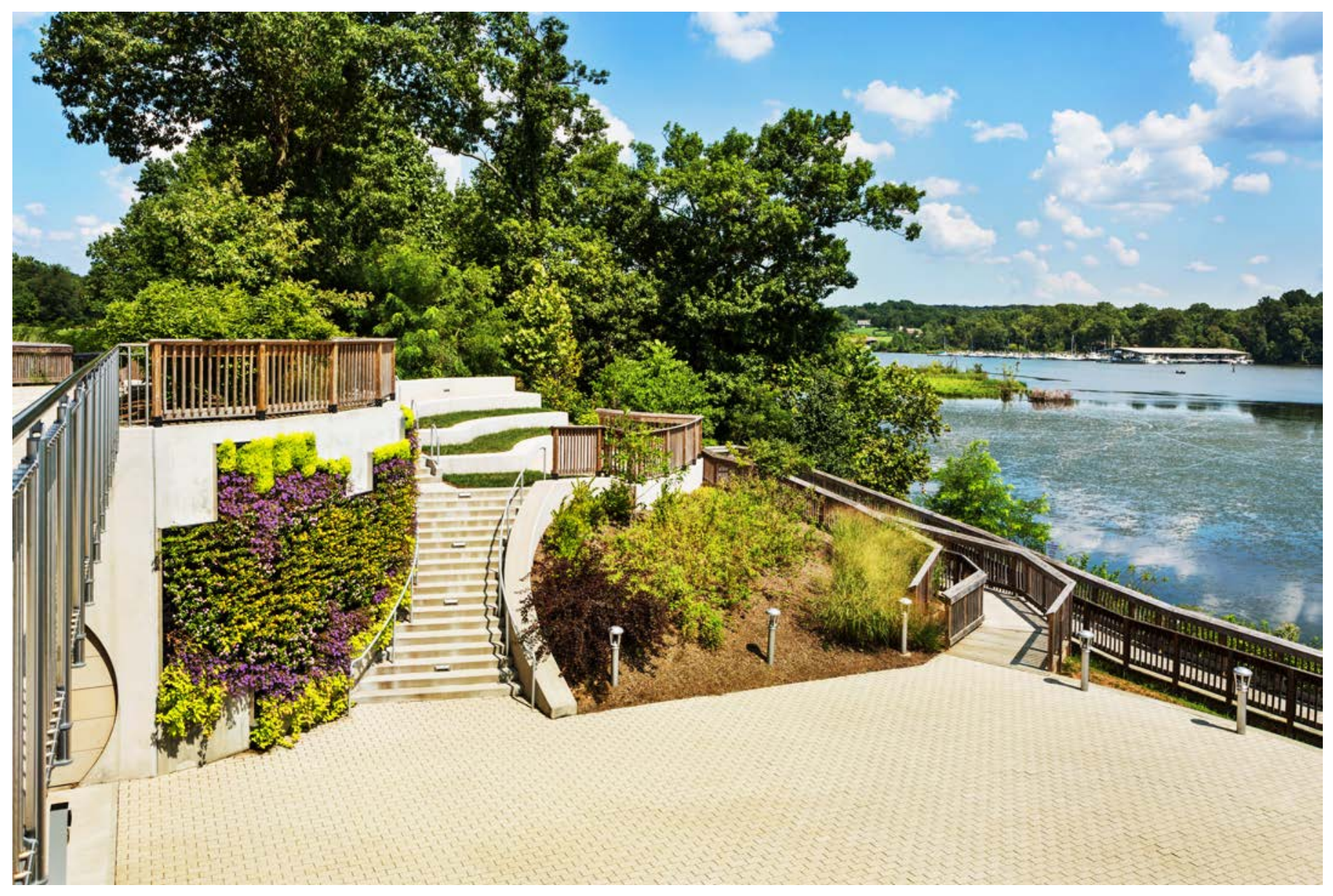


Pictured: Labeled water features at the site.

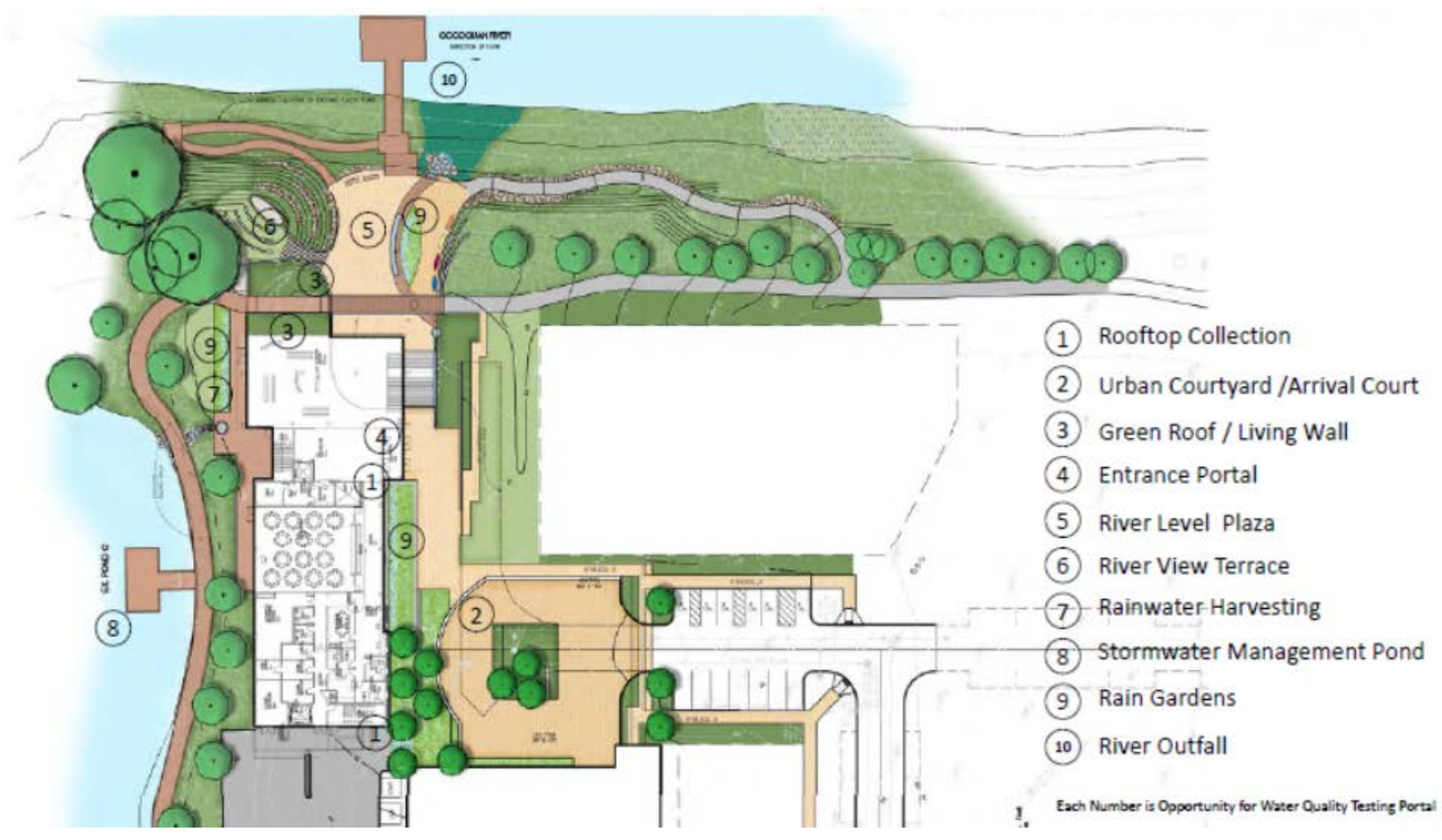

How do you feel like the Water Story features of this site influenced your experience with this site?

$\begin{array}{lllll}1 & 2 & 3 & 4 & 5\end{array}$

0. I was unaware that these Water Story features existed.

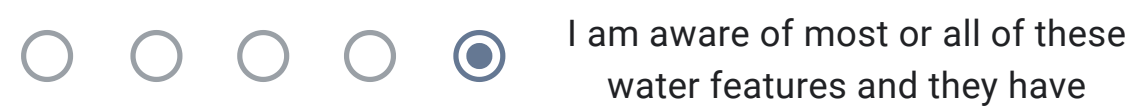
greatly enriched my learning experience at the site. 
What specific features of the Potomac Science Center outdoor landscape have you seen or learned about during your time at the site?

$\checkmark$ a. Roof drain with a weir into a rain garden

$\checkmark$ b. Scuppers installed on the roof

$\checkmark$ c. Table top installation to replicate characteristics of a dry creek bed.

d. 5,000-gallon rainwater harvesting cistern collects water from the roof of the building and water condensation from the air conditioning system.

$\checkmark$ e. A 250-sf green wall located along the main plaza of the outdoor patio

$\checkmark$ f. A series of rain gardens and Infiltration swales throughout the site.

Would the addition of signage explaining the significance of each Water Story feature enhance your learning experience at this site?
() a. Yes
b. No
c. Unsure

Thank you for your participation!

If you are interested in receiving a copy of this final case study - please share your email address with us. Copy and past the following link into your browser to share: https://forms.gle/d7bfZzi4N56F2SDH6

This form was created outside of your domain. 


\section{Potomac Science Center Visitor Assessment Survey}

This research is being conducted to evaluate how the construction and maintenance of the Potomac Science Center landscape has impacted the surrounding community. This information will be used to inform future landscape design projects at George Mason University and the larger landscape design industry (through submission to the Landscape Architecture Foundation).

\section{Informed Consent}

This research is being conducted to evaluate how the construction and maintenance of the Potomac Science Center landscape has impacted the surrounding community. This information will be used to inform future landscape design projects at George Mason University and the larger landscape design industry (through submission to the Landscape Architecture Foundation). If you agree to participate, you will be asked to complete a 10-minute online survey.

RISKS: There are no foreseeable risks for participating in this research.

BENEFITS: There are no benefits to you as a participant other than to further research in the landscape design field.

CONFIDENTIALITY: The data in this study will be confidential. Names and other identifiers will not be placed on research data. Participant's names and contact information will not be included on the surveys and other collectible data. If you choose to opt into sharing your contact information with us, it will be collected through a separate survey and completely separate from the data for this survey. This ensures that all data collected is de-identified immediately. The de-identified data could be used for future research without additional consent from participants. The Institutional Review Board (IRB) committee that monitors the research on human subjects may inspect study records during internal auditing procedures and are required to keep all information confidential.

PARTICIPATION: Your participation is voluntary, and you may withdraw from the study at any time and for any reason. If you decide not to participate or if you withdraw from the study, there is no penalty or loss of benefits to which you are otherwise entitled. There are no costs to you or any other party.

I have read this form, all of my questions have been answered by the research staff, and I agree to participate in this study.

Accept.

Decline. 


\section{Contact}

This research is being conducted by MacKenzie Earl at George Mason University. She may be reached at (540) 270-6483 or mearl@gmu.edu for questions or to report a research-related problem. Cynthia Smith (faculty advisor) be reached at csmitc@gmu.edu.You may contact the George Mason University Institutional Review Board office at 703-993-4121 or $\underline{I R B} @$ gmu.edu if you have questions or comments regarding your rights as a participant in the research. This research has been reviewed according to George Mason University procedures governing your participation in this research.

\section{Overview}

How would you describe your relation to the Potomac Science Center?

I am a resident of the region.

I am a resident of the Belmont Bay Community Home Owner's Association.

I am a one time visitor to the facility.

( I am an employee or contracted worker at the facility.

I am a faculty member or student with George Mason University.

\section{Section 4: Engagement}

How would you rate your level of engagement with the site indicated PRIOR to the construction of the Potomac Science Center in 2017?

0. I never engaged with this site prior to 2017

b. 1 . I rarely engaged with this site prior to 2017

c. 2. I engaged with this site prior to 2017 3-4 times prior to 2017.

d. 3. I often engaged with this site prior to construction in 2017.

e. 4. I often engaged with this site prior to construction in 2017 - including frequent use of the National Heritage Scenic Trail. 
Please indicate all of the ways you engaged with the site PRIOR to the construction of the Potomac Science Center in 2017.

$\square$ a Used the National Heritage Scenic Trail for recreational use.

b. Enjoyed the view of the Occoquan River.

c. Engaged in ecological-based recreation (bird watching, plant identification, ect.)

d. Visited the site to learn about watersheds, water ecology, conservation, and other topics.

e. I did not engage with this site at all prior to the construction of the PSC.

Other:

\section{Untitled Section}

How would you rate your level of engagement with the site indicated AFTER the construction of the Potomac Science Center in 2017?

a. I never engage with this site.

b. I rarely engage with this site.

(1) c. I engaged with this site 3-4 times a year.

d. I often engage with this site.

e. I often engage with this site - including frequent use of the National Heritage Scenic Trail. 
Please indicate all of the ways you engaged with the site AFTER its construction concluded?

$\square$ a Used the National Heritage Scenic Trail for recreational use.

$\square$ b. Enjoyed the view of the Occoquan River.

$\square$ c. Engaged in ecological-based recreation (bird watching, plant identification, ect.)

$\square$ d. Visited the site to learn about watersheds, water ecology, conservation, and other topics.

$\checkmark$ e. Other (Option to write in.)

\section{Section 2: General Information}

\section{Current Aerial of the Potomac Science Center}

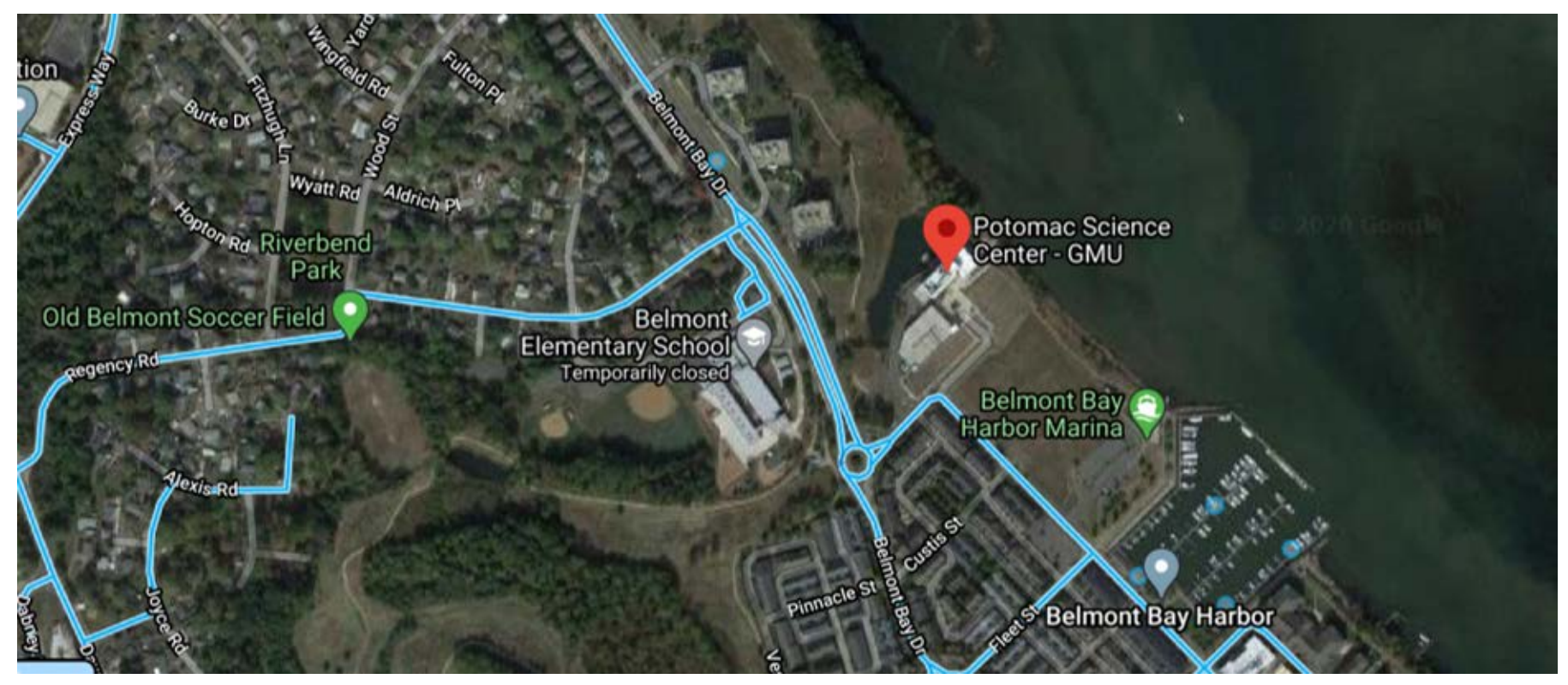


What mode of transport have you used to travel to/ use while at this site?

I have walked to this site as a pedestrian. I did not access this site via the NHST.

b. I have walked to this site as a pedestrian. I accessed this site via the NHST.

(- c. I have driven to the site and walked around the area.

d. I have visited this site as a cyclist from the NHST.

e. I have visited this site via bicycle without use of the NHST.

f. Other (Please specify.)

When you have visited the Potomac Science Center site, who do you come with?

$\checkmark$ a. I visit the site alone.

b. I visit with a friend or spouse.

c. I visit with my family (including children).

d. I visit with my family (including multigenerational family).

e. I have visited with a class or educational program.

Section 2: Residents 
How long have you lived in the [Belmont Bay Community Home Owner's Association] neighborhood?
Less than a year
1-2 years
2-4 years
4-6 years
$6+$ years

Would you say that your residency is more appealing because of its proximity to the Potomac Science Center and the outdoor landscape on its campus?
a. Yes
b. No
c. Unsure
d. I am a non-resident.

\section{Section 3: Site Features}

Six "Water Story" features connect to a specific stage in the movement of water throughout the site. These features are designed to visually demonstrate to visitors how a precipitated water droplet travels through the site and into the Occoquan River. These features include a roof drain with a weir into a rain garden, scuppers installed on the roof, and a table top installation to replicate characteristics of a dry creek bed. This is used to educate students and the public about water quality, erosion, and the Occoquan River it overlooks. 
Pictured: Green wall (left), terraced outdoor classroom (center), and rain garden (mid right). All of these are features of the Water Story.

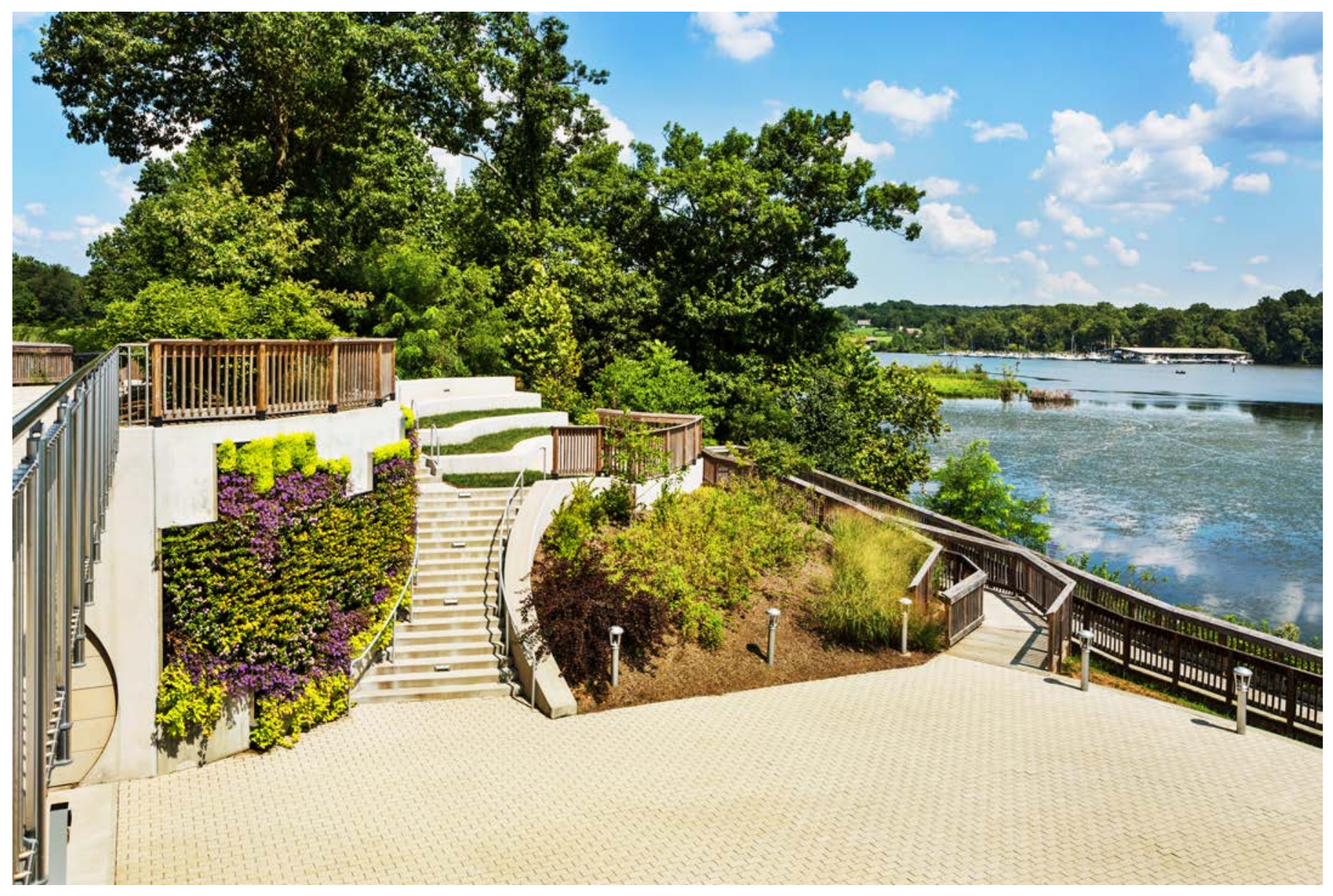


Pictured: Labeled water features at the site.

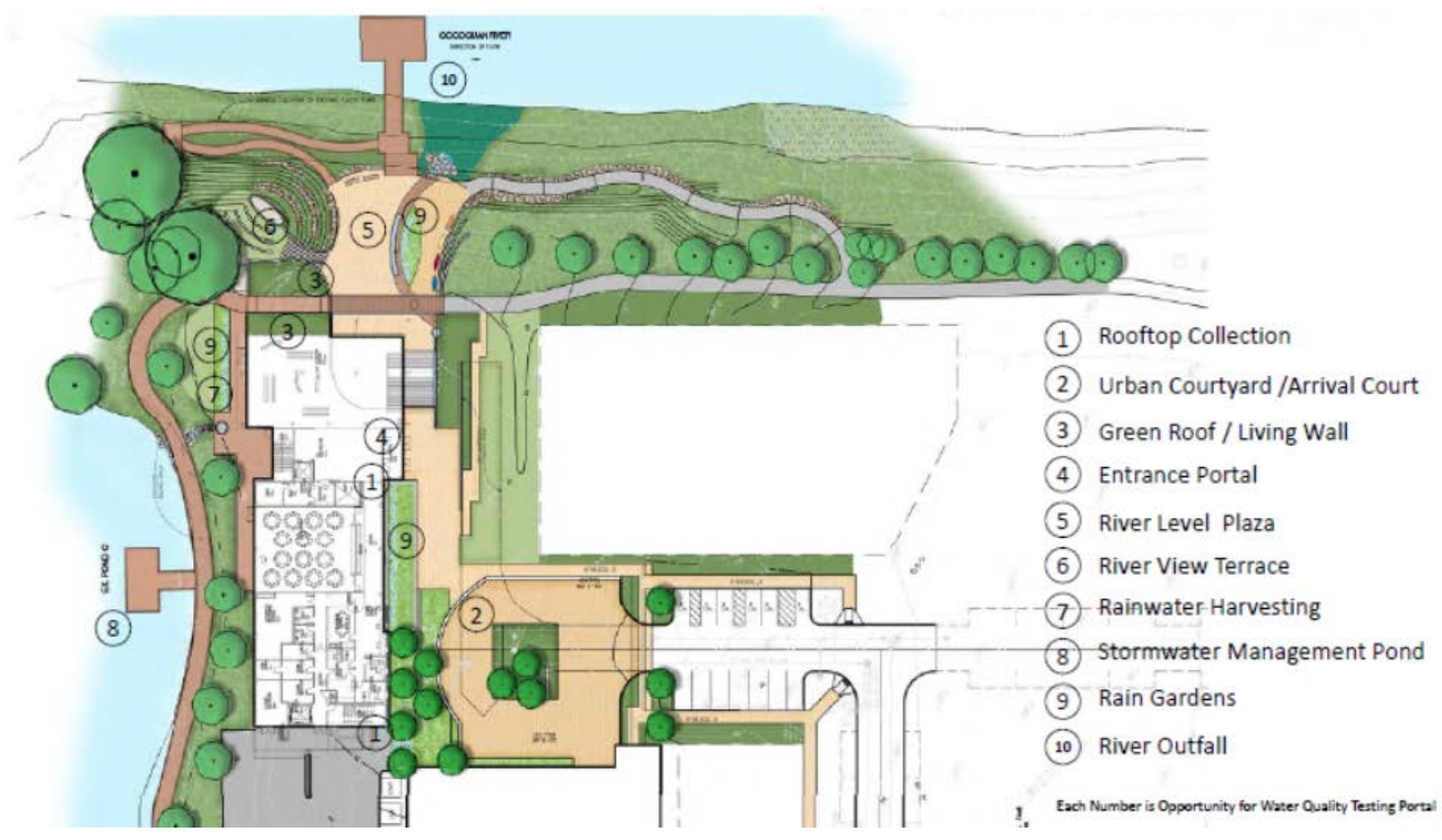

How do you feel like the Water Story features of this site influenced your experience with this site?

$\begin{array}{lllll}1 & 2 & 3 & 4 & 5\end{array}$

0. I was unaware that these Water Story features existed.

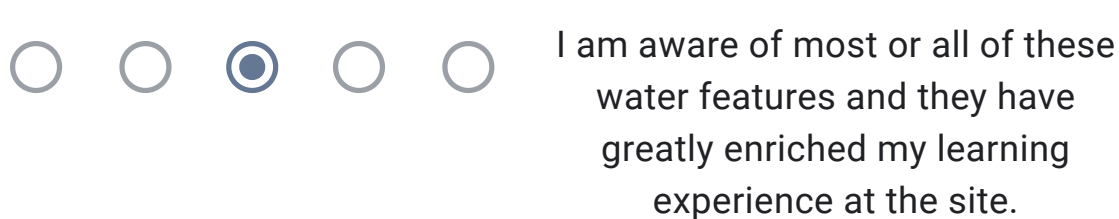


What specific features of the Potomac Science Center outdoor landscape have you seen or learned about during your time at the site?

$\checkmark$ a. Roof drain with a weir into a rain garden

b. Scuppers installed on the roof

c. Table top installation to replicate characteristics of a dry creek bed.

d. 5,000-gallon rainwater harvesting cistern collects water from the roof of the building and water condensation from the air conditioning system.

$\checkmark$ e. A 250-sf green wall located along the main plaza of the outdoor patio

f. A series of rain gardens and Infiltration swales throughout the site.

Would the addition of signage explaining the significance of each Water Story feature enhance your learning experience at this site?
() a. Yes
b. No
c. Unsure

Thank you for your participation!

If you are interested in receiving a copy of this final case study - please share your email address with us. Copy and past the following link into your browser to share: https://forms.gle/d7bfZzi4N56F2SDH6

This form was created outside of your domain.

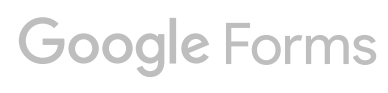




\section{Potomac Science Center Visitor Assessment Survey}

This research is being conducted to evaluate how the construction and maintenance of the Potomac Science Center landscape has impacted the surrounding community. This information will be used to inform future landscape design projects at George Mason University and the larger landscape design industry (through submission to the Landscape Architecture Foundation).

\section{Informed Consent}

This research is being conducted to evaluate how the construction and maintenance of the Potomac Science Center landscape has impacted the surrounding community. This information will be used to inform future landscape design projects at George Mason University and the larger landscape design industry (through submission to the Landscape Architecture Foundation). If you agree to participate, you will be asked to complete a 10-minute online survey.

RISKS: There are no foreseeable risks for participating in this research.

BENEFITS: There are no benefits to you as a participant other than to further research in the landscape design field.

CONFIDENTIALITY: The data in this study will be confidential. Names and other identifiers will not be placed on research data. Participant's names and contact information will not be included on the surveys and other collectible data. If you choose to opt into sharing your contact information with us, it will be collected through a separate survey and completely separate from the data for this survey. This ensures that all data collected is de-identified immediately. The de-identified data could be used for future research without additional consent from participants. The Institutional Review Board (IRB) committee that monitors the research on human subjects may inspect study records during internal auditing procedures and are required to keep all information confidential.

PARTICIPATION: Your participation is voluntary, and you may withdraw from the study at any time and for any reason. If you decide not to participate or if you withdraw from the study, there is no penalty or loss of benefits to which you are otherwise entitled. There are no costs to you or any other party.

I have read this form, all of my questions have been answered by the research staff, and I agree to participate in this study.

Accept.

Decline. 


\section{Contact}

This research is being conducted by MacKenzie Earl at George Mason University. She may be reached at (540) 270-6483 or mearl@gmu.edu for questions or to report a research-related problem. Cynthia Smith (faculty advisor) be reached at csmitc@gmu.edu.You may contact the George Mason University Institutional Review Board office at 703-993-4121 or $\underline{I R B} @$ gmu.edu if you have questions or comments regarding your rights as a participant in the research. This research has been reviewed according to George Mason University procedures governing your participation in this research.

\section{Overview}

How would you describe your relation to the Potomac Science Center?

I am a resident of the region.

I am a resident of the Belmont Bay Community Home Owner's Association.

I am a one time visitor to the facility.

( I am an employee or contracted worker at the facility.

I am a faculty member or student with George Mason University.

\section{Section 4: Engagement}

How would you rate your level of engagement with the site indicated PRIOR to the construction of the Potomac Science Center in 2017?

0. I never engaged with this site prior to 2017

b. 1 . I rarely engaged with this site prior to 2017

c. 2. I engaged with this site prior to 2017 3-4 times prior to 2017.

d. 3. I often engaged with this site prior to construction in 2017.

e. 4. I often engaged with this site prior to construction in 2017 - including frequent use of the National Heritage Scenic Trail. 
Please indicate all of the ways you engaged with the site PRIOR to the construction of the Potomac Science Center in 2017.

$\square$ a Used the National Heritage Scenic Trail for recreational use.

b. Enjoyed the view of the Occoquan River.

c. Engaged in ecological-based recreation (bird watching, plant identification, ect.)

d. Visited the site to learn about watersheds, water ecology, conservation, and other topics.

e. I did not engage with this site at all prior to the construction of the PSC.

Other:

\section{Untitled Section}

How would you rate your level of engagement with the site indicated AFTER the construction of the Potomac Science Center in 2017?

a. I never engage with this site.

b. I rarely engage with this site.

c. I engaged with this site 3-4 times a year.

d. I often engage with this site.

(2) I often engage with this site - including frequent use of the National Heritage Scenic Trail. 
Please indicate all of the ways you engaged with the site AFTER its construction concluded?

a Used the National Heritage Scenic Trail for recreational use.

b. Enjoyed the view of the Occoquan River.

c. Engaged in ecological-based recreation (bird watching, plant identification, ect.)

d. Visited the site to learn about watersheds, water ecology, conservation, and other topics.

e. Other (Option to write in.)

\section{Section 2: General Information}

Current Aerial of the Potomac Science Center

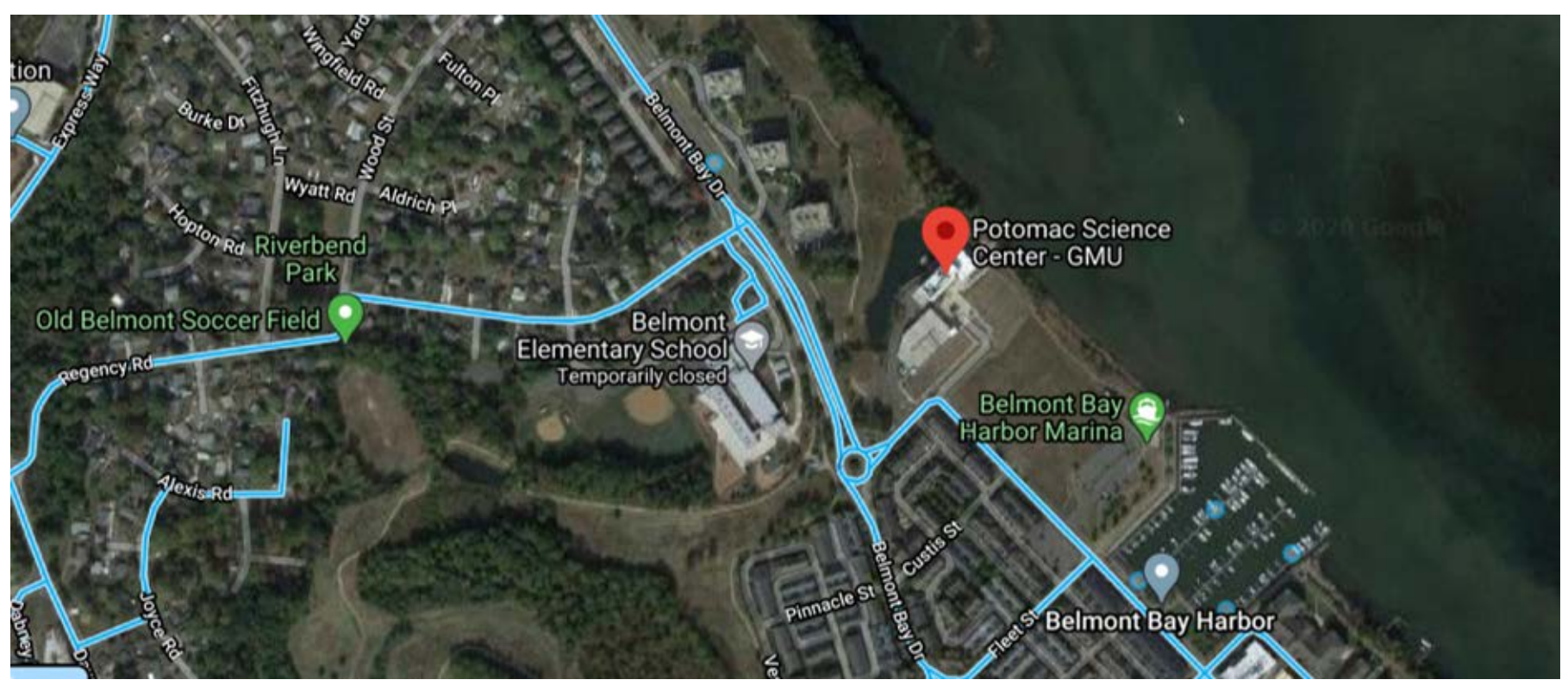


What mode of transport have you used to travel to/ use while at this site?

I have walked to this site as a pedestrian. I did not access this site via the NHST.

b. I have walked to this site as a pedestrian. I accessed this site via the NHST.

(- c. I have driven to the site and walked around the area.

d. I have visited this site as a cyclist from the NHST.

e. I have visited this site via bicycle without use of the NHST.

f. Other (Please specify.)

When you have visited the Potomac Science Center site, who do you come with?

$\checkmark$ a. I visit the site alone.

$\checkmark$ b. I visit with a friend or spouse.

$\checkmark$ c. I visit with my family (including children).

d. I visit with my family (including multigenerational family).

e. I have visited with a class or educational program.

Section 2: Residents 
How long have you lived in the [Belmont Bay Community Home Owner's Association] neighborhood?
Less than a year
1-2 years
2-4 years
4-6 years
$6+$ years

Would you say that your residency is more appealing because of its proximity to the Potomac Science Center and the outdoor landscape on its campus?
a. Yes
b. No
c. Unsure
d. I am a non-resident.

\section{Section 3: Site Features}

Six "Water Story" features connect to a specific stage in the movement of water throughout the site. These features are designed to visually demonstrate to visitors how a precipitated water droplet travels through the site and into the Occoquan River. These features include a roof drain with a weir into a rain garden, scuppers installed on the roof, and a table top installation to replicate characteristics of a dry creek bed. This is used to educate students and the public about water quality, erosion, and the Occoquan River it overlooks. 
Pictured: Green wall (left), terraced outdoor classroom (center), and rain garden (mid right). All of these are features of the Water Story.

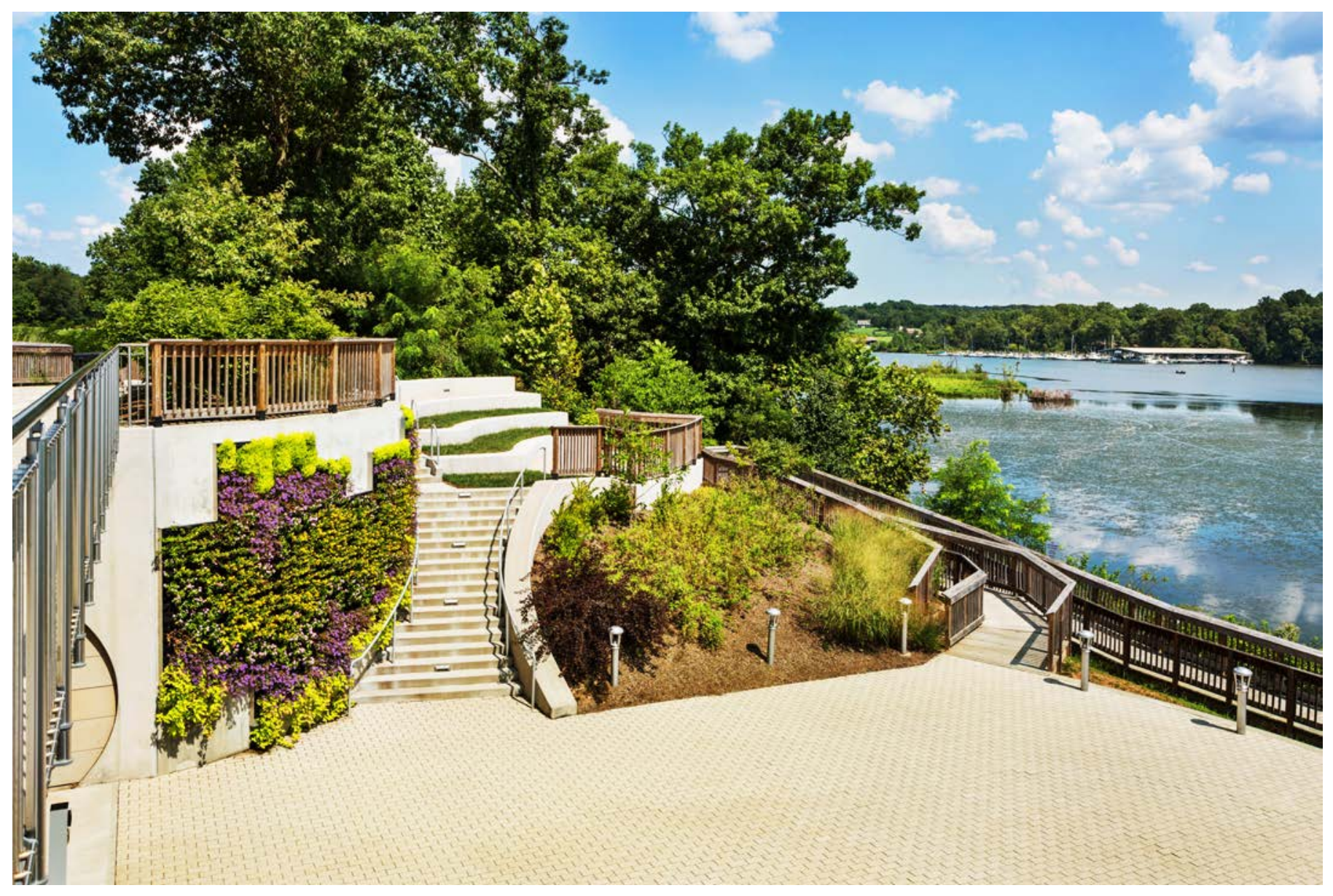


Pictured: Labeled water features at the site.

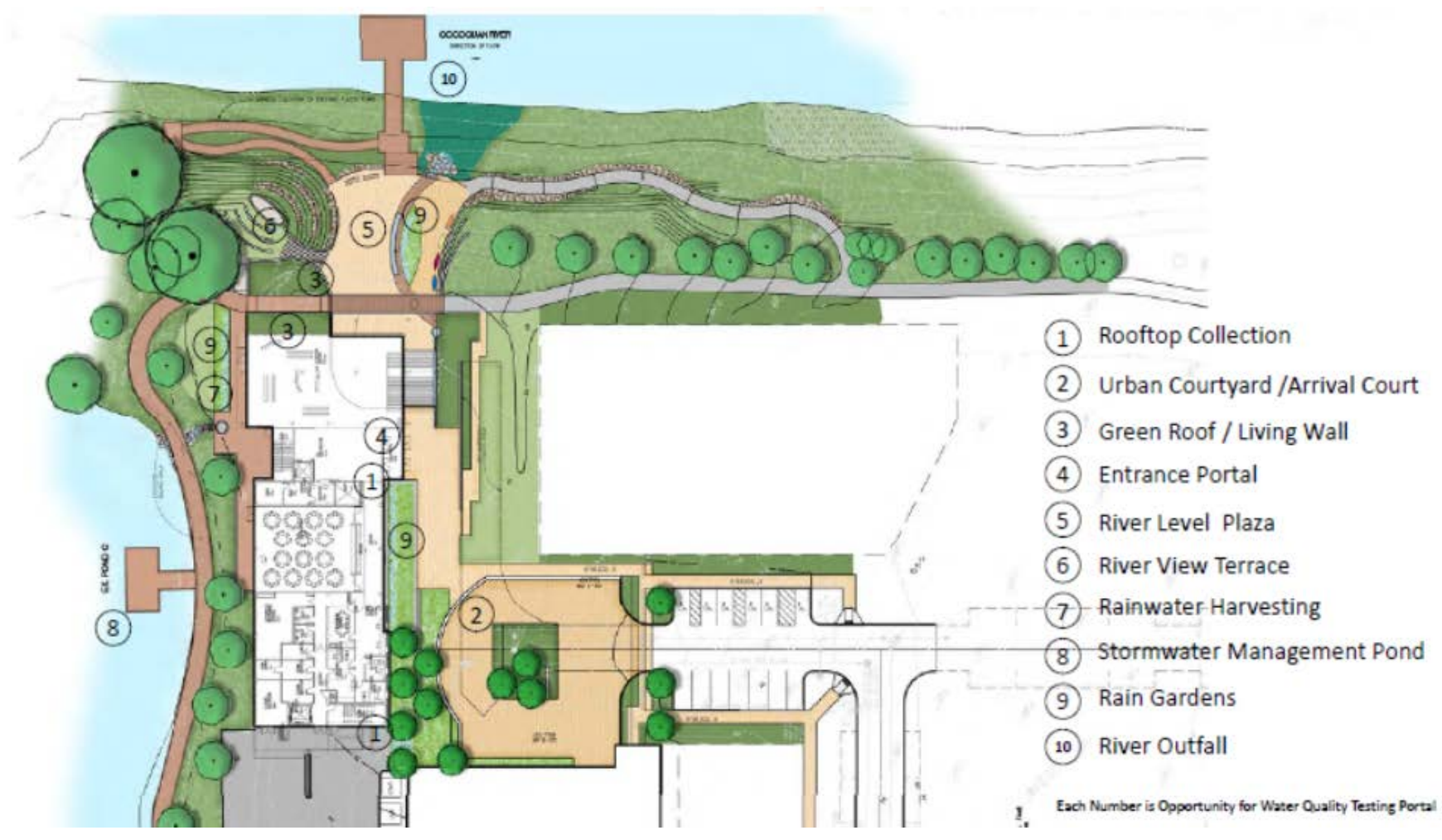

How do you feel like the Water Story features of this site influenced your experience with this site?

$\begin{array}{lllll}1 & 2 & 3 & 4 & 5\end{array}$

0. I was unaware that these Water Story features existed.

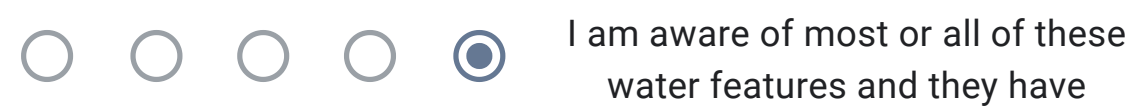
greatly enriched my learning experience at the site. 
What specific features of the Potomac Science Center outdoor landscape have you seen or learned about during your time at the site?

$\checkmark$ a. Roof drain with a weir into a rain garden

$\checkmark$ b. Scuppers installed on the roof

$\checkmark$ c. Table top installation to replicate characteristics of a dry creek bed.

d. 5,000-gallon rainwater harvesting cistern collects water from the roof of the building and water condensation from the air conditioning system.

$\checkmark$ e. A 250-sf green wall located along the main plaza of the outdoor patio

$\checkmark$ f. A series of rain gardens and Infiltration swales throughout the site.

Would the addition of signage explaining the significance of each Water Story feature enhance your learning experience at this site?
() a. Yes
b. No
c. Unsure

Thank you for your participation!

If you are interested in receiving a copy of this final case study - please share your email address with us. Copy and past the following link into your browser to share: https://forms.gle/d7bfZzi4N56F2SDH6

This form was created outside of your domain. 


\section{Potomac Science Center Visitor Assessment Survey}

This research is being conducted to evaluate how the construction and maintenance of the Potomac Science Center landscape has impacted the surrounding community. This information will be used to inform future landscape design projects at George Mason University and the larger landscape design industry (through submission to the Landscape Architecture Foundation).

\section{Informed Consent}

This research is being conducted to evaluate how the construction and maintenance of the Potomac Science Center landscape has impacted the surrounding community. This information will be used to inform future landscape design projects at George Mason University and the larger landscape design industry (through submission to the Landscape Architecture Foundation). If you agree to participate, you will be asked to complete a 10-minute online survey.

RISKS: There are no foreseeable risks for participating in this research.

BENEFITS: There are no benefits to you as a participant other than to further research in the landscape design field.

CONFIDENTIALITY: The data in this study will be confidential. Names and other identifiers will not be placed on research data. Participant's names and contact information will not be included on the surveys and other collectible data. If you choose to opt into sharing your contact information with us, it will be collected through a separate survey and completely separate from the data for this survey. This ensures that all data collected is de-identified immediately. The de-identified data could be used for future research without additional consent from participants. The Institutional Review Board (IRB) committee that monitors the research on human subjects may inspect study records during internal auditing procedures and are required to keep all information confidential.

PARTICIPATION: Your participation is voluntary, and you may withdraw from the study at any time and for any reason. If you decide not to participate or if you withdraw from the study, there is no penalty or loss of benefits to which you are otherwise entitled. There are no costs to you or any other party.

I have read this form, all of my questions have been answered by the research staff, and I agree to participate in this study.

Accept.

Decline. 


\section{Contact}

This research is being conducted by MacKenzie Earl at George Mason University. She may be reached at (540) 270-6483 or mearl@gmu.edu for questions or to report a research-related problem. Cynthia Smith (faculty advisor) be reached at csmitc@gmu.edu.You may contact the George Mason University Institutional Review Board office at 703-993-4121 or $\underline{I R B} @$ gmu.edu if you have questions or comments regarding your rights as a participant in the research. This research has been reviewed according to George Mason University procedures governing your participation in this research.

\section{Overview}

How would you describe your relation to the Potomac Science Center?

I am a resident of the region.

I am a resident of the Belmont Bay Community Home Owner's Association.

I am a one time visitor to the facility.

I am an employee or contracted worker at the facility.

(- I am a faculty member or student with George Mason University.

\section{Section 4: Engagement}

How would you rate your level of engagement with the site indicated PRIOR to the construction of the Potomac Science Center in 2017?

0. I never engaged with this site prior to 2017

b. 1. I rarely engaged with this site prior to 2017.

c. 2. I engaged with this site prior to 2017 3-4 times prior to 2017.

d. 3. I often engaged with this site prior to construction in 2017.

e. 4. I often engaged with this site prior to construction in 2017 - including frequent use of the National Heritage Scenic Trail. 
Please indicate all of the ways you engaged with the site PRIOR to the construction of the Potomac Science Center in 2017.

$\square$ a Used the National Heritage Scenic Trail for recreational use.

b. Enjoyed the view of the Occoquan River.

c. Engaged in ecological-based recreation (bird watching, plant identification, ect.)

d. Visited the site to learn about watersheds, water ecology, conservation, and other topics.

e. I did not engage with this site at all prior to the construction of the PSC.

$\checkmark$ Other: Worked on construction fir the building

\section{Untitled Section}

How would you rate your level of engagement with the site indicated AFTER the construction of the Potomac Science Center in 2017?

a. I never engage with this site.

b. I rarely engage with this site.

c. I engaged with this site 3-4 times a year.

d. I often engage with this site.

e. I often engage with this site - including frequent use of the National Heritage Scenic Trail. 
Please indicate all of the ways you engaged with the site AFTER its construction concluded?

$\square$ a Used the National Heritage Scenic Trail for recreational use.

$\square$ b. Enjoyed the view of the Occoquan River.

$\square$ c. Engaged in ecological-based recreation (bird watching, plant identification, ect.)

$\square$ d. Visited the site to learn about watersheds, water ecology, conservation, and other topics.

e. Other (Option to write in.)

Section 2: General Information

Current Aerial of the Potomac Science Center

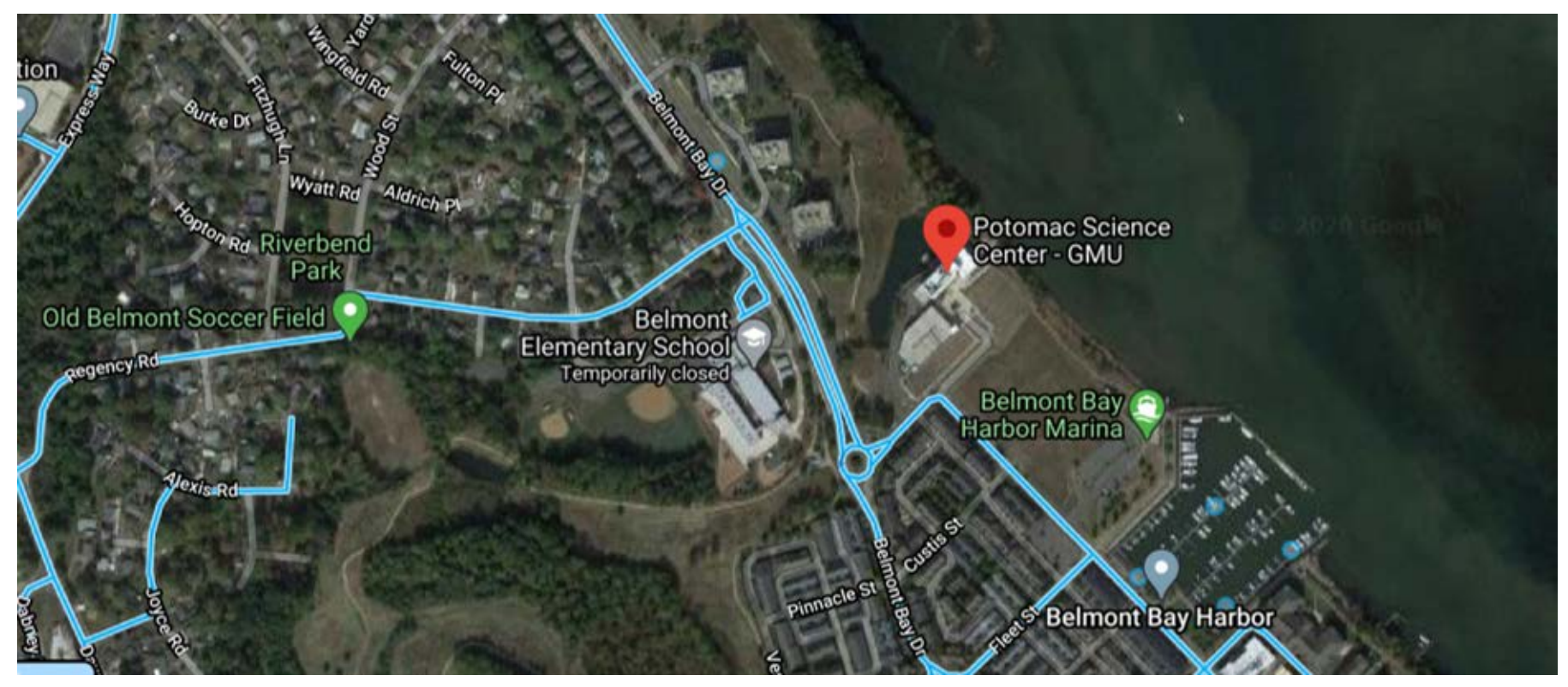


What mode of transport have you used to travel to/ use while at this site?

I have walked to this site as a pedestrian. I did not access this site via the NHST.

b. I have walked to this site as a pedestrian. I accessed this site via the NHST.

(- c. I have driven to the site and walked around the area.

d. I have visited this site as a cyclist from the NHST.

e. I have visited this site via bicycle without use of the NHST.

f. Other (Please specify.)

When you have visited the Potomac Science Center site, who do you come with?

$\checkmark$ a. I visit the site alone.

b. I visit with a friend or spouse.

c. I visit with my family (including children).

d. I visit with my family (including multigenerational family).

e. I have visited with a class or educational program.

Section 2: Residents 
How long have you lived in the [Belmont Bay Community Home Owner's Association] neighborhood?
Less than a year
1-2 years
2-4 years
4-6 years
$6+$ years

Would you say that your residency is more appealing because of its proximity to the Potomac Science Center and the outdoor landscape on its campus?
a. Yes
b. No
c. Unsure
d. I am a non-resident.

\section{Section 3: Site Features}

Six "Water Story" features connect to a specific stage in the movement of water throughout the site. These features are designed to visually demonstrate to visitors how a precipitated water droplet travels through the site and into the Occoquan River. These features include a roof drain with a weir into a rain garden, scuppers installed on the roof, and a table top installation to replicate characteristics of a dry creek bed. This is used to educate students and the public about water quality, erosion, and the Occoquan River it overlooks. 
Pictured: Green wall (left), terraced outdoor classroom (center), and rain garden (mid right). All of these are features of the Water Story.

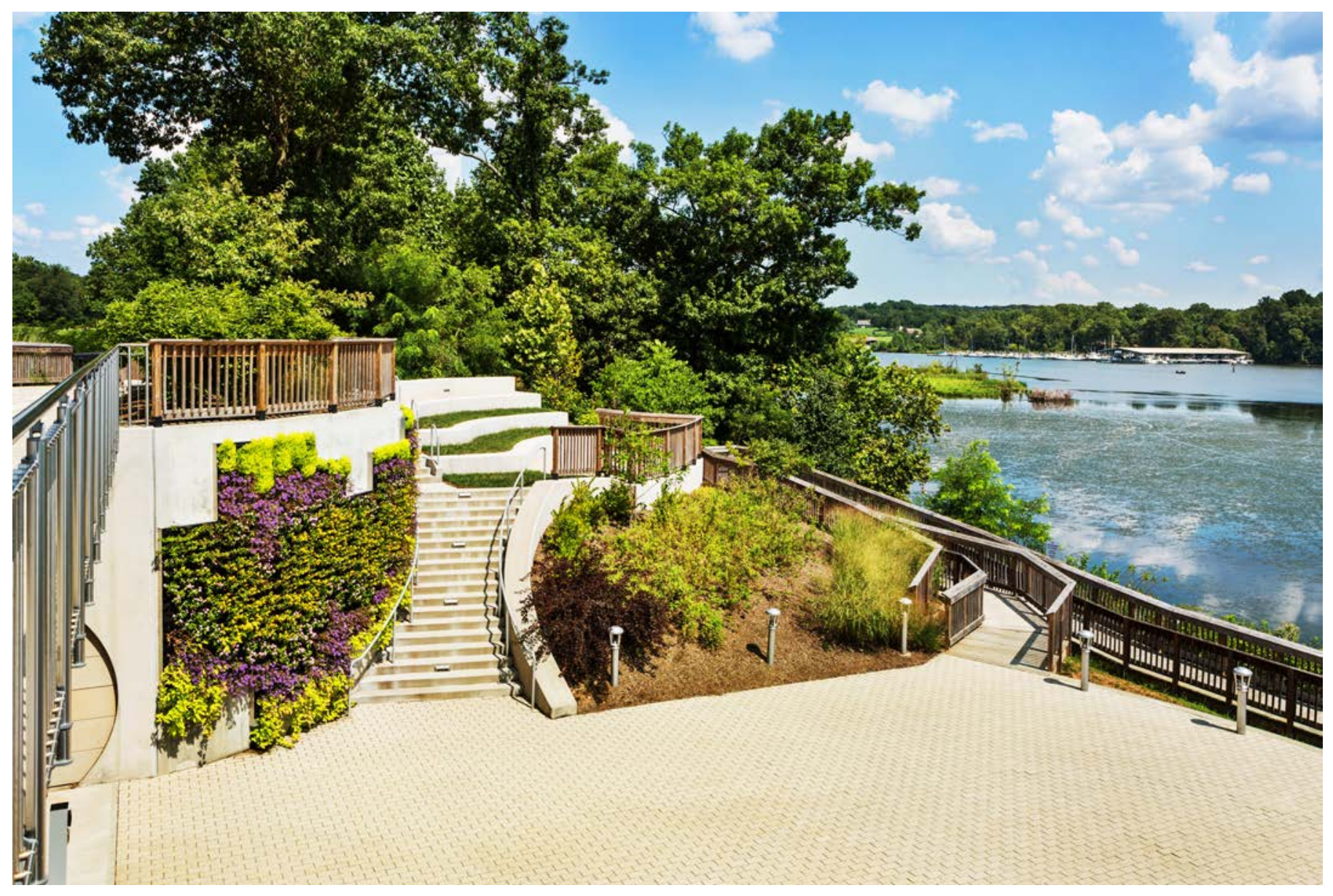


Pictured: Labeled water features at the site.

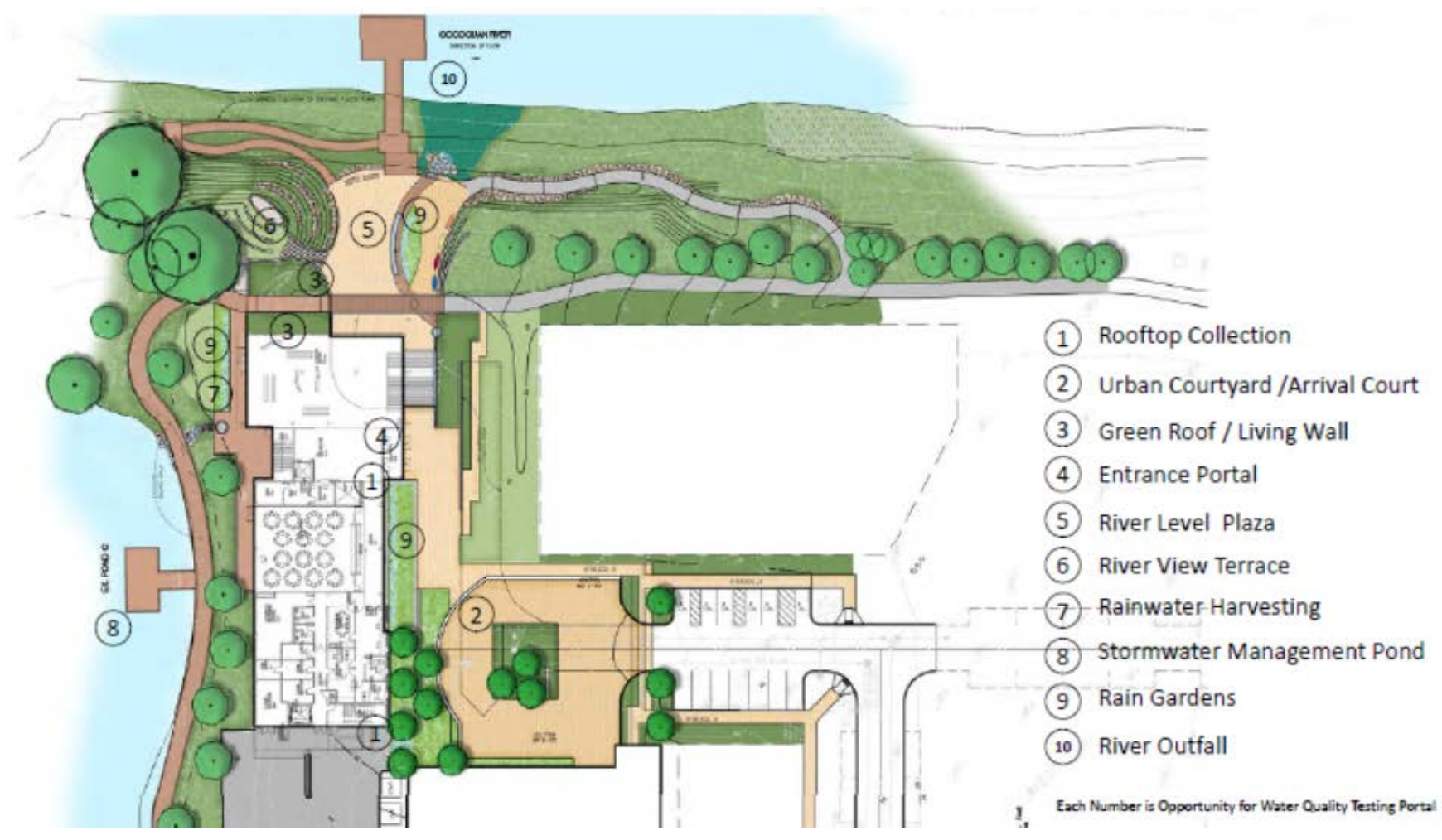

How do you feel like the Water Story features of this site influenced your experience with this site?

$\begin{array}{lllll}1 & 2 & 3 & 4 & 5\end{array}$

0. I was unaware that these Water Story features existed.

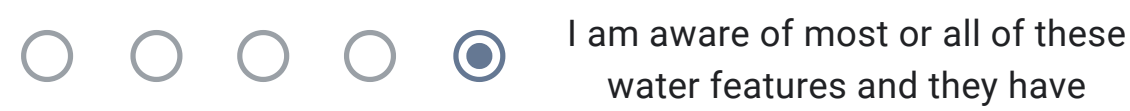
greatly enriched my learning experience at the site. 
What specific features of the Potomac Science Center outdoor landscape have you seen or learned about during your time at the site?

$\checkmark$ a. Roof drain with a weir into a rain garden

$\checkmark$ b. Scuppers installed on the roof

$\checkmark$ c. Table top installation to replicate characteristics of a dry creek bed.

d. 5,000-gallon rainwater harvesting cistern collects water from the roof of the building and water condensation from the air conditioning system.

$\checkmark$ e. A 250-sf green wall located along the main plaza of the outdoor patio

$\checkmark$ f. A series of rain gardens and Infiltration swales throughout the site.

Would the addition of signage explaining the significance of each Water Story feature enhance your learning experience at this site?
() a. Yes
b. No
c. Unsure

Thank you for your participation!

If you are interested in receiving a copy of this final case study - please share your email address with us. Copy and past the following link into your browser to share: https://forms.gle/d7bfZzi4N56F2SDH6

This form was created outside of your domain. 


\section{Potomac Science Center Visitor Assessment Survey}

This research is being conducted to evaluate how the construction and maintenance of the Potomac Science Center landscape has impacted the surrounding community. This information will be used to inform future landscape design projects at George Mason University and the larger landscape design industry (through submission to the Landscape Architecture Foundation).

\section{Informed Consent}

This research is being conducted to evaluate how the construction and maintenance of the Potomac Science Center landscape has impacted the surrounding community. This information will be used to inform future landscape design projects at George Mason University and the larger landscape design industry (through submission to the Landscape Architecture Foundation). If you agree to participate, you will be asked to complete a 10-minute online survey.

RISKS: There are no foreseeable risks for participating in this research.

BENEFITS: There are no benefits to you as a participant other than to further research in the landscape design field.

CONFIDENTIALITY: The data in this study will be confidential. Names and other identifiers will not be placed on research data. Participant's names and contact information will not be included on the surveys and other collectible data. If you choose to opt into sharing your contact information with us, it will be collected through a separate survey and completely separate from the data for this survey. This ensures that all data collected is de-identified immediately. The de-identified data could be used for future research without additional consent from participants. The Institutional Review Board (IRB) committee that monitors the research on human subjects may inspect study records during internal auditing procedures and are required to keep all information confidential.

PARTICIPATION: Your participation is voluntary, and you may withdraw from the study at any time and for any reason. If you decide not to participate or if you withdraw from the study, there is no penalty or loss of benefits to which you are otherwise entitled. There are no costs to you or any other party.

I have read this form, all of my questions have been answered by the research staff, and I agree to participate in this study.

Accept.

Decline. 


\section{Contact}

This research is being conducted by MacKenzie Earl at George Mason University. She may be reached at (540) 270-6483 or mearl@gmu.edu for questions or to report a research-related problem. Cynthia Smith (faculty advisor) be reached at csmitc@gmu.edu.You may contact the George Mason University Institutional Review Board office at 703-993-4121 or $\underline{I R B} @$ gmu.edu if you have questions or comments regarding your rights as a participant in the research. This research has been reviewed according to George Mason University procedures governing your participation in this research.

\section{Overview}

How would you describe your relation to the Potomac Science Center?

I am a resident of the region.

I am a resident of the Belmont Bay Community Home Owner's Association.

( I am a one time visitor to the facility.

I am an employee or contracted worker at the facility.

I am a faculty member or student with George Mason University.

\section{Section 4: Engagement}

How would you rate your level of engagement with the site indicated PRIOR to the construction of the Potomac Science Center in 2017?

0. I never engaged with this site prior to 2017

b. 1. I rarely engaged with this site prior to 2017.

c. 2. I engaged with this site prior to 2017 3-4 times prior to 2017.

d. 3. I often engaged with this site prior to construction in 2017.

e. 4. I often engaged with this site prior to construction in 2017 - including frequent use of the National Heritage Scenic Trail. 
Please indicate all of the ways you engaged with the site PRIOR to the construction of the Potomac Science Center in 2017.

$\square$ a Used the National Heritage Scenic Trail for recreational use.

b. Enjoyed the view of the Occoquan River.

c. Engaged in ecological-based recreation (bird watching, plant identification, ect.)

d. Visited the site to learn about watersheds, water ecology, conservation, and other topics.

e. I did not engage with this site at all prior to the construction of the PSC.

Other:

\section{Untitled Section}

How would you rate your level of engagement with the site indicated AFTER the construction of the Potomac Science Center in 2017?

a. I never engage with this site.

() b. I rarely engage with this site.

c. I engaged with this site 3-4 times a year.

d. I often engage with this site.

e. I often engage with this site - including frequent use of the National Heritage Scenic Trail. 
Please indicate all of the ways you engaged with the site AFTER its construction concluded?

a Used the National Heritage Scenic Trail for recreational use.

b. Enjoyed the view of the Occoquan River.

c. Engaged in ecological-based recreation (bird watching, plant identification, ect.)

d. Visited the site to learn about watersheds, water ecology, conservation, and other topics.

e. Other (Option to write in.)

\section{Section 2: General Information}

Current Aerial of the Potomac Science Center

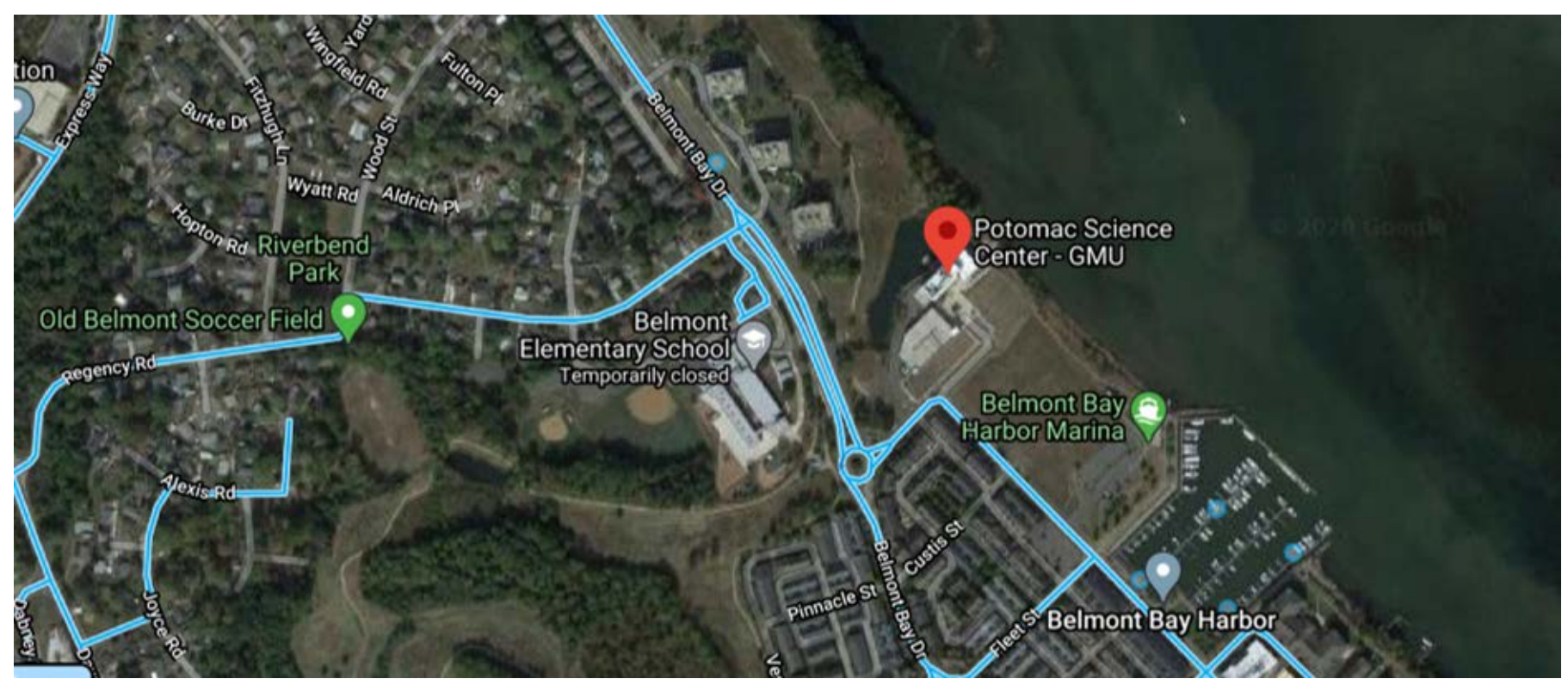


What mode of transport have you used to travel to/ use while at this site?

I have walked to this site as a pedestrian. I did not access this site via the NHST.

b. I have walked to this site as a pedestrian. I accessed this site via the NHST.

c. I have driven to the site and walked around the area.

d. I have visited this site as a cyclist from the NHST.

e. I have visited this site via bicycle without use of the NHST.

f. Other (Please specify.)

When you have visited the Potomac Science Center site, who do you come with?

a. I visit the site alone.

b. I visit with a friend or spouse.

c. I visit with my family (including children).

d. I visit with my family (including multigenerational family).

e. I have visited with a class or educational program.

Section 2: Residents 
How long have you lived in the [Belmont Bay Community Home Owner's Association] neighborhood?
Less than a year
1-2 years
2-4 years
4-6 years
$6+$ years

Would you say that your residency is more appealing because of its proximity to the Potomac Science Center and the outdoor landscape on its campus?
a. Yes
b. No
c. Unsure
d. I am a non-resident.

\section{Section 3: Site Features}

Six "Water Story" features connect to a specific stage in the movement of water throughout the site. These features are designed to visually demonstrate to visitors how a precipitated water droplet travels through the site and into the Occoquan River. These features include a roof drain with a weir into a rain garden, scuppers installed on the roof, and a table top installation to replicate characteristics of a dry creek bed. This is used to educate students and the public about water quality, erosion, and the Occoquan River it overlooks. 
Pictured: Green wall (left), terraced outdoor classroom (center), and rain garden (mid right). All of these are features of the Water Story.

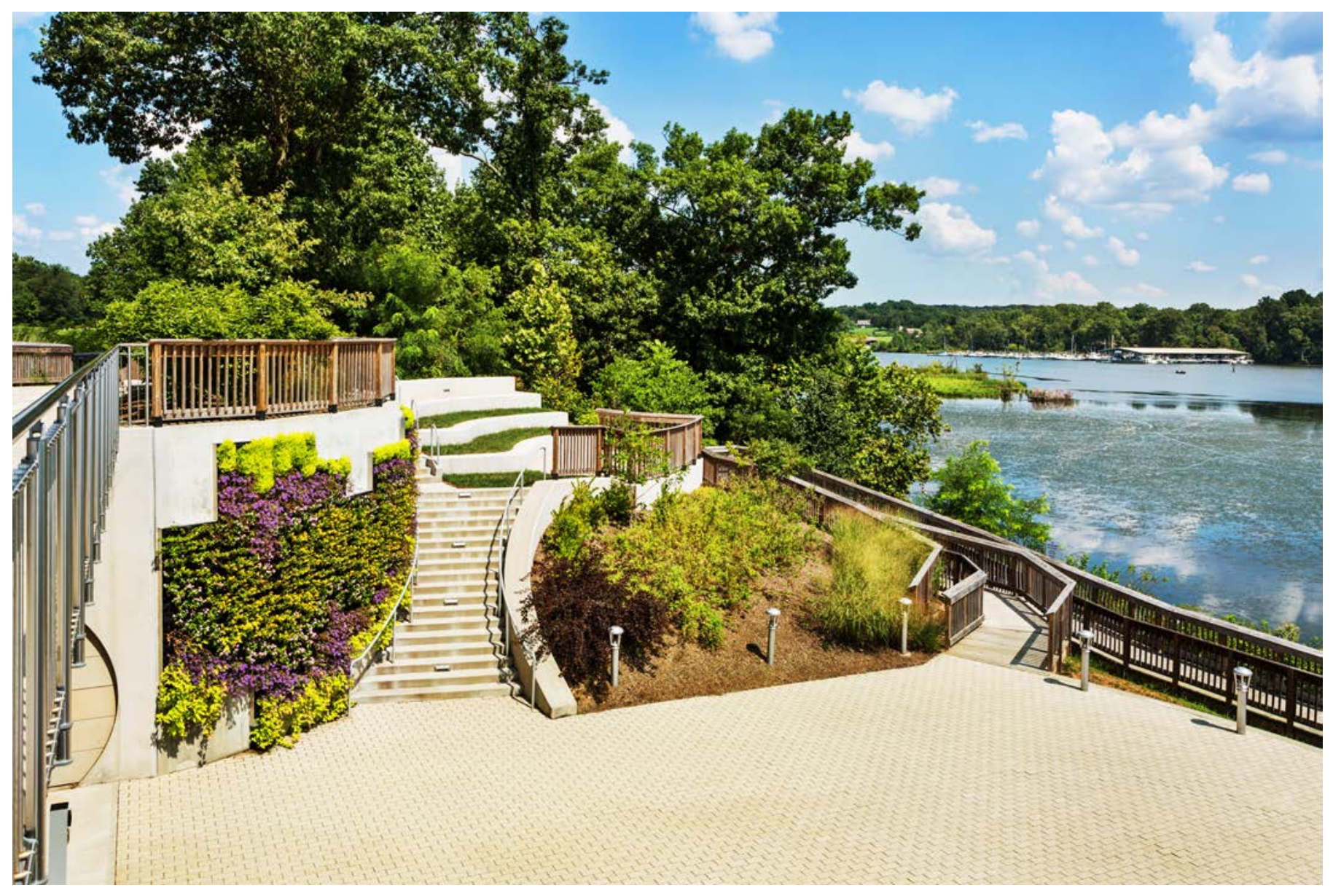


Pictured: Labeled water features at the site.

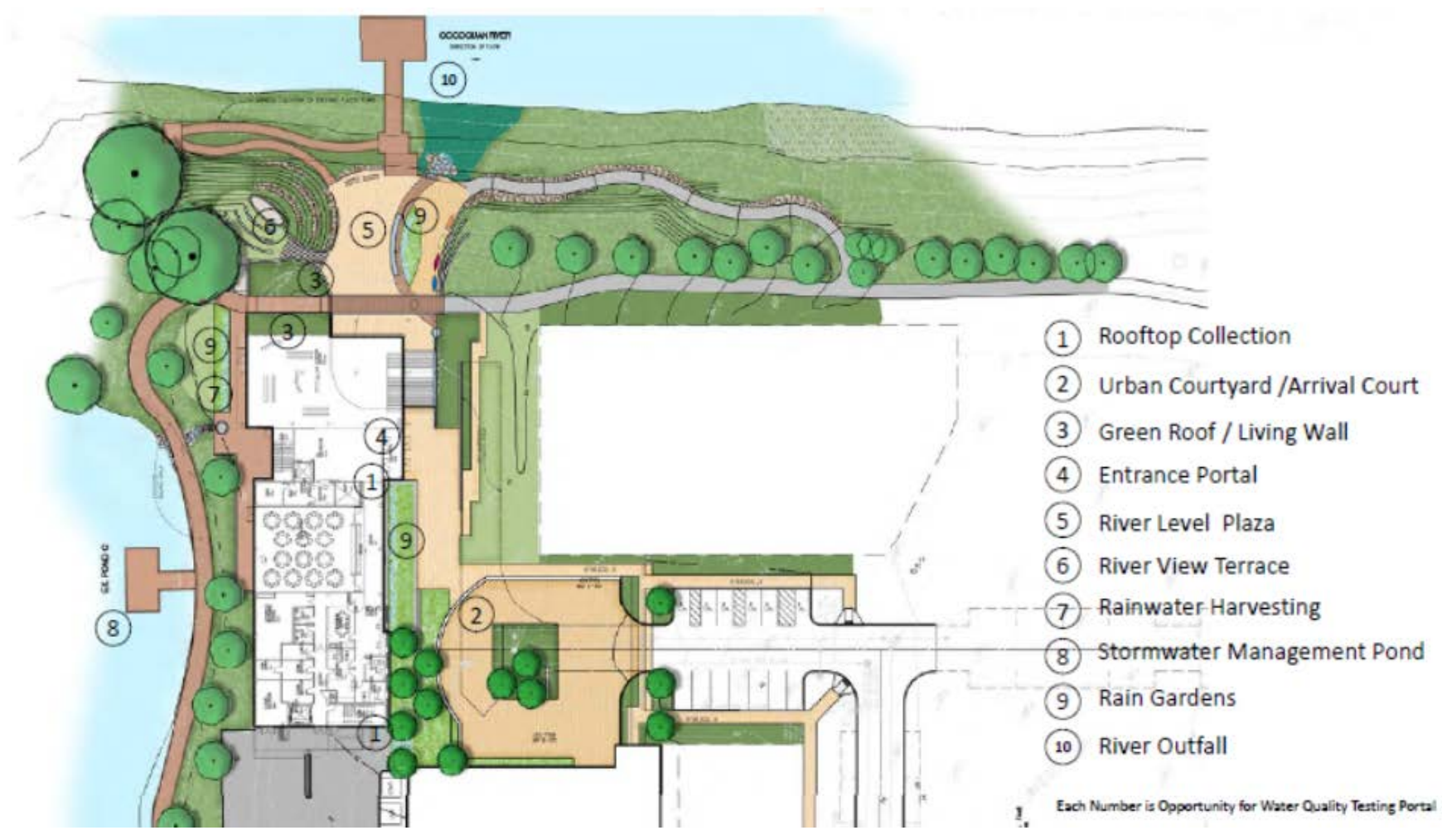

How do you feel like the Water Story features of this site influenced your experience with this site?

$\begin{array}{lllll}1 & 2 & 3 & 4 & 5\end{array}$

0. I was unaware that these Water Story features existed.

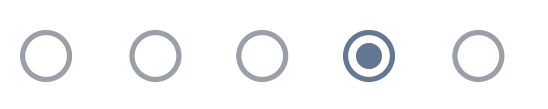

I am aware of most or all of these water features and they have greatly enriched my learning experience at the site. 
What specific features of the Potomac Science Center outdoor landscape have you seen or learned about during your time at the site?

a. Roof drain with a weir into a rain garden

b. Scuppers installed on the roof

c. Table top installation to replicate characteristics of a dry creek bed.

d. 5,000-gallon rainwater harvesting cistern collects water from the roof of the building and water condensation from the air conditioning system.

$\checkmark$ e. A 250-sf green wall located along the main plaza of the outdoor patio

$\checkmark$ f. A series of rain gardens and Infiltration swales throughout the site.

Would the addition of signage explaining the significance of each Water Story feature enhance your learning experience at this site?
() a. Yes
b. No
c. Unsure

Thank you for your participation!

If you are interested in receiving a copy of this final case study - please share your email address with us. Copy and past the following link into your browser to share: https://forms.gle/d7bfZzi4N56F2SDH6

This form was created outside of your domain. 